University of Rhode Island

DigitalCommons@URI

Open Access Dissertations

1997

\title{
Statistical Characterizations of North Atlantic Subtropical Mode Water
}

Michael Aaron Alfultis

University of Rhode Island

Follow this and additional works at: https://digitalcommons.uri.edu/oa_diss

\section{Recommended Citation}

Alfultis, Michael Aaron, "Statistical Characterizations of North Atlantic Subtropical Mode Water" (1997). Open Access Dissertations. Paper 541.

https://digitalcommons.uri.edu/oa_diss/541

This Dissertation is brought to you for free and open access by DigitalCommons@URI. It has been accepted for inclusion in Open Access Dissertations by an authorized administrator of DigitalCommons@URI. For more information, please contact digitalcommons-group@uri.edu. 


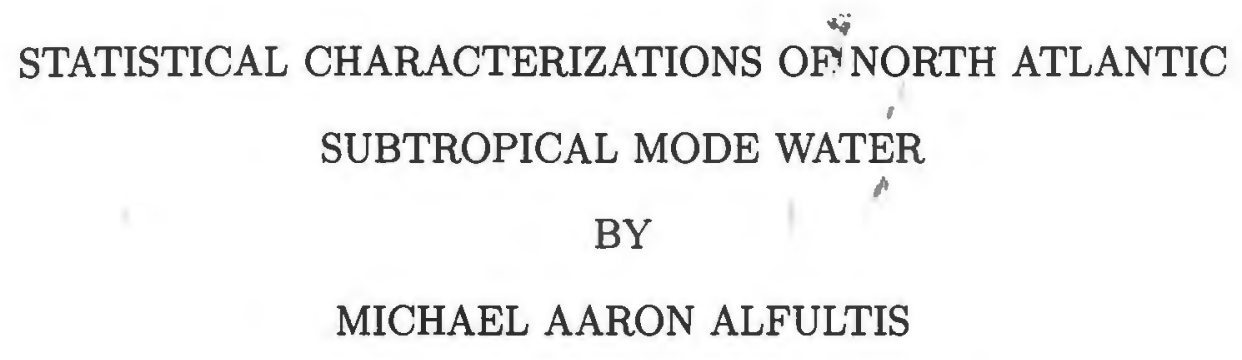

A DISSERTATION SUBMITTED IN PARTIAL FULFILLMENT OF THE REQUIREMENTS FOR THE DEGREE OF DOCTOR OF PHILOSOPHY IN OCEANOGRAPHY

UNIVERSITY OF RHODE ISLAND 1997 


\section{DOCTOR OF PHILOSOPHY DISSERTATION}

$\mathrm{OF}$

MICHAEL AARON ALFUḶ̆TIS

\section{APPROVED:}

Dissertation Commitee

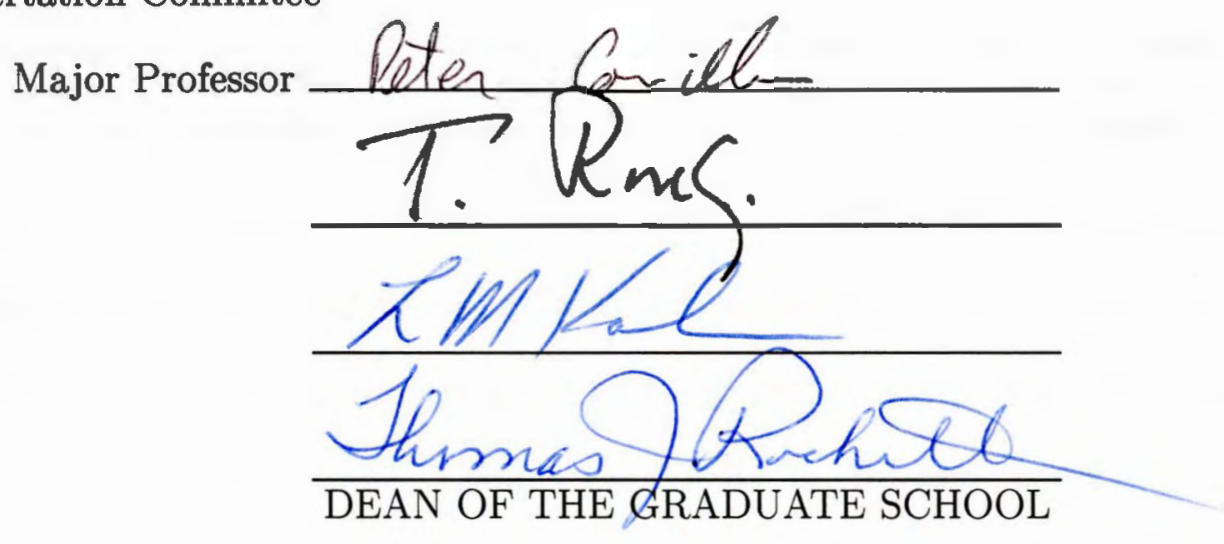

UNIVERSITY. OF RHODE ISLAND

1997 


\section{Abstract}

Subtropical Mode Water (STMW) is a water mass formed in winter by convective mixing on the equatorward side of western boundary currents in the subtropical gyres. After the return of the seasonal stratification.in spring, it is found at the stratification minimum between the seasonal and main pycnoclines. By characterizing STMW primarily at the density gradient miniquum, previous studies were limited in their ability to describe STMW properties over large temporal and spatial scales. Rather than using a density-based characterization, the North Atlantic STMW layer was identified here by its much smaller temperature gradient relative to the more stratified seasonal and main thermoclines. By using a temperaturebased characterization, this study was able to take advantage of the large volume of XBT data collected between 1968 and 1988 to examine STMW properties on large spatial and long temporal scales. There was considerable spatial and temporal variability in the renewal of the STMW layer's vertical homogeneity from 1968 to 1988 . Basin-wide renewal occurred in 1969, 1970, 1977, 1978, 1981, and 1985 , with more localized renewal, usually east of $55^{\circ} \mathrm{W}$, in other years. While STMW is nearly vertically homogeneous upon renewal by convective mixing, the temperature gradient through the layer increases after renewal. The annual rate of increase in the temperature gradient in the year following renewal is $\sim 5-6 \times 10^{-4}$ ${ }^{\circ} \mathrm{C}$ per $100 \mathrm{~m}$ per day, while the interannual rate of increase following winters with no renewal of the STMW layer is $\sim 2.0 \times 10^{-4}{ }^{\circ} \mathrm{C}$ per $100 \mathrm{~m}$ per day. The STMW layer which is the remnant of the previous winter's convective activity is typically found between 175 and $450 \mathrm{~m}$, has an average temperature near $18^{\circ} \mathrm{C}$, and has a 
mean temperature gradient of $0.5^{\circ} \mathrm{C}$ per $100 \mathrm{~m}$. STMW layers in years following winter renewal are $25 \mathrm{~m}$ shallower, colder, and less vertically stratified, but more horizontally stratified, than those STMW layers following winters of no renewal. 


\section{Acknowledgements}

First and foremost, I gratefully acknowledge all the love and support I received from my family, especially my wife, Kim, and sons David and Matthew, during this long ordeal. My parents, Harold and Joyce Alfultis, instilled in me the discipline and commitment which has taken me so far in my life, Professor David McGill, who was first my mentor as an undergraduate and latpr my dear friend, and my grandfather Aaron Ryefield, whose life serves as an ongoing example of the father and Christian I hope to be someday, both played instrumental roles in setting me on this path, but could not see its completion. This dissertation is lovingly dedicated to their memory. My two advisors as a graduate student, Professors Seelye Martin at the University of Washington and Peter Cornillon at the University of Rhode Island, instilled in me a curiosity about the world around us, the desire to satisfy that curiosity, and the patience to overcome obstacles in the pursuit of the answers. Their support and guidance were critical in my completion of this work. The efforts of NOAA's Ocean Climate Laboratory, particularly Syd Levitus and Tim Boyer, in compiling the World Ocean Atlas 1994 have lead to a dataset which will play an instrumental role in increasing our understanding of the ocean. Dr. Igor Belkin kindly provided the LIHMA data, and many hours of enlightening discussions. My fellow graduate students, particularly Ken Casey and Stephanie Dutkiewicz, were always there to pick me up when I was down and keep me going. The financial support of the U.S. Coast Guard is gratefully acknowledged. 


\section{Contents}

1 Background 1

1.1 Definition and General Characteristics ............. 1

1.2 North Atlantic STMW . . . . . . . . . . . . . . . 3

1.3 STMW in Other Gyres . . . . . . . . . . . . . . 7

1.4 STMW Formation $\ldots \ldots \ldots \ldots \ldots$

1.5 STMW Advection and Dissipation $\ldots \ldots \ldots \ldots$

1.6 Interannual Variability $\ldots \ldots \ldots \ldots \ldots \ldots$

1.7 Importance of STMW $\ldots \ldots \ldots \ldots . \ldots \ldots$

2 Procedures: Finding the STMW Layer and Its Mean Properties 27

2.1 Data Sources . . . . . . . . . . . . . . . . 27

2.1 .1 World Ocean Atlas . . . . . . . . . . . . . 27

2.1.2 Long-term Investigation of Hydro-Meteorological

Anomalies ..................... 31

2.2 Data Processing . . . . . . . . . . . . . . . . 34

2.2.1 All World Ocean Atlas Profiles . . . . . . . . . . . . 34

2.2 .2 WOA XBT Profiles . . . . . . . . . . . 36 
2.2.3 LIHMA, WOA Station and CTD Profiles . . . . . . . . 37

2.3 Identifying STMW Layer . . . . . . . . . . . . . . . . 39

2.4 Temperature Gradient Minimum - Potential Vorticity Minimum Comparisons . . . .......................... 51

2.5 Determining STMW Layer Characterisitics $\because \ldots . . . . . .55$

2.6 Assembling Climatologies . . . . . . . . . . . 57

3 Characterizing STMW Renewal Events $\quad 70$

3.1 Winter Mixed Layer Characterizations . . . . . . . . . 80

3.2 STMW Layer Temperature Gradient

Characterization $\ldots \ldots \ldots \ldots \ldots \ldots \ldots$

3.3 Comparison of Characterizations . . . . . . . . . 85

3.4 Comparison with Other Observations of STMW Renewal . . . . . . . . . . . . . . . . 95

3.5 Comparison with North Atlantic Oscillation Index . . . . . . . . 98

3.6 Mean Annual Timing of Renewal Events . . . . . . . . . . 100

3.7 Conclusions . . . . . . . . . . . . . . . . . 102

4 Changes in the STMW Temperature Gradient 108

4.1 Annual Changes . . . . . . . . . . . . . . . . . . . 109

4.1 .1 Temperature Gradient . . . . . . . . . . . . 109

4.1.2 Thickness and Temperature Difference . . . . . . . . . 110

4.2 Interannual Changes $\ldots \ldots \ldots \ldots \ldots \ldots$

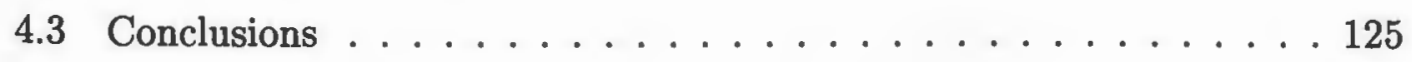


5 Average STMW Layer Characteristics

5.1 Average Distribution of STMW Properties . . . . . . . . . 135

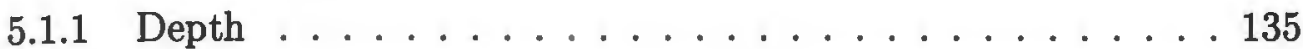

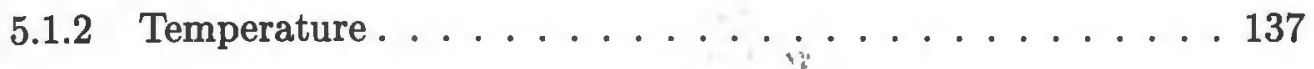

5.1 .3 Temperature Gradient . . . . . . . . . . . . . 139

5.2 Distribution of STMW Properties in

Renewal versus Non-renewal Years . . . . . . . . . . . 143

5.3 Conclusions . . . . . . . . . . . . . . . . . . 148

6 Conclusions $\quad 149$ 


\section{List of Tables}

2.1 "Standard Level" Vertical Sampling . . . . . . . . . . . . . 29

2.2 Distribution of Data Types in WOA '94 Dataset . . . . . . . . . 30

2.3 LIHMA Sections' Spatial and Temporal Sampling. . . . . . . . . . 33

2.4 Summary of Data Processing . . . . . . . . . . . 47

2.5 Comparison of Properties at the Potential Vorticity Minimum with the STMW Layer. . . . . . . . . . . . . . . . . 54

2.6 Measurement Uncertainties for Each Instrument Type. . . . . . . 66

2.7 Small Scale Geophysical Variances for each Parameter . . . . . . . . 68

2.8 Large Scale Geophysical Variances for each Parameter . . . . . . . . 69

3.1 Correlation Coefficients Between Charaterizations . . . . . . . . . 90

3.2 Correlation Coefficients Between STMW Renewal and NAO . . . . 101

$3.3 \quad 1969-1988$ STMW Renewal Events . . . . . . . . . . . . . . 107

4.1 Annual Mean Changes in Temperature Gradient . . . . . . . . . . 112

4.2 Interannual Rates of Change . . . . . . . . . . . . . 126 


\section{List of Figures}

2.1 LIHMA Sections $\ldots \ldots \ldots \ldots \ldots \ldots \ldots \ldots$

2.2 Four Examples of Identifying the STMW Layer $\ldots \ldots \ldots$

2.3 Two Examples of Errors in Identifying the STMW Layer . . . . . 44

2.4 Spatial Distribution of Hydrographic Data . . . . . . . . 48

2.5 Seasonal Distribution of Hydrographic Data . . . . . . . . . 49

2.6 Interannual Distribution of Hydrographic Data . . . . . . . . 50

2.7 Example CTD Profile . . . . . . . . . . . . . . . . 53

2.8 Bottom of STMW Layer versus Maximum Depth of Profile . . . . 56

3.1 February-April profile positions, 1968-1988. . . . . . . . . . 73

3.2 February-April profile positions, 1968-1988. . . . . . . . . . 75

3.3 May-July profile positions, $1968-1988 \ldots \ldots \ldots \ldots \ldots \ldots$. . . . 77

3.4 Mixed Layer and STMW Top Depth Time Series, 1968-1988. . . . 81

3.5 Mixed Layer and STMW Top Temperature Time Series, 1968-1988. 82

3.6 3-Monthly Mean Temperature Gradient Time Series, 1968-1988. . . 86

3.7 Temperature Gradient and Mixed Layer-STMW Top Depth Difference, 1968- 1988. . . . . . . . . . . . . . . . . . . . 88 
3.8 Temperature Gradient and Mixed Layer-STMW Top Temperature Difference, 1968-1988. . . . . . . . . . . . . . . . . 89

3.9 Number of Clusters in Feb, Mar, Apr, 1968-1988. . . . . . . . . . 91

3.10 Example of a Multiple Layer STMW Layer . . . . . . . . . . 94

3.11 The North Atlantic Oscillation Index . . . . . . . . . . 101

3.12 Percent of Deep Mixed Layers January-May, 1968-1988. . . . . . . 103

3.13 Percent of Cold Mixed Layers January-May, 1968-1988. . . . . . . 104

4.1 Annual Changes in STMW Temperature Gradient. . . . . . . . . 111

4.2 Annual Changes in Depth of Top and Bottom of STMW Layer . . . 114

4.3 Annual Changes in Temperature at Top and Bottom of STMW Layer115

4.4 Annual Changes in Thickness of STMW Layer . . . . . . . . 117

4.5 Annual Changes in Temperature Difference STMW Layer . . . . . 118

4.6 Temperature Gradient Time Series. . . . . . . . . . . . . . . . . 122

4.7 STMW Layer Top Depth Time Series. . . . . . . . . . . . . . 123

4.8 STMW Layer Top Temperature Time Series. . . . . . . . . . . . . 124

4.9 Running Median of STMW Layer Temperature Gradient. . . . . . . 125

4.10 Running Median of STMW Layer Thickness . . . . . . . . . . . 126

4.11 Running Median of STMW Layer Temperature Difference . . . . 127

4.12 Potential Vorticity Time Series. . . . . . . . . . . . . . . 131

5.1 Mean STMW Top and Bottom Depths and Temperatures. . . . . 136

5.2 STMW Average Temperature and Temperature Gradient. . . . . 138 
5.3 Potential vorticity computed between the $\sigma_{\theta}=26.3$ and 26.5 surfaces from McDowell et al. (1982). . . . . . . . . . . . . . 141

5.4 1969-1970, 1971-1972, and 1973-1974 STMW Top Depth. . . . . . 144

5.5 1969-1970, 1971-1972, and 1973-1974 STMW Top Temperature. . . 145

5.6 1969-1970, 1971-1972, and 1973-1974 STMW Tẹmperature Gradient. 146 


\section{Chapter 1}

\section{Background}

\subsection{Definition and General Characteristics}

McCartney (1982) defines mode waters in general

... by the existence of minima in vertical gradients. Commonly used properties are temperature and potential density anomaly, for which one speaks of thermostads and pycnostads for the layer of minimum gradient. In a regional volumetric census, this homogeneity leads to relatively large volumes in the temperature and salinity classes associated with the mode water compared to neighboring classes, i.e. a bivariate "mode."

Subtropical Mode Waters (STMW) are a class of mode waters located between the seasonal and main thermoclines in the central portion of the subtropical gyres (Schroeder et al. 1959, Suga and Hanawa 1990, Qui and Joyce 1992). They have been broadly characterized as a relatively thick, horizontally uniform, vertically homogenous layer (Talley and Raymer 1982, Suga and Hanawa 1990, Bingham 
1992). However, there are significant vertical and horizontal gradients, as well as interannual variability, in the layer's properties (Fieux and Stommel 1975, Talley and Raymer 1982, Ebbesmeyer and Lindstrom 1986, Suga et al. 1989, Roemmich and Cornuelle 1992, Suga and Hanawa 1995a,b,c, Klein and Hogg 1996). These water masses are generally understood to form when atmospheric cooling removes the seasonal stratification, exposing thick well- mixed layers on the equatorward side of separated western boundary currents to further cooling and convective mixing (McCartney 1982, Talley and Raymer 1982, Ebbesmeyer and Lindstrom 1986, Suga and Hanawa 1990, Qui and Joyce 1992, Roemmich and Cornuelle 1992). With the return of the seasonal thermocline in spring, the STMW layer can be identified as a layer of high oxygen content and minimum stratification due to the convective nature of its formation (Worthington 1959, McCartney et al. 1980, McCartney 1982, Talley and Raymer 1982, Ebbesmeyer and Lindstrom 1986, Qui and Joyce 1992, Roemmich and Cornuelle 1992). Although the regions of strongest wintertime atmospheric cooling and convective mixing are limited to the northwestern portions of the subtropical gyre, STMW can be found throughout much of the subtropical gyre due to advection (Worthington 1959, McCartney et al. 1980, McCartney 1982, Talley and Raymer 1982, Ebbesmeyer and Lindstrom 1986, Bingham 1992, Hall and Fofonoff 1993, Klein and Hogg 1996). STMW's have been found in the North Pacific (Masuzawa 1969), North Atlantic (Worthington 1959), South Pacific (Roemmich and Cornuelle 1992), and Indian Ocean (Belkin and Gordon 1996) subtropical gyres. 


\subsection{North Atlantic STMW}

North Atlantic STMW (NASTMW) seems most prevalent in a region extending from the Gulf Stream south to $30^{\circ} \mathrm{N}$ and east to $45^{\circ} \mathrm{W}$ (Worthington 1959, Istoshin 1961, McCartney 1982, Ebbesmeyer and Lindstrom 1986), but its characteristics can be observed as far south as $20^{\circ} \mathrm{N}$ and further east (Istoshin 1961). The STMW layer is centered at $300 \mathrm{~m}$ (again, between the seasopal ahd main thermocline) with typical thicknesses of $200 \mathrm{~m}$ (Schroeder et al. 1959, Worthington 1959, Istoshin 1961, Leetmaa 1977, Worthington 1977, Talley and Raymer 1982, Ebbesmeyer and Lindstrom 1986, Taft et al. 1986). Its greatest thicknesses (>250 m) are just south of the Gulf Stream, and thickness decreases to the south, particularly south of $32^{\circ} \mathrm{N}$ (Worthington 1959, Istoshin 1961).

NASTMW is classically defined by temperatures ranging from 17.6 to $18.2^{\circ} \mathrm{C}$ (Worthington 1959), salinities 36.4 to $36.6 \%$ (Schroeder et al. 1959, Worthington 1959) and potential densities at its core $\sim 26.4 \mathrm{~kg} \mathrm{~m}^{-3}$ (Worthington 1959, Talley and Raymer 1982). Since the NASTMW core temperature is very nearly $18^{\circ} \mathrm{C}$, it is often referred to as " $18^{\circ} \mathrm{C}$ Water" (Schroeder et al. 1959, Worthington 1959, Ebbesmeyer and Lindstrom 1986). Worthington (1976) presented two estimates of the volume of NASTMW. The first was based on the definition of the volume of STMW as the excess water,between the 17 and $19^{\circ} \mathrm{C}$ isotherms over the volume of water between the 19 and $20^{\circ} \mathrm{C}$ and between the 16 and $17^{\circ} \mathrm{C}$ isotherms, i.e., if there was no STMW (no thermostad), the volume of water between each of these isotherms would roughly be the same. Using this definition, Worthington 
(1976) found the volume of NASTMW to be $890 \times 10^{3} \mathrm{~km}^{3}$. The second estimate was simply the total volume of water between the 17 and $19^{\circ} \mathrm{C}$ isotherms, $1672 \times 10^{3}$ $\mathrm{km}^{3}$ (Worthington 1976).

The dissolved oxygen content of water not in direct physical contact with the atmosphere decreases due to biological consumption. The STMW layer has had recent exposure to the atmosphere, and is therefore higher in dissolved oxygen content than other waters at $300 \mathrm{~m}$ (Worthington 1959). Dissolved oxygen concentrations in the NASTMW layer range from 4.45 to $5.4 \mathrm{ml} \mathrm{l}^{-1}, 80-90 \%$ of saturation (Worthington 1959, Leetmaa 1977, Worthington 1977, McCartney et al. 1980, McCartney 1982, Taft et al. 1986).

The vertical homogeneity of the STMW layer is its most widely discussed characteristic. It has been broadly characterized as a vertically homogeneous layer (Talley and Raymer 1982, Bingham 1992, Klein and Hogg 1996). While the STMW layer does represent a stratification minimum between the seasonal and main thermoclines, it "is not strictly homogeneous; it has a gravitational stability, and this stability varies from time to time" (Schroeder et al. 1959). When discussing the degree of stratification of the STMW layer, it is important to distinguish the STMW layer in winter when it is exposed to atmospheric cooling and convective mixing from the STMW layer when it is isolated from atmospheric forcing with the return of the seasonal thermocline. While it is experiencing convective mixing in winter, the STMW layer's temperature and salinity are vertically homogeneous with high dissolved oxygen content (Worthington 1959, Istoshin 1961, Worthington 1972, Leetmaa 1977, Worthington 1977, Hall and Fofonoff 1993). However, 
once the STMW layer is isolated from atmospheric forcing with the return of the seasonal stratification, it is no longer strictly vertically homogeneous (Schroeder et al. 1959, Worthington 1972, Leetmaa 1977, Worthington 1977, McCartney et al. 1980). Rather, it has a small temperature gradient ranging from $0.03^{\circ} \mathrm{C}$ per $100 \mathrm{~m}$ to $0.08^{\circ} \mathrm{C}$ per $100 \mathrm{~m}$ in NASTMW recently exposed to atmospheric cooling (Worthington 1977 , McCartney et al. 1980) to 0.7 to $0.8^{\circ} \mathrm{C}$ per $100 \mathrm{~m}$ in NASTMW which has had no recent exposure to atmospheric cooling (Leetmaa 1977, Worthington 1977, Taft et al. 1986, Klein and Hogg 1996). (A positive temperature gradient represents temperatures decreasing as depths increase.) However, the variation in time and space of this vertical temperature gradient is not well known.

Again, these small vertical temperature gradients represent the stratification minimum between the seasonal and main thermoclines. Therefore, the STMW layer can be identified by its small vertical density gradient (McCartney 1982, Talley and Raymer 1982, Suga and Hanawa 1995a). However, when a water parcel circulates through the subtropical gyre, its vertical density gradient changes to conserve its potential vorticity (McCartney 1982, Talley and Raymer 1982). If relative vorticity is neglected, the potential vorticity simplifies to a conservation of thickness (or vortex stretching) between isopycnals:

$$
\frac{f}{\rho_{\theta}} \frac{\partial \sigma_{\theta}}{\partial z}
$$

Therefore, the potential vorticity, like the vertical density gradient, has a minimum in the STMW layer, and, assuming mixing and relative vorticity can be neglected, has the added advantage of being a conservative tracer. Because of this, the po- 
tential vorticity has been frequently used to identify the STMW layer (McCartney 1982, Talley and Raymer 1982, Ebbesmeyer and Lindstrom 1986, and Klein and Hogg 1996). The potential vorticity values for the NASTMW layer range from less than $2.5 \times 10^{-11} \mathrm{~m}^{-1} \mathrm{~s}^{-1}$ in recently formed STMW to values less than $9 \times 10^{-11}$ $\mathrm{m}^{-1} \mathrm{~s}^{-1}$ in STMW with no recent exposure to the atmosphere (McCartney 1982, Ebbesmeyer and Lindstrom 1986, Hall and Fofonoff 1993). Talley and Raymer (1982) found potential vorticities less than $5 \times 10^{-1} \mathrm{~m}^{-1} \mathrm{~s}^{-1}$ corresponded to the core of the NASTMW layer near Bermuda. For comparison, Ebbesmeyer and Lindstrom (1986) found the potential vorticity values of the seasonal and main pycnoclines to be greater than $50 \times 10^{-11}$ and $15 \times 10^{-11} \mathrm{~m}^{-1} \mathrm{~s}^{-1}$, respectively. Again, these values indicate that although the STMW layer coincides with the stratification minimum between the seasonal and main pycnoclines, it is not truly vertically homogeneous, but has a density gradient/stratification associated with it.

The STMW also appears to have horizontal gradients in its properties which vary with time of year. Newly formed NASTMW has been observed in patches of "homogeneous regions separated by sharp gradients" (Ebbesmeyer and Lindstrom 1986) on scales of 100's of kilometers (Leetmaa 1977, Talley and Raymer 1982, Ebbesmeyer and Lindstrom 1986). Ebbesmeyer and Lindstrom (1986) showed that these patches of NASTMW with horizontally homogeneous properties can exist for up to 16 months after they were formed. Brundage and Dugan (1986) document the properties of several anticyclonic eddies imbedded in the NASTMW layer. The typical length scales of these eddies were $100 \mathrm{~km}$, and the NASTMW in the eddies was typically thicker (over $500 \mathrm{~m}$ thick) and more isothermal than the 
surrounding NASTMW. They speculated that the eddy they observed near $30^{\circ} \mathrm{N}$, $69^{\circ} \mathrm{W}$ in July and August of 1981 was formed to the northwest during the previous winter by convective mixing of the NASTMW layer.

A general east-west gradient in the STMW layyer temperature, salinity, and density properties is also well documented. STMW is warmer, saltier, and less dense to the west than to the east. To the west, the NASTMW layer properties tend to be $18.0-18.6^{\circ} \mathrm{C}, 36.49-36.57 \%$, and $26.29-26.46 \mathrm{~kg} \mathrm{~m}^{-3}$; while to the east they tend to be $17.40-17.74{ }^{\circ} \mathrm{C}, 36.45-36.50 \%$, and $26.44-26.55 \mathrm{~kg} \mathrm{~m}^{-3}$ (McCartney et al. 1980, Talley and Raymer 1982, Ebbesmeyer and Lindstrom 1986, Hall and Fofonoff 1993). These east-west gradients have been observed in newly formed NASTMW (Talley and Raymer 1982, Hall and Fofonoff 1993), and persist as the STMW is advected through the subtropical gyre (Ebbesmeyer and Lindstrom 1986, Klein and Hogg 1996).

\subsection{STMW in Other Gyres}

The STMW layer in the North Pacific (NPSTMW) is found between the seasonal and main thermoclines south of the Kuroshio Extension to approximately $20^{\circ} \mathrm{N}$, similar to NASTMW, and east to approximately $180^{\circ} \mathrm{E}$ (Masuzawa 1969 , Masuzawa 1972, Suga et al. 1989, Qui and Joyce 1992, Hanawa and Suga 1995). The NPSTMW layer is thinner and shallower than in the North Atlantic (Warren 1972, Hanawa and Hoshino 1988, Hall 1989). In the North Pacific, the STMW layer tends to lie between depths of 100 and $300 \mathrm{~m}$ ( $200 \mathrm{~m}$ thickness, centered near $200 \mathrm{~m}$ ), with maximum depths to $400 \mathrm{~m}$ (Masuzawa 1969, Masuzawa 1972, Hanawa 
1987, Suga et al. 1989, Qui and Joyce 1992). In comparison, the NASTMW layer tends to be found between 200 and $400 \mathrm{~m}$ ( $200 \mathrm{~m}$ thickness, centered at $300 \mathrm{~m}$ ), with maximum depths to 500-600 m (Schroeder et al. 1959, Istoshin 1961, Leetmaa 1977, Worthington 1977, Ebbesmeyer and Lindstrom 1986, Taft et al. 1986, Hall and Fofonoff 1993). These differences in thickness and depth of the North Atlantic and North Pacific STMW layers may be explained in part by the shallower and sharper thermocline in the North Pacific than in the North Atlantic, allowing for deeper mixed layers to form in winter in the North Atlantic (Warren 1972).

The NPSTMW has a wider range of temperatures and is typically less dense than its North Atlantic counterpart. The core of the NPSTMW layer has temperatures ranging from $16-18{ }^{\circ} \mathrm{C}$ (some authors use the range $15-19^{\circ} \mathrm{C}$ ), salinities $34.75-34.85 \%$, densities $25.0-25.4 \mathrm{~kg} \mathrm{~m}^{-3}$, and dissolved oxygen concentrations approximately $5 \mathrm{ml} \mathrm{l}^{-1}$ (Masuzawa 1969, Masuzawa 1972, Hanawa and Suga 1995). Based on a volumetric census of the upper $1000 \mathrm{~m}$ of the central North Pacific, the volume of STMW ranges from 670 to $1000 \times 10^{3} \mathrm{~km}^{3}$, depending on the temperaturesalinity ranges used to characterize NPSTMW (Masuzawa 1969, Masuzawa 1972).

Just as in the North Atlantic, the NPSTMW layer contains vertical and horizontal gradients in its properties. Vertical temperature gradients through the STMW layer range from $0.2^{\circ} \mathrm{C}$ per $100 \mathrm{~m}$ in layers recently exposed to atmospheric cooling to $0.7-0.8^{\circ} \mathrm{C}$ per $100 \mathrm{~m}$ in layers with no recent exposure to the atmosphere (Masuzawa 1972, Hanawa 1987, Hanawa and Suga 1995). A vertical temperature gradient of $1.5^{\circ} \mathrm{C}$ per $100 \mathrm{~m}$ has been used as an upper limit in identifying the NPSTMW layer (Hanawa and Suga 1995, Yasuda and Hanawa 1997). 
The potential vorticity values used to identify the NPSTMW layer are $2-3 \times 10^{-10}$ $\mathrm{m}^{-1} \mathrm{~s}^{-1}$ (Suga et al. 1989, Bingham 1992, and Suga and Hanawa 1995b), which are

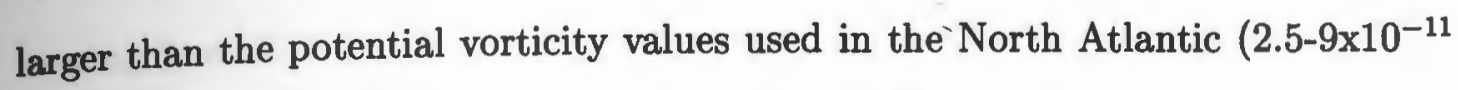
$\left.\mathrm{m}^{-1} \mathrm{~s}^{-1}\right)$.

As in the North Atlantic, the NPSTMW layer has an east-west gradient in its properties. The NPSTMW layer is again warmer and less dense in the west than in the east (Masuzawa 1969, Suga et al. 1989). To the west, the NPSTMW layer properties tend to be $17.5-19.0^{\circ} \mathrm{C}$ and $24.75-25.35 \mathrm{~kg} \mathrm{~m}^{-3}$; while to the east they tend to be $16.5-17.7^{\circ} \mathrm{C}$ and $25.0-25.6 \mathrm{~kg} \mathrm{~m}^{-3}$ (Massuzawa 1972, Warren 1972, Suga et al. 1989, Suga and Hanawa 1990, Bingham 1992). An east-west gradient in salinity is less apparent than temperature (Masuzawa 1972, Suga and Hanawa 1990).

Using Expendable Bathythermograph (XBT) observations collected primarily during the austral summer, Roemmich and Cornuelle (1992) were able to demonstrate the existence of a STMW layer in the South Pacific Ocean. This STMW layer lies equatorward of the East Australia current to approximately $25^{\circ} \mathrm{S}$, and east to approximately $160^{\circ} \mathrm{W}$. It is shallower and thinner than the NPSTMW layer. In the South Pacific, it is approximately $120 \mathrm{~m}$ thick, and centered at a depth of $150 \mathrm{~m}$. In comparison, the NPSTMW layer has typical thicknesses of $200 \mathrm{~m}$, centered near $200 \mathrm{~m}$ (Masuzawa 1969, Hanawa 1987, Qui and Joyce 1992). This is again attibuted to a shallower main thermocline equatorward of the East Australia Current than equatorward of the Kuroshio (Roemmich and Cornuelle 1992). 
The South Pacific STMW (SPSTMW) layer has temperatures ranging from 15 to $17^{\circ} \mathrm{C}$ from 30 to $35^{\circ} \mathrm{S}$ and 17 to $19^{\circ} \mathrm{C}$ from 30 to $25^{\circ} \mathrm{S}$, with salinities ranging from 35.4 to $35.6 \%$, and potential densties at its core of $26.0 \mathrm{~kg} \mathrm{~m}^{-3}$ (Roemmich and Cornuelle 1992). While the SPȘTiMW has a temperature range similar to NPSTMW, it has higher salinities and is therefore denser.

As in the North Atlantic and North Pacific, vertica, and horizontal temperature gradients are found in the SPSTMW layer. In general, the SPSTMW layer is not as vertically homogeneous, horizontally uniform, or found as extensively throughout the subtropical gyre as the other STMW layers (Roemmich and Cornuelle 1992). Vertical temperature gradients through the layer range from 1.4 to $1.7^{\circ} \mathrm{C}$ per $100 \mathrm{~m}$, which are larger than the gradients reported in the North Atlantic or North Pacific. (Again, the South Pacific temperature gradients are biased towards summer observations when the layer would experience its highest degree of stratification.) The SPSTMW also has an east-west horizontal gradient in its properties with the thickest layers again having colder temperatures to the east than the west (Roemmich and Cornuelle 1992).

\subsection{STMW Formation}

STMW forms in late winter to early spring (February through April in Northern Hemisphere) after atmospheric cooling has removed the seasonal stratification on the equatorward side of separated western boundary currents, exposing thick mixed layers to direct atmospheric cooling (Schroeder et al. 1959, Istoshin 1961, Ebbesmeyer and Lindstrom 1986, Hanawa 1987, Suga et al. 1989, Bingham 1992). 
During this time, the STMW layer experiences convective mixing which removes any pre-existing vertical gradients, thus "renewing" its vertical homogeneity, and increasing the dissolved oxygen content from the surface down to the top of the main thermocline, thus "ventilating" these waters while they are in direct contact with the atmosphere (Worthington 1959, Istoshin 1961, Worthington 1972, Leetmaa 1977, Worthington 1977, Talley and Raymer 1982, Ebbesmeyer and Lindstrom 1986, Hanawa 1987, Suga and Hanawa 1990). Temperature and salinity along isopycnals also increase through STMW formation (Jenkins 1982, Marsh and New 1996). The convective mixing events seem to increase the horizontal temperature gradients in the STMW layer while making it more vertically homogeneous. McCartney et al. (1980) found the STMW layer to be more horizontally uniform before wintertime cooling and convection than after.

The areas in the North Atlantic and North Pacific where the STMW layer is exposed to direct atmospheric cooling and active renewal lie in extensive, although poorly delineated, regions south of the Gulf Stream and the Kuroshio. In the North Atlantic, the southern limit of the STMW formation region is approximately 33$35^{\circ} \mathrm{N}$, based on wintertime air and sea surface temperatures (Worthington 1959, Istoshin 1961, Warren 1972, Fieux and Stommel 1975), while the northern and western limits are the Gulf Stream (Worthington 1959). The eastern limit has not been well established, but is generally thought to lie near $45^{\circ} \mathrm{W}$ (Worthington 1959, Worthington 1972). Woods and Barkmann (1986) found through a lagrangian integration of a mixed layer model forced by surface heat fluxes that STMW could form as far east as the Azores Islands. 
Suga and Hanawa (1990) defined the NPSTMW formation region as those areas south of the Kuroshio with February and March mixed layer depths greater than $300 \mathrm{~m}$. Based on this definition, they found the formation region to lie south of the Kuroshio and east of $132^{\circ} \mathrm{E}$. The southern limit varied with longitude from $29^{\circ} \mathrm{N}$ between 132 and $140^{\circ} \mathrm{E}$, to $30^{\circ} \mathrm{N}$ between 140 and $150^{\circ} \mathrm{E}$, and $31^{\circ} \mathrm{N}$ east of $150^{\circ} \mathrm{E}$. The eastern limit of STMW formation was again ${ }_{\mu}$ difficult to determine due to the lack of data.

These STMW formation/renewal regions are also those areas south of the separated western boundary currents with the deepest main thermocline, allowing for the thickest mixed layers once the seasonal stratification is removed (Worthington 1977, Suga and Hanawa 1990, Bingham 1992). Suga and Hanawa (1990) and Bingham (1992) found the temperatures and salinities of wintertime mixed layers deeper than $300 \mathrm{~m}$ corresponded to NPSTMW temperatures and salinities. They found a weaker correlation for winter mixed layers only $200 \mathrm{~m}$ deep. The deepest depressions of the main thermocline are associated with anti-cyclonic eddies, rings, and meanders. These features are sites of the thickest mixed layers and deepest convection in winter (Leetmaa 1977, Bingham 1992, Roemmich and Cornuelle 1992, Suga and Hanawa 1995b, Klein and Hogg 1996). Brundage and Dugan (1986) document the properties of several anticyclonic eddies with typical length scales of $100 \mathrm{~km}$ imbedded in the NASTMW layer. The STMW layer was thicker, the main thermocline was depressed downward, and the seasonal thermocline was compressed upward in these eddies relative to the surrounding STMW layer, implying they were sites of thicker winter mixed layers and deeper convection than 
the surrounding waters.

Rather than form STMW by convective mixing in the thick mixed layers south of the Kuroshio, Bingham (1992) described NPSTMW formation in two steps: cooling of water parcels above the Kuroshio's relatively shallow thermocline as they move downstream, and thickening of the mixed layer south of the Kuroshio as the parcels leave the Kuroshio. The presence of the shallow thermocline in the Kuroshio allows the intense wintertime cooling to decrease the temperature of the water parcels as they travel with the Kuroshio. These water parcels then accumulate south of the Kuroshio, thickening the mixed layers, and forming STMW "source regions." The temperature of the STMW advected away from these "source regions" is determined by where the water parcels leave the Kuroshio. The temperature of the water parcels in the source regions to the east are colder than to the west because they were subject to atmospheric cooling for a longer period in the Kuroshio.

I will define STMW formation/renewal as the removal of the seasonal stratification and the resetting of the temperature gradient through the STMW layer to zero.

Estimates of the amount of NASTMW formed each winter have been found using a variety of mixed layer mass and heat flux models. Woods and Barkmann (1986) used a lagrangian integration of a one-dimensional mixed layer model forced by surface heat fluxes and Ekman pumping to arrive at an estimate of $446 \times 10^{3} \mathrm{~km}^{3}$ formed each year. Speer and Tziperman (1992) found $440 \times 10^{3} \mathrm{~km}^{3}$ of NASTMW formed each year based on the cross-isopycnal mass flux estimated from air-sea heat 
and freshwater fluxes. Qui and Huang (1995) estimated the mass flux between the mixed layer and permanent thermocline by integrating along particle trajectories initially at the maximum mixed layer depth in March to the following March using climatological hydrographic and wind stress data.' They attributed the peak mass flux of $419 \times 10^{3} \mathrm{~km}^{3}$ per year between densities 26.0 and $27.0 \mathrm{~kg} \mathrm{~m}^{-3}$ to NASTMW formation. If the volume of NASTMW is $1672 \times 10^{3} \mathrm{~km}^{3}$ (the volume of water with temperatures ranging from 17 to $19^{\circ} \mathrm{C}$ ), these formation estimates indicate that roughly $25 \%$ of the NASTMW layer is renewed each winter, or the entire NASTMW layer is renewed every four years.

However, the degree of STMW formation/renewal varies considerably from one winter to the next. By looking at the changes in salinity along isopycnals, Jenkins (1982) found the annual NASTMW renewal rate varied by as much as a factor of two between 1954 and 1980. The NASTMW layer is known to have undergone significant, large-scale renewal in the mid- and late 1960's, 1977, and 1982, with less to no renewal in other winters (through 1988) (McCartney et al. 1980, Jenkins 1982, Talley and Raymer 1982, Klein and Hogg 1996, Jenkins (In Press) ). Jenkins (1982) suggests that the STMW layer responds rapidly to the large-scale convective events which set its core properties, and that its properties relax more slowly during years of poor ventilation. The STMW layer, then, contains an interannual memory of the degree of ventilation/renewal the subtropical gyre experiences down to the main thermocline in a particular winter (Jenkins 1982, Woods and Barkmann 1986, Roemmich and Cornuelle 1992). 


\subsection{STMW Advection and Dissipation}

Although STMW formation appears limited to the northwestern portions of the subtropical gyre, its temperature, salinity, and density characteristics can be found at the stratification minimum throughout much of the subtropical gyre. Since the sea surface in the southern portions of the subtropical gyre is never cooled enough to expose these waters to direct atmospheriq cooling and convective mixing, these waters must have been advected from the formation regions to the north by the anticyclonic (clockwise) subtropical gyre circulation (Schroeder et al. 1959, Worthington 1959, Istoshin 1961, McCartney et al. 1980, McCartney 1982, Talley and Raymer 1982, Ebbesmeyer and Lindstrom 1986, Suga et al. 1989, Suga and Hanawa 1990, Klein and Hogg 1996). The horizontal gradients in the STMW layer (colder, fresher to the east, warmer, saltier to the west) are maintained as the STMW is advected around the subtropical gyre, at least for several months after their winter formation (Ebbesmeyer and Lindstrom 1986, Suga and Hanawa 1995b). The warmer STMW to the west is advected eastward, while the colder STMW is advected southwestward (McCartney et al. 1980, Talley and Raymer 1982). Suga et al. (1989) found a bimodal distribution of NPSTMW properties along a repeated north-south section at $137^{\circ} \mathrm{E}$. They found the warmer, saltier NPSTMW which formed east of $137^{\circ} \mathrm{E}$ in winter would arrive at the $137^{\circ} \mathrm{E}$ section the following summer, and the colder fresher NPSTMW which formed farther to the east would arrive the following winter and farther south than the warmer NPSTMW had in summer. Since the warmer NPSTMW formed closer to the 
$137^{\circ} \mathrm{E}$ meridian, it had a shorter path than the colder NPSTMW which formed farther to the east. The colder NPSTMW took a longer path which also advected it farther south.

The suggested advection rates of NASTMW range from four to seven $\mathrm{cm} \mathrm{s}^{-1}$ (Talley and Raymer 1982, Ebbesmeyer and Lindstrom 1986, Suga and Hanawa 1990, Klein and Hogg 1996). Based on changes in temperature and salinities from two sections along the $55^{\circ} \mathrm{W}$ meridian three months apart, McCartney et al. (1980) estimated advection rates as high as $25 \mathrm{~cm} \mathrm{~s}^{-1}$ from west to east in the northern portion of the section and $11 \mathrm{~cm} \mathrm{~s}^{-1}$ from northeast to southwest in the southern portion of the section.

STMW layers have been identified for six to eighteen months after their formation based on their oxygen content (Suga et al. 1989), potential vorticity (Suga and Hanawa 1995b), or horizontal homogeneity (Ebbesmeyer and Lindstrom 1986). STMW formed in a particular winter loses its distinguishing characteristics two years after its formation (Jenkins 1982, Suga et al. 1989). Suga et al. (1989) found that the thickness of the NPSTMW layer decreased from $\sim 90 \mathrm{~m}$ six months after formation to $\sim 65 \mathrm{~m}$ one year after formation. The mechanism(s) responsible for the dissipation of STMW layer within two years of its formation are not clearly known. However, several authors have suggested the STMW layer experiences turbulent vertical mixing as it is advected around the subtropical gyre. The fact that the potential vorticity of the STMW layer increases as the STMW moves away from its formation region suggests that some mixing in the layer does occur (McCartney 1982). Suga et al. (1989) and Bingham (1992) suggest that the bottom of 
the NPSTMW layer undergoes diapycnal mixing with the main thermocline. Suga and Hanawa (1995c) found indications of mixing by salt fingering at the core and bottom of the NPSTMW layer. Warren (1972) explains the relatively constant salinity of the NASTMW layer and the southward extension of STMW away from its formation area using a one-dimensional model and vertical diffusion of heat and salt. He found a vertical diffusivity of $1 \mathrm{~cm}^{2} \mathrm{~s}^{-1}$ for both $\mathrm{f}_{\mathrm{f}}$ temperature and salinity. Since these diffusivities are equal and much larger than the molecular diffusivities of heat and salt, Warren's one-dimensional model suggests some sort of turbulent mixing is taking place in the NASTMW layer. McCartney (1982) discusses lateral advection-lateral diffusion and lateral advection-cross-isopycnal (double-diffusive) balances in explaining the distribution of STMW properties in the subtropical gyre.

\subsection{Interannual Variability}

Although the STMW layer's properties were initially thought to be relatively constant (Schroeder et al. 1959, Worthington 1959), significant interannual variations in its properties have more recently been observed. Using hydrographic data collected once or twice monthly in the vicinity of Bermuda $\left(32^{\circ} 10^{\prime} \mathrm{N}, 64^{\circ} 30^{\prime} \mathrm{W}\right)$ by the Bermuda Biological Station's Vessel Panulirus, Talley and Raymer (1982) were able to identify four different periods between 1954 and 1978 in which the NASTMW layer near Bermuda had distinctly different properties.

1. From 1954 to 1964 , the NASTMW layer had temperatures, salinities, and densities very near the "typical/classical" values previously discussed ( 
$18^{\circ} \mathrm{C}, \sim 36.5 \%$ \% $\sim 26.4 \mathrm{~kg} \mathrm{~m}^{-3}$ ).

2. From 1964 to 1972 , the NASTMW layer became progressively colder (to $17.1^{\circ} \mathrm{C}$ ), saltier (to $36.6^{\circ} \%$ ), and denser $\left(26.6 \mathrm{~kg} \mathrm{~m}^{-3}\right.$ ), resulting in warmer temperatures (by 0.2 to $0.3^{\circ} \mathrm{C}$ ) along isopycnál surfaces. Fieux and Stommel (1975) found the mean March sea surface temperatures at the latitudes consistent with NASTMW formation $\left(34-38^{\circ} \mathrm{N}\right.$ ) , were also colder in the 1960 's to 1972 than they were in the 1950 's.

3. Talley and Raymer (1982) argued that no NASTMW formed from 1972 to 1975 due to the increased stratification of the layer over this time.

4. NASTMW formation resumed in 1975 or 1976 , with the NASTMW in 1978 again having temperatures, salinities, and densities similar to the "typical/classical" values $\left(18.1{ }^{\circ} \mathrm{C}, 36.5 \%\right.$ oo $\left.26.5 \mathrm{~kg} \mathrm{~m}^{-3}\right)$.

In discussing Talley and Raymer's results, McCartney (1982) highlighted the different scales of the temporal variability near Bermuda, ranging from the annual cycle to the four multiple-year trends to the large episodic changes such as large increases in density at the end of 1964 and 1977 . He also emphasized the similarity in the range of temporal variability of STMW properties at one location and the range of spatial variability in a synoptic section.

Klein and Hogg (1996) looked at the variations in the NASTMW layer in 1988, 1989, and 1990 using Panulirus hydrographic, XBT, and current meter data. They found over these three years that the NASTMW layer was warmer and saltier than the "classic" definition of NASTMW $\left(18.18 \pm 0.3^{\circ} \mathrm{C}, 36.5 \pm 0.005^{\circ} \%\right)$. They also 
argued that no recently NASTMW was observed off Bermuda in 1989 or 1990, again due to the increased stratification of the NASTMW layer.

By using hydrographic data collected twice a year along a north-south section at $137^{\circ} \mathrm{E}$ south of Japan, Suga et al. (1989) found the themperatures at the core the NPSTMW layer varied by $\sim 1.5^{\circ} \mathrm{C}$, salinity by $\sim 0.1 \%$, and density by $\sim 0.5 \mathrm{~kg}$ $\mathrm{m}^{-3}$, and they found the range of interannual variability to decrease with time after formation. Because the SPSTMW layer is thinner, it experiences more interannual variability in its properties and volume formed than the North Atlantic or North Pacific (Roemmich and Cornuelle 1992). Roemmich and Cornuelle (1992) showed that warmer sea surface and air temperatures lead to a decrease in the volume of STMW formed between 1986 and 1991, increased stratification, and increased temperature at the stratification minimum.

Although STMW formation/renewal is often described in terms of wintertime cooling and convective cooling, a direct connection between the degree of renewal the STMW experiences during a particular winter and the ocean-atmosphere heat flux during that winter has been difficult to establish (Jenkins 1982, Talley and Raymer 1982, Hanawa and Hoshino 1988). Observations of newly formed STMW in or near the limited STMW formation regions are dependent on the amount of wintertime cooling, which determines the intensity of local convection and the degree of ventilation/renewal of the local STMW (Klein and Hogg 1996). STMW properties later in the year and outside of the formation areas, however, depend on a "complicated nonlinear interaction between the seasonal (ocean-atmosphere) boundary layer and the gyre circulation" (Woods and Barkmann 1986). The 
STMW properties at a particular location could change due to changes in the STMW formed the previous winter and advected to that location, and/or changes in the circulation changing the type of STMW advected to the location.

It is a general problem of studies of $18^{\circ} \mathrm{C}$. Water variability based on hydrographic data at a fixed point, away from the formation areas (and not spanning the whole gyre), to distinguish between changes in $18^{\circ} \mathrm{C}$ Water properties that are caused by variations in the external forcing and those that are caused due to changes in the circulation (Klein and Hogg 1996).

In trying to explain the interannual variability in NASTMW properties at the Panulirus hydrographic station, Talley and Raymer (1982) looked for a correlation between the observed STMW properties and the heat flux over the region 34$36^{\circ} \mathrm{N}, 65-70^{\circ} \mathrm{W}$. They found "little direct relation" between the two. Given the STMW arriving at Panulirus $\left(32^{\circ} 10^{\prime} \mathrm{N}, 64^{\circ} 30^{\prime} \mathrm{W}\right)$ would most likely have formed to the northeast and then be advected to the southwest by the subtropical gyre recirculation, there may be a stronger relation between the heat flux farther to the east and the STMW properties at Panulirus.

Warren (1972) examined the influence of variations in atmospheric cooling on the upper ocean heat balance using a one-dimensional model, neglecting horizontal and vertical advection and diffusion of heat. Using this model and climatological wind speed, air temperature, humidity, and sea surface temperature, he was able to closely match the observed sea surface temperature and winter maximum mixed layer depth in the STMW region. He concluded that, since (1) most of the cooling 
in winter goes into removing the seasonal thermocline, (2) the STMW layer is exposed to direct atmospheric cooling for only 1-2 months, and (3) the STMW is a thick layer with a large heat capacity, STMW characteristics are insensitive to variations in the winter ocean-atmosphere heat flux.

Along the same lines as Warren (1972), Jenkins (1982) argued using ${ }^{3} \mathrm{He}$ tracer data that the STMW layer contains an "interannual memory" wherein its properties are set during severe winters of strong atmospheric cooling and convective mixing, but relax slowly during years of little or no renewal. Using salinity and tracer data, he also argued that the ventilation of the STMW layer occurs mainly along isopycnals, and that any change in the strength of winter cooling must affect a large enough area that it affects the widely distributed winter outcrop areas of the isopycnals.

Marsh and New (1996) used an Isopycnic-Coordinate Ocean Circulation model to examine the relationship between the buoyancy flux (driven by the oceanatmosphere heat flux) and variations in NASTMW properties at Panulirus. They were able to replicate the change in NASTMW properties at Panulirus in the late 1960's (colder, denser) by forcing the model with five anomalously cold winters driving an anomalously strong buoyancy flux, creating thicker, denser mixed layers south of the Gulf Stream. However, unlike Talley and Raymer (1982), they found a strong correlation between variations in heat loss and NASTMW properties at Panulirus. Also, since the subtropical gyre circulation varied little within the model, they were unable to examine how changes in the advection of STMW may contribute to variations in STMW properties over time at a fixed point. 
Klein and Hogg (1996) used current meter, XBT, and Panulirus hydrographic observations to look at the variations in NASTMW properties in 1987, 1988, and 1989. They found that the temperatures at the STMW core were $0.1-0.3^{\circ} \mathrm{C}$ warmer than the "classic" definition $\left(17.9^{\circ} \mathrm{C}\right)$, and that the temperatures at the STMW core increased by $0.4^{\circ} \mathrm{C}$ from 1987 to 1989 . They found that the ocean- atmosphere heat loss in the winters of 1987 and 1988 was larger than the 1987-1992 mean, while the heat loss in 1989 (and 1990 and 1991) was much less than the six-year mean. Therefore, the reason the NASTMW was warmer in 1989 than 1987 or 1988 seems to be due to the decrease in the atmospheric cooling in winter. However, the heat loss in 1988 was greater than the six-year mean and yet the temperatures at the NASTMW core increased from 1987 to 1988 . Also, Hall and Fofonoff (1993) and Klein and Hogg (1996) found a thick NASTMW layer with colder, fresher, denser properties formed in the eastern portion of the subtropical gyre in 1988. However, this class of STMW was advected to the east, not southwest, by changes in the circulation, and not incorporated into the subtropical gyre (Klein and Hogg 1996). Therefore, the reason NASTMW was warmer in 1988 than in 1987 was determined more by changes in circulation than changes in winter ocean-atmosphere heat flux. Klein and Hogg (1996) also point out that winters of stronger atmospheric cooling are now required in order to reset the warmer STMW temperatures to "classical" temperatures, supporting Jenkin's (1982) description of STMW properties which are set during severe winters and relax more slowly during years of little or no renewal, i.e., an "interannual memory." 
Changes in the North Pacific subtropical gyre circulation also have a strong influence on its STMW properties. The Kuroshio exhibits a very different behavior than the Gulf Stream, with the Kuroshio existing in one of two stable paths. The Kuroshio south of Japan can exist in either an inş̧ore "non-meander" path or an offshore "large meander" path for several years at a time (Shoji 1972, Taft 1972, Kawabe 1985). The NPSTMW seems to be thicker, denser, and horizontally more uniform in meander than non-meander years (Suga and Hanawa 1995b). However, less NPSTMW is observed along the $137^{\circ} \mathrm{E}$ north-south repeat section south of Japan during meander than non-meander years (Suga et al. 1989, Suga and Hanawa 1995a,b,c). Suga and Hanawa (1995a,b,c) used changes in the subtropical gyre circulation associated with changes in the path of the Kuroshio to explain these observations. During years when the Kuroshio is in its non-meander path, an intense anti-cyclonic gyre forms near $30-35^{\circ} \mathrm{N}, 135-140^{\circ} \mathrm{E}$, resulting in NPSTMW formed east of $137^{\circ} \mathrm{E}$ to be advected southwest to $137^{\circ} \mathrm{E}$. However, during years when the Kuroshio is in its large meander path, there is no advection from east of $140^{\circ} \mathrm{E}$ to the west (Suga and Hanawa 1995b). While Suga and Hanawa (1995a) did not find a significant correlation between oxygen content (degree of ventilation) or potential vorticity (degree of stratification) of the STMW layer and wintertime cooling when looking at all years, they found a good correlation for non-meander periods only. Thus, they were able to explain changes in NPSTMW properties by changes in the amount of atmospheric cooling when they took into account changes in the circulation. 
In looking at decadal changes in the NPSTMW, Yasuda and Hanawa (1997) found the NPSTMW was colder east of $140^{\circ} \mathrm{E}$, warmer west of $140^{\circ} \mathrm{E}$, and had a greater eastern extent during the period 1976-1985 than 1966-1975. They explained the colder STMW temperatures in 1976-1985 to thie east by an intensification of the Aleutian Low and the associated westerly winds leading to increased winter ocean-atmosphere heat loss and heat divergence in the Ekman layer. They argue the warmer STMW temperatures to the west as well as the greater eastern extent of STMW in 1976-1985 were due to an increase in the Kuroshio transport leading to increased advection of warmer waters to the western STMW formation regions.

\subsection{Importance of STMW}

The STMW layer is important for several reasons:

1. The STMW formation regions are sites of the largest winter-time oceanatmosphere heat loss. We now understand that some of this heat flux is used to remove the seasonal stratification and some of it is used to reset the vertical homogeneity through the STMW layer.

2. The STMW may contribute to the maintenance of the subtropical front (Suga et al. 1989, Suga and Hanawa 1990). Hydrographic observations in the North Pacific have found a stronger subtropical front farther to the north when a thick NPSTMW layer has been advected to just north of the front, and the opposite (weaker front farther south) when a thinner NPSTMW layer has been advected to the south (Suga et al. 1989). 
3. The STMW is the largest water mass above the main thermocline, and, as such, contains the interannual memory of the subtropical gyre (Roemmich and Cornuelle 1992). The STMW layer's "interannual memory," which is set during winters of strong cooling but relaxes during periods of little or no cooling (Jenkins 1982), will have an important influence on the subtropical gyre's winter mixed layer temperatures for several ,years (Hanawa 1987).

4. The STMW's ventilate the central waters (McCartney 1982) and main thermocline (Woods and Barkmann 1986) of the subtropical gyre. This ventilation is important in that it is a means by which variations in climate may be introduced to the main thermocline (Leetmaa 1977, McCartney et al. 1980, Woods and Barkmann 1986).

5. The STMW layer is a dynamically active layer. Not only does the circulation have an influence on the STMW properties, several numerical modelling studies have demonstrated an intimate relationship between the STMW layer and the anticyclonic recirculation gyre south of the Gulf Stream and Kuroshio (Cushman-Roisin 1987 and Huang 1990).

Therefore, characterizing the STMW layer and the range of its interannual variability is an important step in assessing the impact changes in climate can have on the characteristics and circulation of the subtropical gyre.

The previous studies of STMW discussed thus far have characterized the STMW layer based primarily on the properties at the potential vorticity minimum. Because of the need for temperature and salinity data to find potential density, this 
approach limited these studies to individual years and locations of data-intensive oceanographic studies such as POLYMODE (Ebbesmeyer and Lindstrom 1986), or SYNOP (Hall and Fofonoff 1993 and Klein and Hogg 1996) or to the Panulirus time series near Bermuda (Talley and Raymer 1982). Rather than characterize the STMW layer using a density gradient-based criteria and $a_{i}$ single point in the layer, this study characterizes the North Atlantic STMW layer ysing a temperature-based criteria. By using temperature alone, this study has the advantage over the previous studies of being able to use the large volumes of XBT data collected since 1965 to look at STMW properties over large time and space scales. In the next chapter, the methods used to identify the STMW layer and determine its properties will be discussed. Following this, two characterizations of STMW renewal events will be presented, along with a criteria based on these characterizations which establishes the years and locations in the North Atlantic of STMW layer renewal by convective mixing. Next, the annual and interannual changes in the NASTMW layer will be discussed. Finally, the mean spatial distribution of properties in the NASTMW layer will be discussed. 


\section{Chapter 2}

\section{Procedures: Finding the STMW Layer and Its Mean Properties}

The goal here is to form a climatology of NASTMW properties by combining Hydrographic Station, Conductivity/Temperature/Depth (CTD), and Expendable Bathythermograph (XBT) data. Yasuda and Hanawa (1997) formed a NPSTMW climatology by combining similar data types. Following a description of the data types used to form the climatology, the methods used to identify the NASTMW layer, determine the NASTMW layer characteristics, and finally assemble the climatology will be discussed.

\subsection{Data Sources}

\subsubsection{World Ocean Atlas}

The major source of hydrographic data for this study was the World Ocean Atlas (WOA) 1994, produced by the National Oceanographic Data Center's (NODC) Ocean Climate Laboratory (OCL). This dataset is a compilation of all hydographic data in the NODC archives as of 1993 with data gathered by NODC's 
Oceanographic Data Archaeology and Rescue (NODAR) and the Intergovernmental Oceanographic Commission (IOC) Global Oceanographic Data Archaeology and Rescue (GODAR) projects (Boyer and Levitus 1994).

The historical hydrographic data in this datasset were collected using three different methods:

1. Hydrographic Casts (Station Data) measured temperature using deep-sea reversing thermometers and measured salinity, oxygen, and/or nutrients using sampling bottles. The vertical sampling interval was usually at "Standard Levels" (Table 2.1) which had a finer sampling interval above the main thermocline and a coarser sampling interval below.

2. Conductivity/Temperature/Depth (CTD) instruments (as well as Salinity/ Temperature/Depth (STD) instruments) continuously measured temperature, conductivity (from which salinity can be determined), and pressure as the instrument was lowered through the water column. Although the instrument continuously measured these properties with depth, the data were typically subsampled to every $20-25$ meters or Standard Levels.

3. Bathythermograph probes (BT's) continuously measured temperature as they fell through the water column at a known rate, so time is equivalent to depth. There are three types of bathythermographs in the dataset - the early mechnical BT's (MBT's), the more recent and widely used Expendable BT's (XBT's), and Digital BT's (DBT's). Again, although the probe continuously measured temperature as it fell through the water column, the data 
Table 2.1: "Standard Level" Vertical Sampling

\begin{tabular}{|c|c|}
\hline Standard Level & Depth (m) \\
\hline 1 & 0 \\
\hline 2 & 10 \\
\hline 3 & 20 \\
\hline 4 & 30 \\
\hline 5 & 50 \\
\hline 6 & 75 \\
\hline 7 & 100 \\
\hline 8 & 125 \\
\hline 9 & 150 \\
\hline 10 & 200 \\
\hline 11 & 250 \\
\hline 12 & 300 \\
$\downarrow$ & Every $100 \mathrm{~m}$ \\
\hline 24 & 1500 \\
\hline 25 & 1750 \\
\hline 26 & 2000 \\
\hline 27 & 2500 \\
\hline 28 & 3000 \\
\hline 29 & 4000 \\
\hline 30 & 5000 \\
\hline
\end{tabular}

were usually subsampled to the inflection points in the temperature profile necessary to reproduce the profile or at Standard Levels.

There are far more BT profiles in the WOA '94 dataset than profiles from the other two measurement techniques (Table 2.2). Although there are more MBT profiles in the dataset than XBT or DBT profiles (Table 2.2), most had a maximum depth less than $300 \mathrm{~m}$ and were therefore too shallow to be used in this study.

Each Station, CTD, and BT profile in the WOA '94 dataset was recorded in two formats: the observed data at the actual observation depths ("Observed 
Table 2.2: Distribution of Data Types in WOA '94 Dataset (Boyer and Levitus 1994).

\begin{tabular}{cr}
\hline Profile Type & Number of Profiles (\% of Total) \\
\hline CTD & $143,455(3 \%)$ \\
Station & $1,194,407(26 \%)$ \\
DBT & $35,015(<1 \%)$ \\
MBT & $1,912,170^{\prime}(42 \%)$ \\
XBT & $1,281,942(28 \%)$ \\
\hline
\end{tabular}

Level" data) and data interpolated to Standard Depth Levels ("Standard Level" data). Quality control procedures were performed on each profile before and after interpolation to Standard Levels. Observed Level profiles were checked for:

1. Duplicate records.

2. Errors in the recorded depths.

3. Errors in the recorded temperatures.

Standard Level profiles were checked for:

1. Density inversions.

2. Data outliers at each depth level.

Only profiles identified as duplicates were removed from the WOA '94 dataset. No other data were eliminated as a result of these quality control procedures. Rather, quality control flags are included to indicate which quality control criteria a profile failed to meet (Boyer and Levitus 1994).

The Standard Level data were then averaged into $1^{\circ}$ latitude $\times 1^{\circ}$ longitude squares in preparation for interpolating the data to a $5^{\circ}$ latitude $\times 5^{\circ}$ longitude 
grid. Profiles which created large gradients or "bulleyes" in the $1^{\circ} \times 1^{\circ}$ averages were flagged as outliers. In some cases, all profiles from a particular cruise were outliers relative to other data in a square. In this case these profiles were flagged in both the Observed Level and Standard Level datásęts (Boyer and Levitus 1994).

Although more quality control checks were performed, on the Standard Level data, the Observed Level data were chosen for determing the STMW properties in this study in order to maximize the vertical sampling in the STMW layer, from $\sim 200$ to $\sim 400 \mathrm{~m}$. The Standard Level data only sampled every 50 or $100 \mathrm{~m}$ at these depth levels (Table 2.1), while the vertical sampling in the Observed Level data was either based on the inflection points in the temperature profile or every $\sim 25 \mathrm{~m}$ (on average).

\subsubsection{Long-term Investigation of Hydro-Meteorological Anomalies}

The second source of hydrographic data for this study was a set of hydrographic profiles collected along 15 repeated sections as part of the Russian North Atlantic research program DIGMA (this Russian acronym stands for the Long-term Investigation of Hydro-Meteorological Anomalies, LIHMA (Belkin, personal communication)). Temperature, salinity, oxygen, and nutrient data were collected using a combination of CTD's and sampling bottles. The data made available for this study were temperature and salinity interpolated to standard levels. Lappo et al. (1995) discusses some of the results from the LIHMA program.

Five of the 15 LIHMA sections transitted through the subtropical gyre and therefore were likely to sample the STMW layer. These sections are shown in Fig- 
ure 2.1 and tabulated in Table 2.3. Although these sections were repeated several times from 1971 through 1985, the temporal sampling was not uniform, i.e., not every section was sampled with the same frequency over the time period. The spatial sampling frequency along a section also variẹd, i.e., not every station along a section was occupied for every transect. Table 2.3 lists the number of stations for each section, along with the spatial and temporal sampling characteristics. Although the $36^{\circ} \mathrm{N}$ section was repeated the most over the time period, 164 transects (or $\approx 11$ times per year), on average less than half of the stations, $(2660 / 164=$ ) 16 of 42 , were occupied per transect. The New York to Bermuda section was also repeated frequently during the time period (on average 7 times per year), but little more than half of its stations (13 of 22) were occupied per transect. The other three sections were repeated on average 2 to 3 times per year. There are a total number of 2452 LIHMA profiles collected in the subtropical gyre region (20 to $45^{\circ} \mathrm{N}, 80$ to $\left.40^{\circ} \mathrm{W}\right)$, far less than the number of WOA '94 profiles in the same region. However, since these sections have been repeated several times over periods ranging from seven to fourteen years, they have an added importance when looking at interannual variability of the STMW characteristics.

The temperature and salinity profiles were quality controlled by contouring each section and identifying gross errors as those which created large gradients ("bullseye's") in the contour plots. Three of the 2452 LIHMA profiles were found to have an erroneous salinity value using this method. These values were either very small $(35.41 \%$ and $35.43 \%$ or very large $(44.14 \%)$ when compared with the surrounding profiles, were most likely due to data recording errors, and 


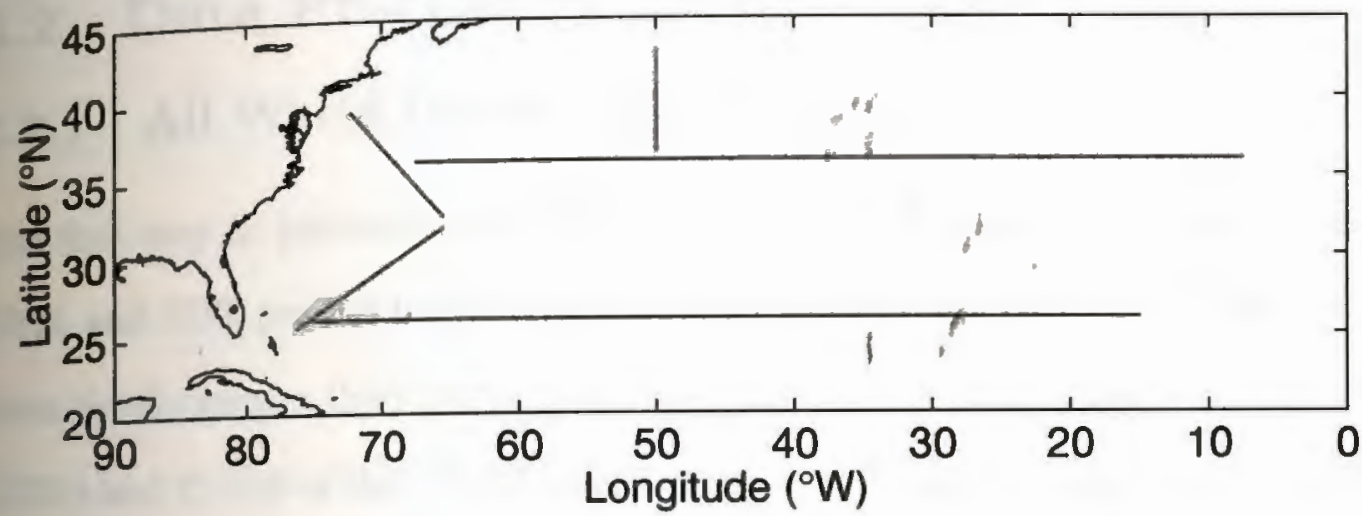

Figure 2.1: The Five LIHMA Sections Used in This Study

Table 2.3: LIHMA Sections' Spatial and Temporal Sampling.

\begin{tabular}{lccccc}
\hline Section & \# Stations & $\begin{array}{c}\text { Station } \\
\text { Spacing }\end{array}$ & Years & \# Transects & $\begin{array}{c}\text { Total } \\
\text { Profiles }\end{array}$ \\
\hline $\begin{array}{c}36^{\circ} \mathrm{N} \\
67.5^{\circ} \mathrm{W}-7.5^{\circ} \mathrm{W}\end{array}$ & 42 & $\sim 250 \mathrm{~km}^{*}$ & $1971-85$ & 164 & 2660 \\
\hline $\begin{array}{c}50^{\circ} \mathrm{W} \\
36.5^{\circ} \mathrm{N}-43^{\circ} \mathrm{N}\end{array}$ & 14 & $\sim 55 \mathrm{~km}$ & $1981-85$ & 14 & 175 \\
\hline $\begin{array}{c}26^{\circ} \mathrm{N} \\
75^{\circ} \mathrm{W}-15^{\circ} \mathrm{W}\end{array}$ & 29 & $\sim 250 \mathrm{~km}$ & $1973-85$ & 35 & 581 \\
\hline $\begin{array}{l}\text { Bermuda - } \\
\text { Bahamas }\end{array}$ & 24 & $50-60 \mathrm{~km}$ & $1973-80$ & 16 & 256 \\
$\begin{array}{c}\text { New York - } \\
\text { Bermuda }\end{array}$ & 22 & $20-70 \mathrm{~km}$ & $1972-81$ & 72 & 970 \\
'Station Spacing $~$ & $45 \mathrm{~km}$ from 40 to $50^{\circ} \mathrm{W}$. & & & \\
\hline
\end{tabular}


were replaced with values based on the surrounding profiles.

\subsection{Data Processing}

\subsubsection{All World Ocean Atlas Profiles}

The first step in processing the WOA '94 data entailed/selecting those Station, CTD, and XBT profiles in the region from 20 to $45^{\circ} \mathrm{N}$ and 80 to $40^{\circ} \mathrm{W}$ with maximum depths greater than $300 \mathrm{~m}$. 145,028 of the 213,837 XBT's, 8,467 of the 21,328 CTD's and 27,229 of the 77,928 Station profiles in this region met this criterion.

The selected profiles were then screened using some preliminary quality control criteria. First records which were exact duplicates (i.e., the same value at each depth level) or had the same latitude, longitude, and date of the preceding profile in the data set were eliminated. Although the WOA '94 dataset had been searched for duplicates and any identified duplicates eliminated, some duplicate records are known to still exist in the dataset (Boyer, personal communication). Most duplicate records will be adjacent records in the dataset since the data were sorted and stored by latitude, longitude, and date.

Next, profiles flagged by the NODC Ocean Climate Laboratory (OCL) as coming from cruises with consistently poor quality control were rejected. Any observation in a profile flagged during processing at the OCL as an outlier, a large temperature inversion, or large temperature gradient was removed from the profile. Outliers were identified by the OCL using a list of depth dependent ranges of temperature and salinity for each ocean basin. Large temperature inversions were defined as an average increase (with increasing depth) of $0.3^{\circ} \mathrm{C} \mathrm{m}^{-1}$ between 
adjacent observations. Large temperature gradients were defined as temperature decreases greater than $0.7^{\circ} \mathrm{C} \mathrm{m}^{-1}$ between adjacent observations (Boyer and Levitus 1994).

The final step in the initial screening process éţ̧ailed selecting only those Station, CTD, and XBT profiles which were in the subtropical gyre and therefore likely to have sampled the STMW layer. The northern and western edges of the subtropical gyre (i.e., the Gulf Stream) were determined based on the depth of an indicative isotherm. The traditional indicator of the Gulf Stream axis is the location of the $15^{\circ} \mathrm{C}$ isotherm at $200 \mathrm{~m}$ (McCartney et al. 1980, Halkin and Rossby 1985). Based on data from free-falling velocity profilers, Halkin and Rossby (1985) found the horizontal midpoint between the $12^{\circ} \mathrm{C}$ isotherm at $400 \mathrm{~m}$ and at $600 \mathrm{~m}$ as a better indicator of the high transport region of the Gulf Stream. However, since many of the XBT profiles used in this study have maximum depths less than $600 \mathrm{~m}$, a shallower equivalent of Halkin and Rossby (1985)'s criterion was needed. Based on their published velocity and temperature sections, the $17^{\circ} \mathrm{C}$ isotherm was located at depths greater than $350 \mathrm{~m}$ on the offshore side (i.e., the subtropical gyre side) of the high velocity core of the Gulf Stream. Johns et al. (1989)'s and Hall and Fofonoff (1993)'s results also support the $17^{\circ} \mathrm{C}$ isotherm at $350 \mathrm{~m}$ as an indicator of the offshore side of the Gulf Stream. Therefore, any profile whose maximum temperature was less than $17^{\circ} \mathrm{C}$ was rejected, as was any profile in the vicinity of the Gulf Stream (north of $35^{\circ} \mathrm{N}$ or west of $70^{\circ} \mathrm{W}$ ) whose $17^{\circ} \mathrm{C}$ isotherm was less than $350 \mathrm{~m}$ deep. 


\subsubsection{WOA XBT Profiles}

Additional processing performed on XBT profiles included correcting for systematic depth errors and removing temperature spikes in the data. The T4, T6, and T7 XBT's have been found to contain systematio errors in the depths estimated using elapsed time and their manufacturer's published fall+rate (Hanawa and Yoritaka 1987, Singer 1990, Hanawa and Yoshikawa 1991, Hallock and Teague 1992, and Hanawa et al. 1995). In general, they fall faster than the published drop rates, resulting in the depths of the actual temperature measurements being greater than the estimated depths. The T4 and T6 XBT probes have a maximum depth of $\sim$ $460 \mathrm{~m}$, while the T7 probes have a maximum depth of $\sim 760 \mathrm{~m}$. The actual drop rate of T-5 XBT probes (maximum depth $>1000 \mathrm{~m}$ ) is within acceptable limits of published values (Boyd and Linzell 1992).

The OCL applied the following drop-rate correction to XBT's with depths shallower than $725 \mathrm{~m}$ before they interpolated the XBT data to Standard Levels:

$$
\begin{gathered}
z_{c}=6.733 t-0.00254 t^{2} \\
t=1498.14-\left(2244447.430-462.963 z_{0}\right)^{1 / 2}
\end{gathered}
$$

where $z_{c}=$ the corrected depth in meters

$$
\begin{aligned}
& \mathrm{t}=\text { elapsed time since deployment of the probe } \\
& z_{0}=\text { the originally estimated/calculated depth }
\end{aligned}
$$

However, the Observed Level Data used here were not corrected. Although there are several published XBT drop-rate corrections, Equations 2.1 and 2.2 were chosen 
for this study to maintain consistency with the WOA '94 Standard Level data. All XBT's shallower than $800 \mathrm{~m}$, rather than the $725 \mathrm{~m}$ used by the OCL, were corrected in this fashion since the maximum depth of T-7 XBT's is nominally $760 \mathrm{~m}$.

Although the OCL flagged large temperature inversions $\left(>0.3^{\circ} \mathrm{C} \mathrm{m}^{-1}\right)$, which were indicative of reporting errors, smaller temperature spikes in the XBT profiles were not identified. To eliminate these spikes, each profile was first screened for positive temperature gradients greater than $0.03{ }^{\circ} \mathrm{C} \mathrm{m}^{-1}$. These "large" positive temperature gradients were removed from a profile if the two observations causing the temperature increase were within $6.5 \mathrm{~m}$ of each other or if the depth difference between the large positive temperature gradient and the associated large negative temperature gradient were within $30 \mathrm{~m}$ of each other. A temperature spike was removed from a profile by removing the data points above and below the spike. Less than $7 \%$ of the XBT profiles in the subtropical gyre had "large" positive temperature gradients meeting these criteria removed from them, while $2 \%$ had "large" gradients not meeting these criteria and these profiles were unchanged. The net effect of this processing was to remove the spikes in the temperature profile which were indicative of instrument noise while retaining larger temperature inversions which may have geophysical significance.

\subsubsection{LIHMA, WOA Station and CTD Profiles}

Additional processing on all LIHMA, WOA Station and CTD profiles included removing "large" density inversions and ensuring the selected profiles had adequate 
data at typical STMW depths. The OCL checked for density inversions only in the WOA Standard Level Profiles. The criteria used here to eliminate density inversions in the LIHMA and WOA Observed Level profiles are similar to those used by Boyer and Levitus (1994) and Suga and Hạnawa (1990). "Large" density inversions were defined as greater than $0.03 \mathrm{~kg} \mathrm{~m}^{-3}$ at depths shallower than $30 \mathrm{~m}$, greater than $0.02 \mathrm{~kg} \mathrm{~m}^{-3}$ at depths from 30 to $400 \mathrm{~m}$, and greater than $0.001 \mathrm{~kg}$ $\mathrm{m}^{-3}$ at depths greater than $400 \mathrm{~m}$. All "large" density inversions at depths less than $30 \mathrm{~m}$ were eliminated. A density inversion was eliminated by removing the temperature and salinity at both depth levels (i.e., above and below the inversion) from the profile. If there was only one "large" density inversion deeper than $30 \mathrm{~m}$, it was removed; 75 of the WOA CTD and 439 of the Station profiles in the subtropical gyre had at most one density inversion meeting these criteria. 5 WOA CTD and 13 Station profiles had two or more "large" density inversions deeper than $30 \mathrm{~m}$, and were rejected. No LIHMA profiles contained density inversions.

Unlike the Observed Level XBT profiles, many of which were manually subsampled to the profile's inflection points, the LIHMA, WOA Observed Level Station and CTD profiles depth levels were evenly spaced (every 20-25 m or Standard Levels) and predetermined based on the oceanographic process being studied (i.e., upper ocean versus deep ocean, mesoscale versus large scale, etc.). Therefore, a LIHMA, WOA Station or CTD profile in the subtropical gyre may have inadequate vertical sampling at STMW depths. For this study, if a profile had a minimum depth greater than $200 \mathrm{~m}$, less than four samples between 100 and $500 \mathrm{~m}$, or a mean depth difference between samples at these depths greater than $100 \mathrm{~m}$, the 
profile was rejected.

\subsection{Identifying STMW Layer}

The goal here was to identify the STMW layer in onge of three different configurations:

1. A STMW layer with an overlying seasonal thermocline and mixed layer. In this case, the STMW layer will be the layer of minimum temperature gradients between the more stratified seasonal and permanent thermoclines.

2. A STMW layer with all of the seasonal stratification removed and a thickening mixed layer above. Here, the top of the STMW layer is beginning to be renewed by the convective mixing which is deepening the mixed layer. Therefore in this case, there are in fact two STMW layers - a new STMW layer beginning to form as the mixed layer continues to deepen and the older STMW layer below. The temperature gradients in the older STMW layer will be slightly larger than in the mixed layer, but they will still be much smaller than the temperature gradients found in the permanent thermocline below.

3. Convective mixing has completely renewed/ventilated the STMW layer. In this case, the top of the STMW layer is the sea surface and the bottom of the STMW layer equals the mixed layer depth.

Once the appropriate profiles were selected and initially processed (Section 2.2), the mixed layer temperature and depth were determined. The temperature recorded 
at the depth closest to $10 \mathrm{~m}$ was chosen as the mixed layer temperature (Hanawa and Hoshino 1988, Suga and Hanawa 1990). This temperature was chosen rather than the sea surface temperature to avoid errors in reported sea surface temperatures resulting from insufficient time for the temperature thermistor to equilibrate as it moves from air to water (XBT's and CTD's) or the use of a bucket thermometer to find the sea surface temperature (Station profiles). No mixed layer was found for profiles with no observation shallower than $20 \mathrm{~m}$.

The mixed layer base is commonly identified as the depth where the temperature is $1.0^{\circ} \mathrm{C}$ less than the surface temperature (Lamb 1984, Hanawa and Hoshino 1988, Suga et al. 1989, Suga and Hanawa 1990). However, in the second STMW configuration where the seasonal thermocline is absent, this criterion tends to identify the bottom of the older STMW layer as the bottom of the mixed layer due to the small temperature differences between the old STMW layer top (the actual mixed layer base) and the old STMW layer bottom. In this study, the mixed layer will be distinguished from the STMW layer underneath by the difference in the temperature gradients in each layer.

The mixed layer was identified first by finding the depths with observed temperatures within $0.5^{\circ} \mathrm{C}$ of the mixed layer temperature. Next, the mean of the temperature gradients between adjacent pairs of points in this layer was determined. Finally, the shallowest layer of data points with temperature gradients within one standard error (standard deviation divided by the square root of the number of points) of the mean was chosen as the mixed layer. The deepest of these points was the mixed layer base. 
Once the mixed layer was determined, the STMW layer was identified based on its temperature gradient and thickness. A profile was said to have a STMW layer if it met one or both of two sets of criteria. First, the deepest layer at least $95 \mathrm{~m}$ thick with temperatures between 16.5 and $19.5^{\circ} \mathrm{C}$, and temperature gradients between adjacent pairs of points less than or equal to $0.95{ }^{\circ} \mathrm{C}$ per $100 \mathrm{~m}$ was identified as a candidate STMW layer. These values were chosen to ideptify the general part of the water column containing STMW without biasing any subsequent results. The second method identified as a possible STMW layer the thickest layer exceeding $95 \mathrm{~m}$ with temperatures between 16.5 and $19.5^{\circ} \mathrm{C}$ and a temperature difference through the layer less than or equal to $0.95^{\circ} \mathrm{C}$. This method had the advantage of being less sensitive to noise in the profile than the first method. When the layers identified by the two methods differed, the thickest layer encompassing both layers was chosen. If neither method could identify a layer with these characteristics, the profile was rejected.

Two tests were next performed on points in the vicinity of the top and bottom of the layer to determine if these points should be removed or added to the layer. In the first test, the mean of the temperature gradients between adjacent pairs of points in the layer was found. Next, the top and bottom end points of the layer were tested against this mean. If the temperature gradients of the end points were greater than the standard error from the mean, they were rejected.

In the second test, points outside of the selected layer were tested to see if they were likely to belong to the layer. A least squares line was fitted to the data points in the layer, and the rms difference between the data points and the best-fit line 
was found. Next, a new line was fitted to the points in the layer plus one point above the layer, and a new rms was calculated. If the rms of the new best-fit line was smaller than that of the initial line, the point was included in the layer. This was repeated for two points above and below the initially selected layer.

Figure 2.2 illustrates the performance of the entire STMW layer selection process outlined above as applied to four XBT profiles in the three STMW configurations defined at the beginning of this section. The XBT profile in the upper left panel has a deepening mixed layer on top of a STMW layer. The mean temperature gradient through the STMW layer is $0.53{ }^{\circ} \mathrm{C}$ per $100 \mathrm{~m}$, while the temperature gradient between the bottom of the mixed layer and the STMW layer top is $0.96{ }^{\circ} \mathrm{C}$ per $100 \mathrm{~m}$. The XBT profile in the upper right panel is that of a newly formed STMW layer with a temperature very near $18^{\circ} \mathrm{C}$ and a depth of $450 \mathrm{~m}$. The temperature gradients under this layer are all greater than $1.0^{\circ} \mathrm{C}$ per $100 \mathrm{~m}$. Given the small temperature gradients in the STMW layer in the lower left panel $\left(0.15^{\circ} \mathrm{C}\right.$ per $\left.100 \mathrm{~m}\right)$, this is most likely a STMW layer which was just formed, and the surface layers are beginning to become warmed and re-stratified. The temperature gradients between the shallow mixed layer and the STMW layer, as well as below the STMW layer, are greater than $1.0^{\circ} \mathrm{C}$ per $100 \mathrm{~m}$. Based on the date and small temperature gradients through the STMW layer (average temperature gradient is $0.19^{\circ} \mathrm{C}$ per $100 \mathrm{~m}$ ), the XBT profile in the lower right panel is another example of a recently formed STMW layer between a developing seasonal thermocline and the top of the main thermocline. 


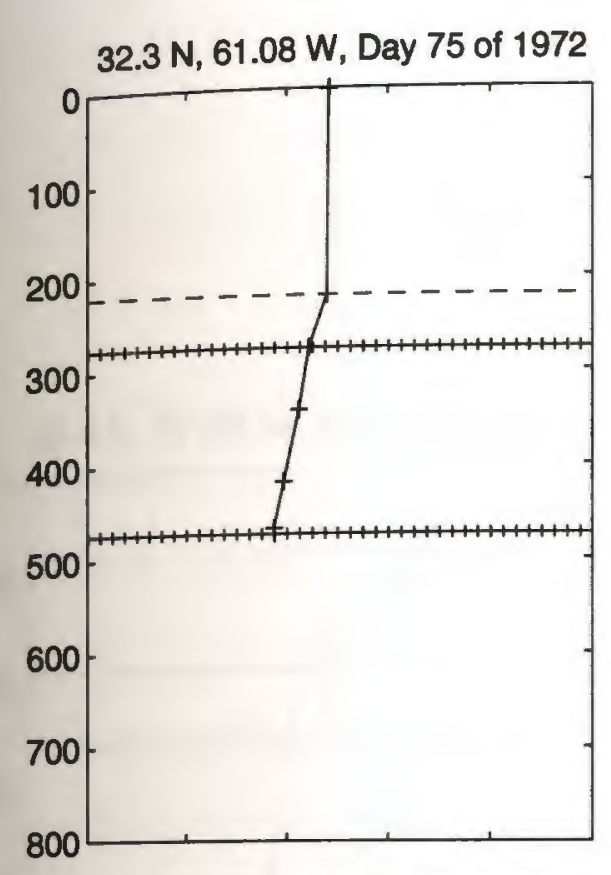

39.72 N, 49.65 W, Day 83 of 1993

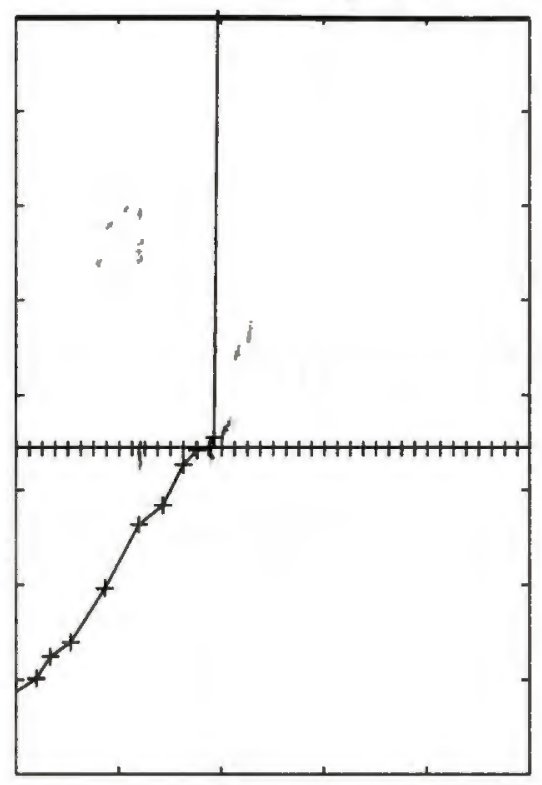

37.25 N, 68 W, Day 99 of 1977

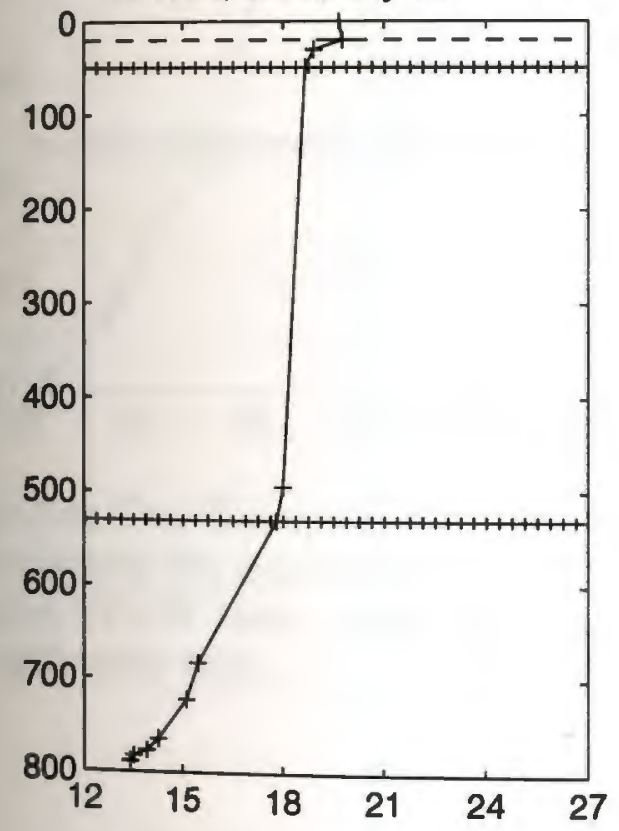

$32.68 \mathrm{~N}, 69.63$ W, Day 126 of 1980

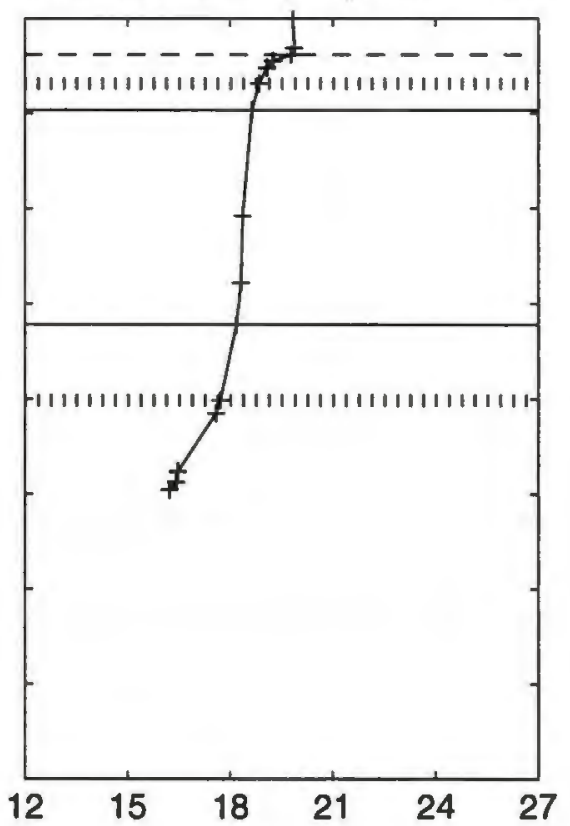

Figure 2.2: Four Examples of Identifying the STMW Layer. The dashed line represents the mixed layer base. The short vertical lines represent the initially identfied STMW layer, while the solid line represents the STMW layer after the two uniformity tests. See text for details. 
36.4 N, 57.88 W, Day 296 of 1976

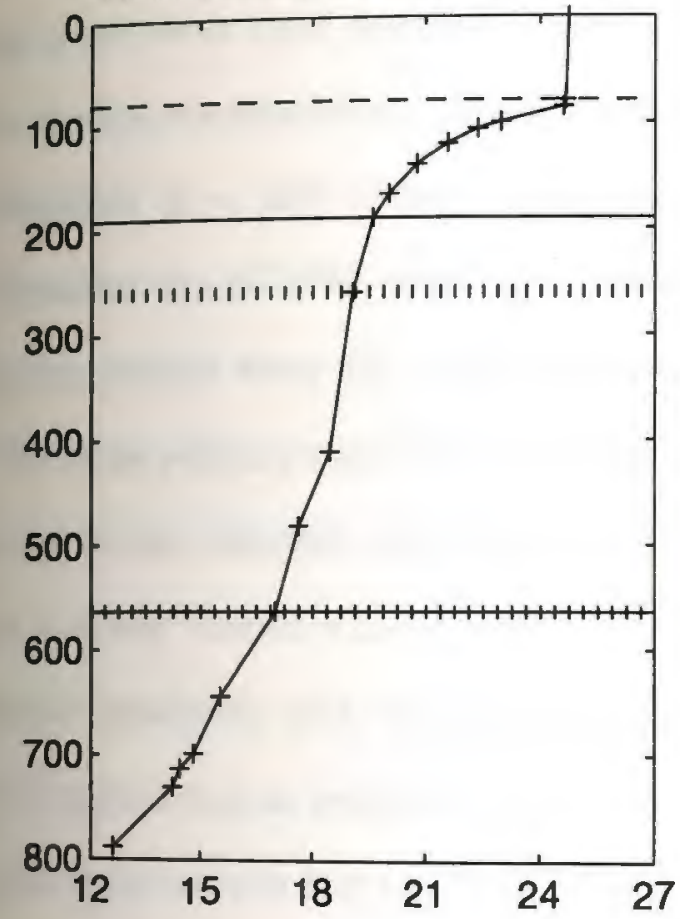

33.45 N, 47.93 W, Day 52 of 1968

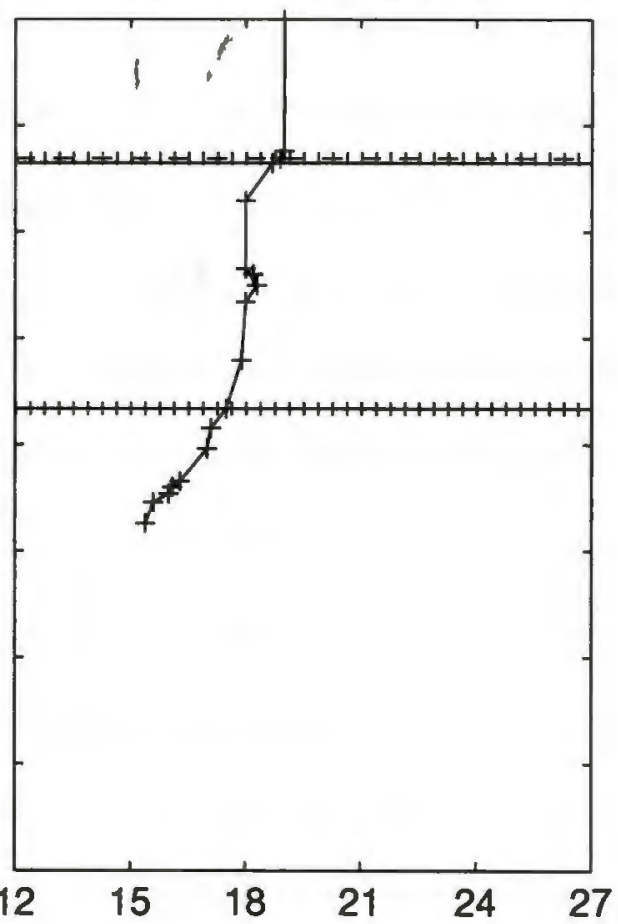

Figure 2.3: Two Examples of Errors in Identifying the STMW Layer. The dashed line represents the mixed layer base. The short vertical lines represent the initially identfied STMW layer, while the solid line represents the STMW layer after the two uniformity tests. 
The performance of this STMW layer identification process was assessed in a general sense by examining a total of $150 \mathrm{XBT}$ profiles north of $32^{\circ} \mathrm{N}$ and uniformly distributed over all 12 months. The STMW layer identified in each of these profiles by this method was compared with the STMW layer selected by visual inspection. This process worked reasonably well when the seasonal thermocline was present, as in the lower right panel of Figure 2.2 (June-January yhen the STMW layer is in the first configuration). The top and bottom of the STMW layer were correctly identified in $\sim 90 \%$ of the profiles during this time. Furthermore, it correctly identified the STMW layer top and bottom in $~ 80 \%$ of the late winter/early spring profiles when the STMW layer was in the second and third configurations. The three primary reasons for an incorrect determination of the STMW layer were noise in the observed temperatures, the presence of multiple STMW layers (such as a newly formed STMW layer sitting on top of an older layer with a slightly higher gradient), or a temperature inversion in the STMW layer. The left panel of Figure 2.3 is an example of the second case. By visual inspection, I concluded that there were in fact two STMW layers here. The upper, more recently formed, portion of the STMW layer with a temperature gradient of $\sim 0.5{ }^{\circ} \mathrm{C}$ per 100 m extends from approximately 200 to $400 \mathrm{~m}$. The lower, older layer, with a temperature gradient of $\sim 0.9{ }^{\circ} \mathrm{C}$ per $100 \mathrm{~m}$ extends from 400 to $575 \mathrm{~m}$. The temperature gradients of both layers were within the standard error of each other, and were included in one layer. An example of the third case, is shown in the right panel of Figure 2.3 where a temperature inversion occurs at $250 \mathrm{~m}$, in the middle of a STMW layer that extends from 140 to $375 \mathrm{~m}$. 
In these cases of incorrect STMW layer determination, the rms error between the best-fit line and the actual data points in the STMW layer would be large. In the first example, the rms error was $0.12^{\circ} \mathrm{C}$, and in the second example it was $0.16^{\circ} \mathrm{C}$. $94 \%$ of the profiles had an rms error in the STMW layer less than $0.1^{\circ} \mathrm{C}$. These profiles were able to reliably find the STMW layer top and bottom. $1 \%$ of the profiles had an rms error in the STMW layer greater than $0.2^{\circ} \mathrm{C}$. These profiles were manually examined. If a STMW layer thicker than $100 \mathrm{~m}$ could be correctly identified, the STMW layer top and bottom were corrected. If no such layer could be found, the profile was rejected. Of the 549 profiles inspected, 217 were corrected and retained, while 332 were rejected.

$5 \%$ of the profiles had an rms error between 0.1 and $0.2^{\circ} \mathrm{C}$. Most of these profiles were collected in February through June. As illustrated with the two examples in Figure 2.3, these profiles were able to find the STMW layer top and bottom, but there is some anomaly within the STMW layer, such as noise, a second STMW layer, or a temperature inversion, which made the standard error from the mean of the temperature gradients within the layer relatively large. This prevented the end points from being correctly tested and eliminated. Visual inspection of Figure 2.3 indicates the bottom of the most recently formed STMW layer in the left panel is more likely 400 rather than $600 \mathrm{~m}$, and the top of the STMW layer in the right panel is more likely $\sim 180$ versus $\sim 130 \mathrm{~m}$. In both of these cases, temperature gradients between these end points were within the large standard error of the selected layer and were therefore retained. However, in these cases (where the RMS error is between 0.1 and $0.2^{\circ} \mathrm{C}$ ), this method does not catastrophically fail. 
Table 2.4: Summary of Data Processing

\begin{tabular}{lcccc}
\hline & CTD & Station & XBT & LIHMA \\
\hline \# profiles in region $20-45^{\circ} \mathrm{N}, 80-40^{\circ} \mathrm{W}$ & 21,328 & 77,928 & 213,837 & 2452 \\
- w/Depth < 300 m & 12,861 & 50,699 & 68,809 & 32 \\
- Duplicates & 319 & 2184 & 1513 & 4 \\
- Missing Temp/Salinity Data & 112 & 770 & 0 & 0 \\
- Failed QC & 34 & 706 & 7 & 0 \\
- Inadequate Data 100 - 500 m & 80 & 1351 & - & 0 \\
- Max Temp 17 < ${ }^{\circ} \mathrm{C}$ & 2029 & 7081, & 15,127 & 227 \\
- Depth 17 ${ }^{\circ} \mathrm{C}$ isotherm < 350 m & 2124 & 6678 & 42,267 & 767 \\
- > 1 Density Inversion & 8 & 13 & - & 0 \\
- No STMW Layer & 518 & 1915 & 22,586 & 164 \\
- STMW Layer RMS > 0.19 & 1 & 10 & 421 & 1 \\
- \# Profiles w/STMW Layer & $\mathbf{3 2 4 2}$ & $\mathbf{6 5 2 1}$ & $\mathbf{6 3 , 1 0 7}$ & $\mathbf{1 2 5 7}$ \\
\hline
\end{tabular}

Rather, it still finds reasonably close limits for the top and bottom of the layer of minimum stratification between the mixed layer and permanent thermocline.

Table 2.4 shows the flow of data through these data processing steps. Most of the profiles rejected were either too shallow, outside of the subtropical gyre, or contained no STMW layer. Approximately $30 \%$ of the XBT profiles, $10 \%$ of the Station data, and $15 \%$ of the CTD's in the region were used to construct the STMW climatology.

The spatial and temporal distribution of the three different data types vary considerably (Figures 2.4, 2.5, and 2.6). The XBT data have the most uniform distribution in space and time of year. Large numbers ( $>1000 /$ year) of XBT profiles are found in the dataset from 1968 through 1991, with the 1970's the most heavily sampled. The CTD data are the most heavily clustered data in both space and time. In addition, there is a significant "fair weather" bias to the CTD 

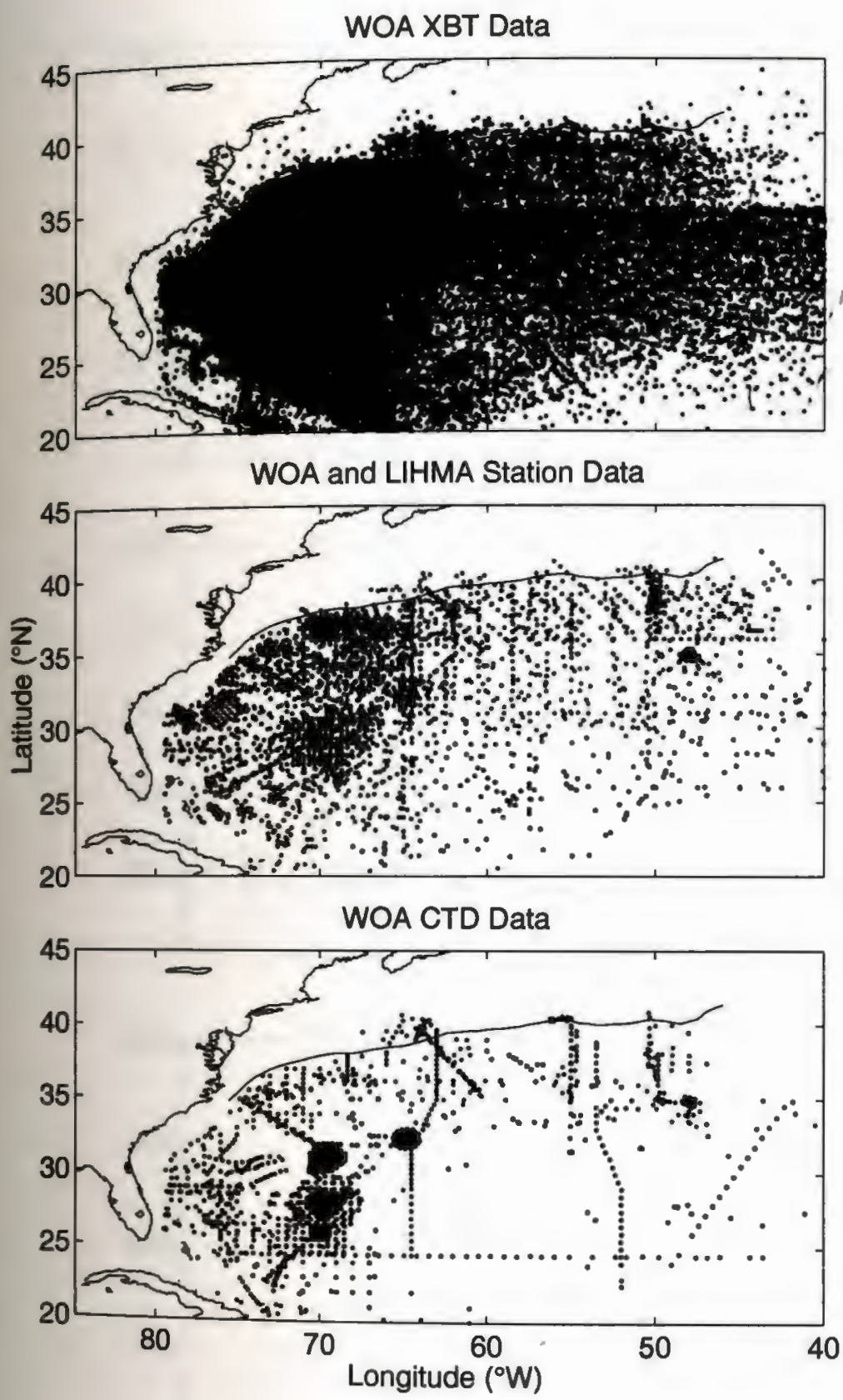

Figure 2.4: Spatial Distribution of Hydrographic Data Containing a STMW Layer. The solid line extending from Cape Hatteras to the northeast in each plot is the mean position of the north wall of the Gulf Stream, based on twelve years of satellite sea surface temperature data. 
WOA XBT Data
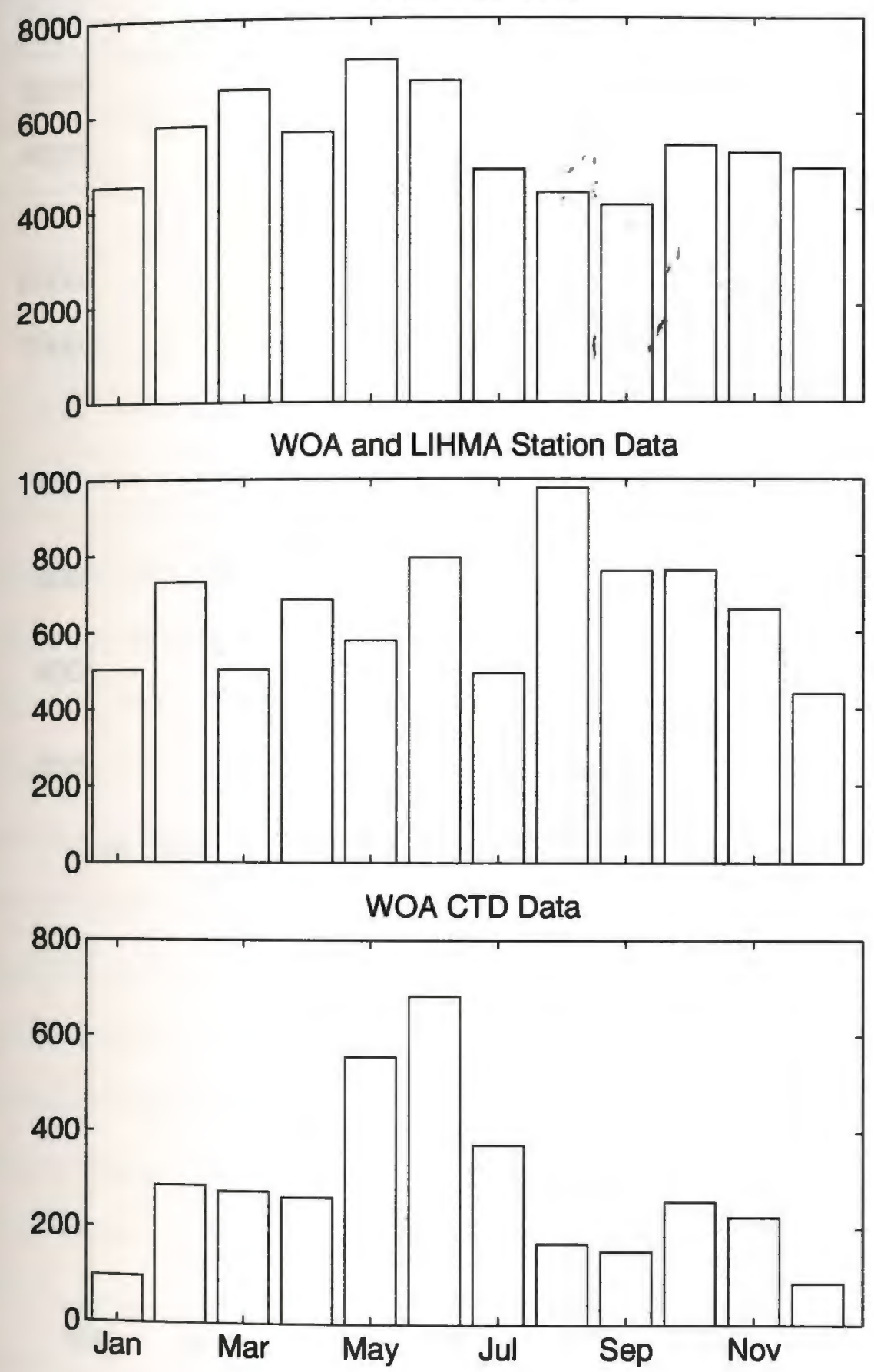

Figure 2.5: Seasonal Distribution of Hydrographic Data Containing a STMW Layer. 
WOA XBT Data

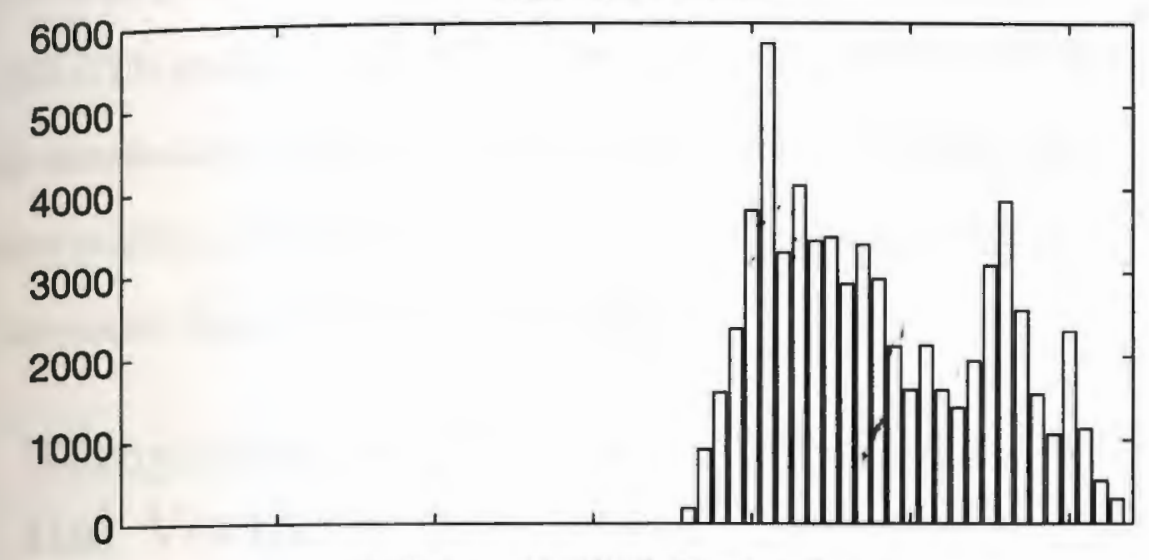

WOA and LIHMA Station Data

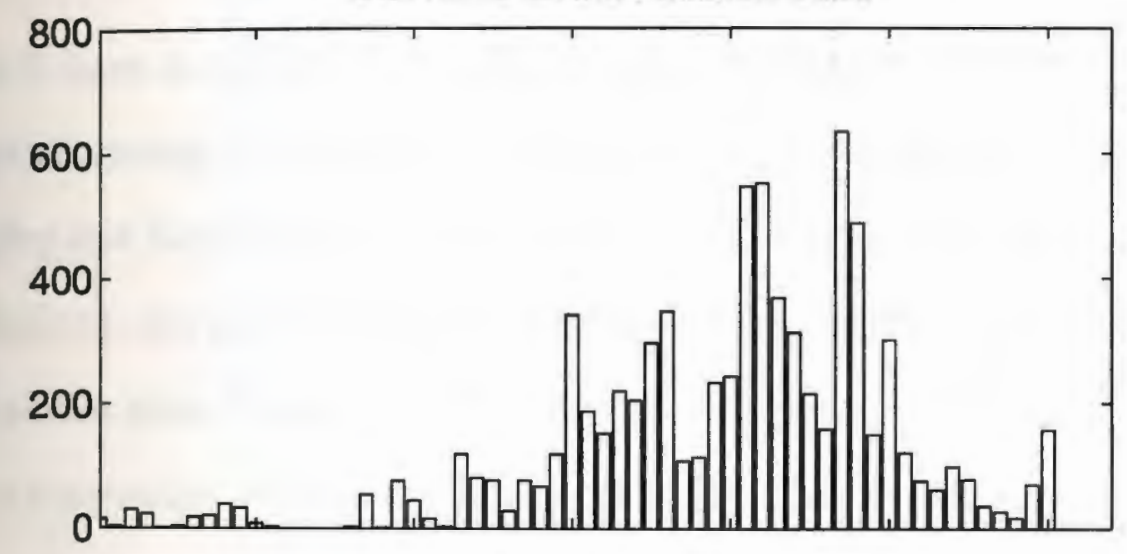

WOA CTD Data

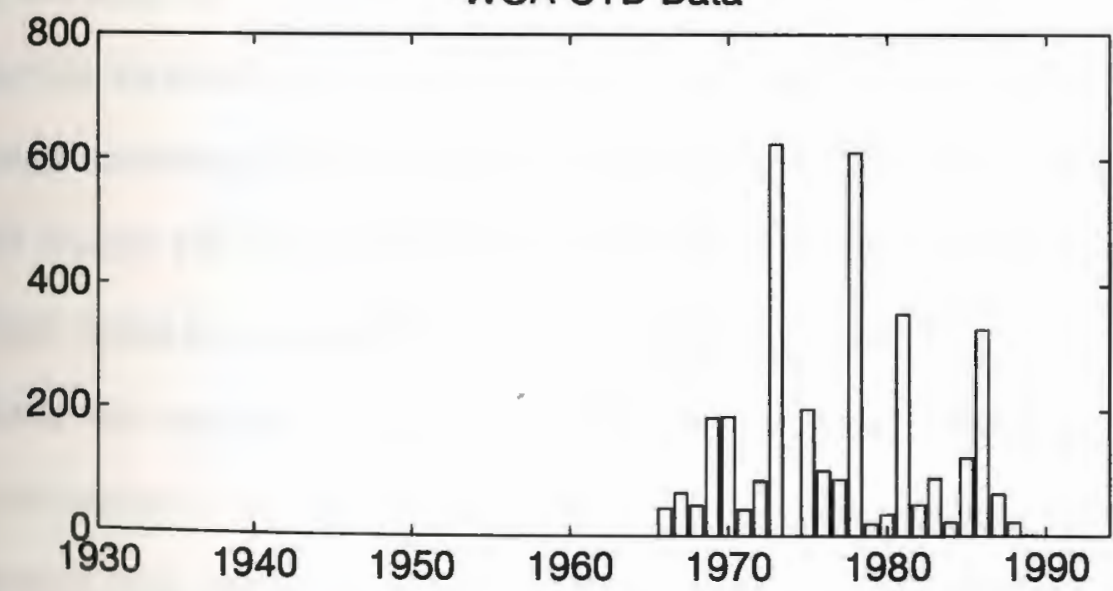

Figure 2.6: Interannual Distribution of Hydrographic Data Containing a STMW Layer. 
data, with most profiles collected in May, June, or July. There are only four years with > 200 CTD profiles: $1973,1978,1981$, and 1986. The Station data are more uniformly distributed in space and time of year than the CTD data. Although there are Station profiles going as far back as 1930, significant numbers ( $>100 /$ year) of profiles are found from the 1960's to the 1980's.

\subsection{Temperature Gradient Minímum - Poten- tial Vorticity Minimum Comparisons}

The STMW layer is commonly identified based on its stratification minimum using the vortex stretching component of potential vorticity, Equation 1.1 (McCartney 1982, Talley and Raymer 1982, Ebbesmeyer and Lindstrom 1986, Klein and Hogg 1996). However, the goal here is to utilize the order of magnitude greater number of XBT profiles than Station and CTD profiles. In comparing XBT's with Station profiles in the vicinity of Bermuda, Klein and Hogg (1996) found that temperature gradients less than $0.8^{\circ} \mathrm{C}$ per $100 \mathrm{~m}$ corresponded with the stratification minimum from potential vorticity. To verify that the process used here correctly found the stratification minimum based on temperature alone, the potential vorticity minima for all Station (WOA and LIHMA) and CTD profiles were compared with the STMW layer found in these profiles using temperature alone. The potential vorticity minimum was required to be deeper than $100 \mathrm{~m}$ to avoid finding the potential vorticity minimum in the surface mixed layer. Over 7500 profiles with maximum depths greater than $600 \mathrm{~m}$ found a STMW layer with the method outlined above and a potential vorticity minimum using the method described in Section 2.5. The 
potential vorticity minimum was within the STMW layer in $84 \%$ of these profiles. $10 \%$ of the profiles had the potential vorticity minimum below the STMW layer, while $6 \%$ had the potential vorticity minimum above the STMW layer. In most of the profiles with the potential vorticity minimum below the STMW layer, the potential vorticity profile was very uniform with only a slight, difference between the potential vorticity minimum and the potential vorticity yithin the STMW layer. In most of these cases, the potential vorticity minimum was only one depth level below the bottom of the STMW layer, and was caused by an increasing salinity gradient compensating an increasing temperature gradient. This caused the potential density to be more uniform to deeper depths than either temperature or salinity alone. Figure 2.7 is an example of such a profile; the method based on temperature alone described above found the layer with the most uniform temperature and salinity, the likely remnant of a convectively mixed layer, while the potential vorticity minimum was in a layer of decreasing temperature and salinity.

Table 2.5 compares the temperature, salinity, and temperature gradient at the potential vorticity minimum with the mean temperature, salinity, and temperature gradient within the STMW layer. When the potential vorticity minimum was within the STMW layer, the two methods agreed very well. When the potential vorticity minimum was below the STMW layer, the temperature and salinity of the STMW layer still agreed with typical STMW values $\left(17.9 \pm 0.3^{\circ} \mathrm{C}, 36.5 \pm 0.1^{\circ} \%\right.$, $\sim 26.4 \mathrm{~km} \mathrm{~m}^{-3}$ (Worthington 1959)), although the STMW layer was shallower, warmer, less dense, and weaker (more stratified) than when the potential vorticity minimum was within the STMW layer. More importantly, the temperature and 


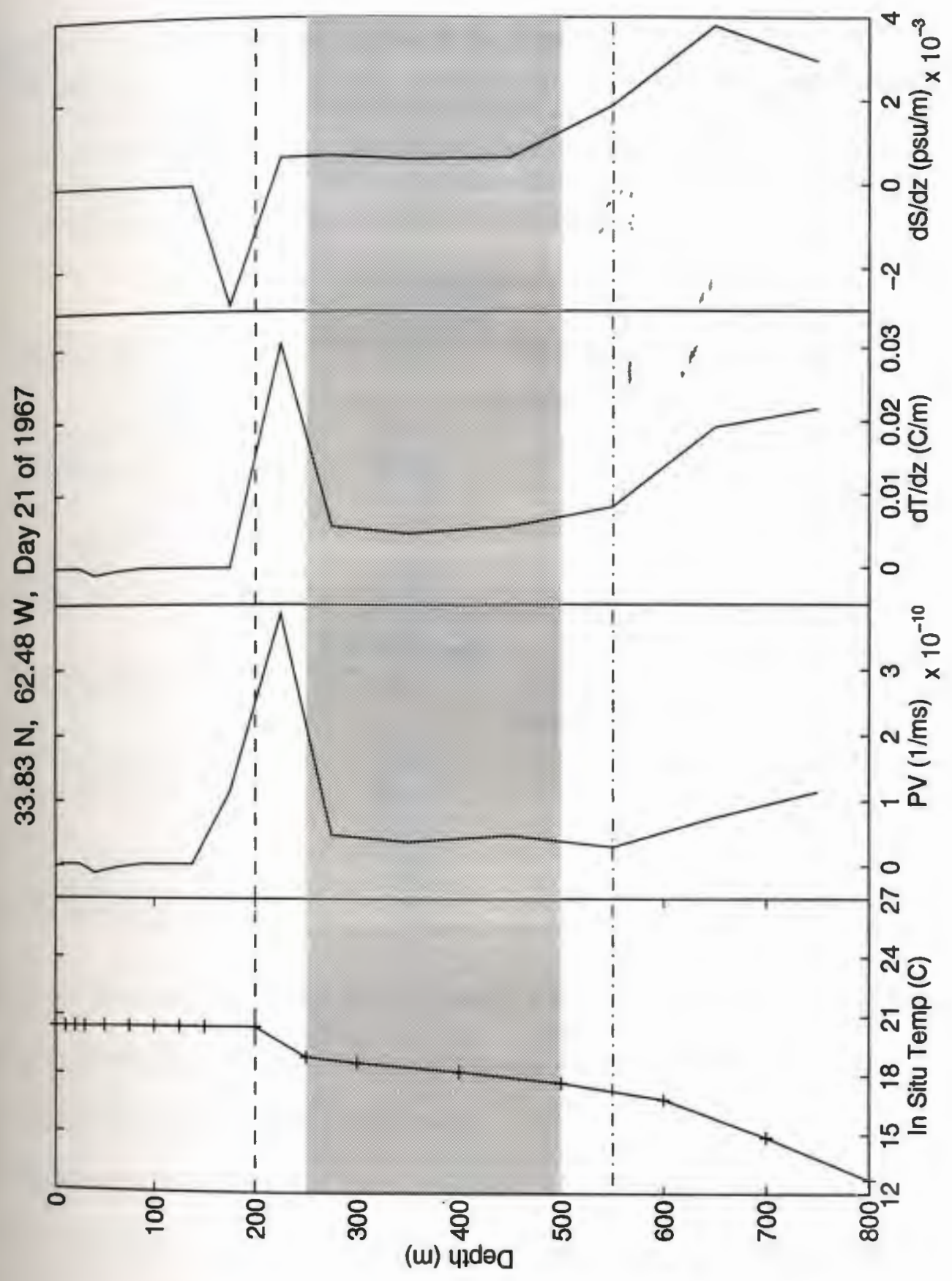

Figure 2.7: Example CTD Profile showing Potential Vorticity minimum below STMW Layer identified using temperature alone. Dotted line represents mixed layer depth. Shaded region represents STMW layer. Dashed-dotted line indicates depth of potential vorticity minimum. 
Table 2.5: Comparison of Properties at the Potential Vorticity Minimum with the STMW Layer. The temperature, salinity, and potential density of the STMW layer are weighted means of all values found within the layer. The temperature gradient of the STMW layer was found from the slope of a linear least squares fit to all points in the layer, while the potential vorticity of the STMW layer was found using Equation 2.3. See Section 2.5 for details:

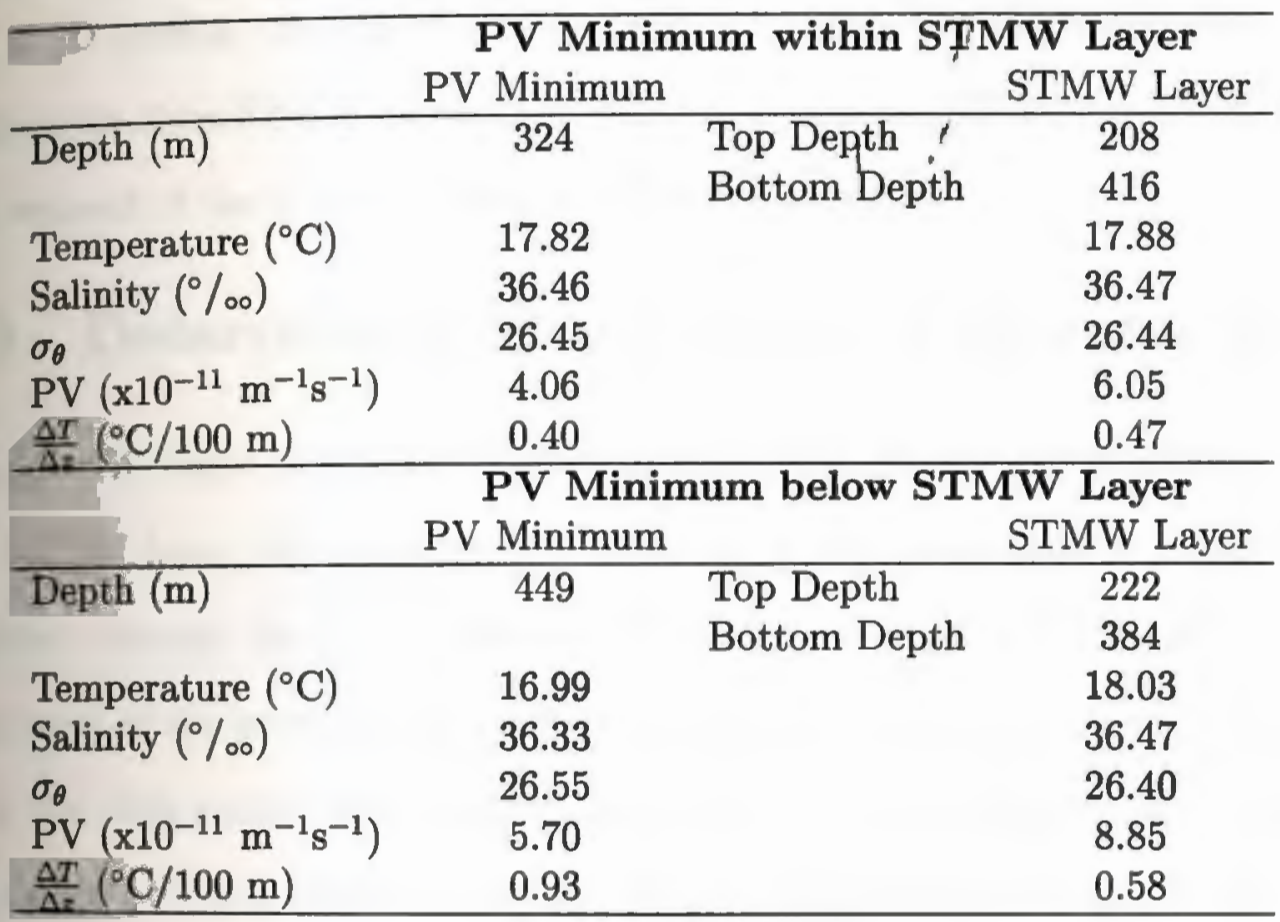

salinity at the potential vorticity minimum were colder and fresher than typical STMW values, and the mean temperature gradient was almost twice the temperature gradient in the STMW layer above.

Nearly all of the profiles with the potential vorticity minimum above the STMW layer occurred in January through April in a thickening mixed layer (deeper than $100 \mathrm{~m}$ ) above the STMW layer, i.e., the second STMW configuration. Again, the goal here was to distinguish this thickening mixed layer/new STMW layer from 
the older STMW layer below.

In summary, using temperature alone this method identified the deepest, thickest, most uniform layer with STMW characteristics. The potential vorticity (i.e., the stratification) minimum was within this STMW layer in most of the Station and CTD profiles. In cases where they did not agree, this method either distinguished the older STMW layer below from the developing STMW layer or it found the remnant of the previous winter's convective mixing.

\subsection{Determining STMW Layer Characterisitics}

The STMW Layer properties of most interest here are the depth of the top of the STMW layer, the temperature at the top of the layer, and the temperature gradient through the layer. The top of the STMW layer was identified as the shallowest of the points in the most uniform layer. Next, a least squares line was fit to the data points in the most uniform layer. The mean temperature gradient through the STMW layer was determined from the slope of this best fit line.

If a profile was deep enough, the depth of the bottom, the temperature at the bottom, and the potential vorticity of the STMW layer were also determined. Figure 2.8 indicates that profiles less than $600 \mathrm{~m}$ deep can cut off the bottom of the STMW layer. Therefore, these additional STMW layer properties were determined if the maximum depth of the profile was greater than $600 \mathrm{~m}$ and the bottom of the STMW layer was found before the bottom of the profile. For Station and CTD profiles, the potential vorticity of the STMW layer was calculated neglecting 


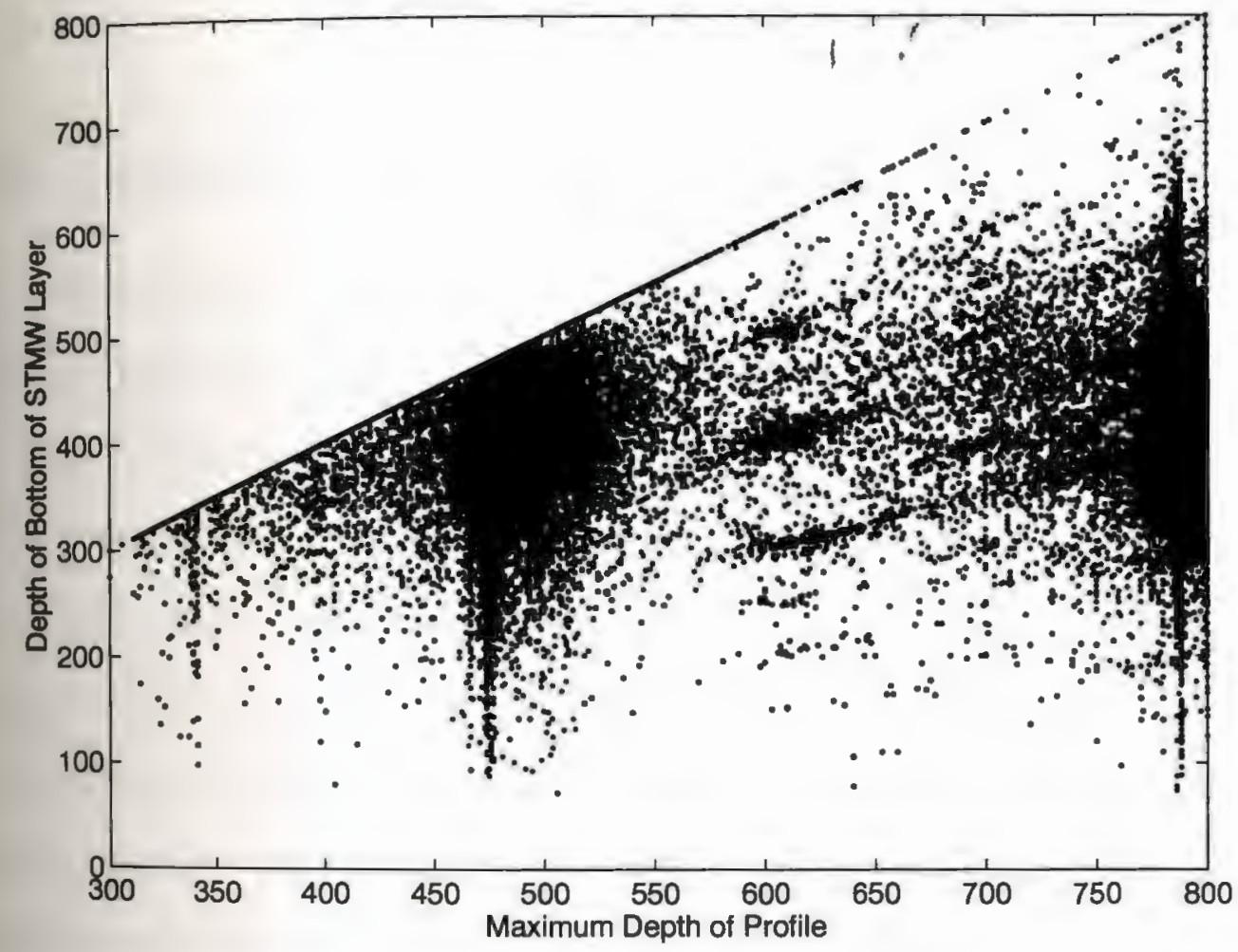

Figure 2.8: Bottom of STMW Layer versus Maximum Depth of Profile. 
relative vorticity and using

$$
\frac{f}{\rho_{\theta}} \frac{\Delta \sigma_{\theta}}{\Delta z}
$$

where $\rho_{\theta}=$ the mid-density of the layer

$\frac{\Delta \sigma_{\theta}}{\Delta z}$ was estimated from the slope of the best-fit line to the potential density values in the STMW layer

\subsection{Assembling Climatologies}

The WOA '94 hydrographic data are unevenly distributed in space and time. Large amounts of data were collected during times of specific cruises or experiments, with less data collected at other times/places (Figures 2.4, 2.5, and 2.6). Therefore, climatologies constructed by finding the straight average of all observations in a certain region will be biased toward those years with large data volumes. For example, 1082 of the $3977(\sim 27 \%)$ profiles in the $2.5^{\circ}$ latitude by $5^{\circ}$ longitude box bounded by 30 to $32.5^{\circ} \mathrm{N}$ and 65 to $70^{\circ} \mathrm{W}$ were collected in 1978 , most in May through August. Therefore, any statistics for this box would be biased toward the summer of 1978 . Since these 1000 profiles may not represent 1000 independent samples of the STMW layer, they should not be weighted uniformly when averaged with the remaining profiles from the summer months of other years. To avoid the seasonal and year-to-year biases in the distribution of North Pacific Station, CTD, and BT observations, Yasuda and Hanawa (1997) first found seasonal averages on a $2^{\circ}$ latitude $\mathrm{x} 2^{\circ}$ longitude grid for each year and then averaged the seasonal means for their two decadal periods (1966-1975 and 1976-1985). 
To find an unbiased estimate of the climatological STMW properties in this study, all profiles collected close in time and space were grouped into one cluster, and averaged. The time and length scales used to group the data were chosen based on previously published estimates of the autocorrelation function zero-crossing scales. Three such estimates were the result of data collected in 1978 during the POLYMODE Local Dynamics Experiment, an intensiye data collection effort aimed at examining the mesoscale variability in the vicinity of the southern region of the subtropical gyre recirculation (Taft et al. 1986).

Taft et al. (1986) examined the covariance structure of two scalar properties (salinity and oxygen) on the $26.420 \mathrm{~kg} \mathrm{~m}^{-3}$ isopycnal surface $(303 \mathrm{db}$ ) and one dynamical property (pressure) on the $26.773 \mathrm{~kg} \mathrm{~m}^{-3}$ isopycnal surface (601 db). (Note that the salinity isopycnal corresponds to the center of the STMW layer.) While the covariance structure for both properties was anisotropic with a zerocrossing near $\sim 75 \mathrm{~km}$ in the NW/SE direction and greater than $200 \mathrm{~km}$ in the $\mathrm{NE} / \mathrm{SW}$ direction, the variability of the scalar properties was at shorter scales than the dynamical properties. With $50 \%$ of the salinity variance occurring at horizontal scales less than $25 \mathrm{~km}$, the decay away from the zero lag was considerably greater for the salinity covariance than for pressure, which had only $10 \%$ of its variability at scales less than $25 \mathrm{~km}$.

Rossby et al. (1986) obtained similar results at $700 \mathrm{~m}$ in the same area using neutrally buoyant floats. They found the $700 \mathrm{~m}$ autocorrelation function had a zero-crossing at 15 days and 10 days for the meridional and zonal velocities, respectively. The spatial correlation scales at $700 \mathrm{~m}$ again had considerable 
anisotropy with the longitudinal autocorrelation function having a zero-crossing slightly greater than $200 \mathrm{~km}$, while the transverse autocorrelation had a $100 \mathrm{~km}$ autocorrelation. The longitudinal correlation was highest in the NNE-SSW direction where the correlation was $\sim 0.75$ at a radial distance of $100 \mathrm{~km}$, while it was 0.30 normal to this direction. The transverse correlation was more symmetric and near zero at $100 \mathrm{~km}$ in all directions.

Using the same hydrographic data as Taft et al. (1986), Shen et al. (1986) estimated the azimuthally averaged covariance functions for two scalar properties (salinity and oxygen) and two dynamical properties (pressure and dynamic height) at four depth levels - the surface layer (0-200 db), the STMW layer (200-500 db), the main thermocline $(500-1100 \mathrm{db})$, and the deep water (1100-3000 db). For the surface layer, the zero-crossing scales were approximately $75 \mathrm{~km}$ and $80 \mathrm{~km}$ for the dynamical and scalar properties, respectively, while in the STMW layer they were 94-100 km for both properties. Both Taft et al. (1986) and Shen et al. (1986) suggest that the similarity in the zero-crossing scales of the dynamical and scalar properties imply the distribution of the scalar properties is influenced by the large scale dynamical fluctuations, but that the scalar field has more variability on shorter scales than the dynamical field.

Using POLYMODE and other ancillary data, Ebbesmeyer and Lindstrom (1986) argued that the STMW layer was homogenous on scales less than 100-300 km and one month. Besides these quanitative estimates of the temporal and spatial scales of the STMW layer variability, there are other qualitative examples of the variability within the STMW layer. Anticyclonic eddies with typical length scales of 100 
$\mathrm{km}$ have been observed within STMW both in winter during active convection and after the STMW layer has been isolated from atmospheric forcing by the seasonal thermocline (Leetmaa 1977, Worthington 1977, Brundage and Dugan 1986).

Given the significant anisotropy in the covariance structure seen in the POLYMODE results, the shortest time and spatial autocorrelation zero-crossings in these results ( $75 \mathrm{~km}$ and 10 days) were chosen as the scales to, cluster the profiles here. While the decorrelation temporal and spatial scales of the STMW layer will likely vary in time and space and may have longer decorrelation scales, the POLYMODE results were obtained in a relatively high energy region of the subtropical gyre (Rossby et al. 1986, Shen et al. 1986, Taft et al. 1986), and the STMW layer is therefore unlikely to have decorrelation scales much shorter than the ones chosen here. For comparison, Yasuda and Hanawa (1997) used a Gaussian filter with an e-folding scale of $0.5^{\circ}$ in latitude $(56 \mathrm{~km})$ and $0.75^{\circ}$ in longitude $(\sim 72 \mathrm{~km})$ and first found seasonal averages in constructing their NPSTMW climatology on a $2^{\circ}$ latitude $\times 2^{\circ}$ longitude grid.

Following Casey and Cornillon (1997), an agglomerative hierarcial clustering algorithm (Gong and Richman 1995) was used to find the profiles which were within $75 \mathrm{~km}$ and 10 days of each other. This type of clustering process builds up clusters from the set of individual profiles "by the process of accumulation", and yields "hard clusters" wherein each profile is either in or out of a cluster with no overlap between clusters (Gong and Richman 1995). The similarity measurement used here to determine if a profile belonged in a cluster was its "distance" from the profile specified as the cluster center. This distance was determined using the 
differences in time and space from the center profile:

$$
\text { distance }=\sqrt{\Delta x^{2}+\Delta y^{2}+\Delta t^{2}}
$$

where $\Delta x$ and $\Delta y$ are the $\mathrm{x}$ and $\mathrm{y}$ distances in $\mathrm{km}$.from the center profile, and $\Delta t$ is the temporal difference between the profile and the center profile, scaled to $\mathrm{km}$, i.e.,

$$
\Delta t=\frac{\text { difference in days } \times \text { spatial clustering radius }}{\text { temporal clustering radius }}
$$

This distance (Equation 2.4) from a center profile had to be less than $37.5 \mathrm{~km}$ in order for a profile to be grouped with the center profile. This requirement meant all profiles within $37.5 \mathrm{~km}$ and on the same day of the center profile were grouped together, while profiles 5 days before or after the center profile would have to have $\Delta x$ and $\Delta y$ equal zero (i.e., at the same location) in order to be grouped with the center profile.

The seed points needed to initialize the algorithm were chosen sequentially from the dataset (Gong and Richman 1995); each profile was chosen as a cluster center and all profiles meeting the similarity criteria were grouped into a cluster. The initial clusters were then sorted by number of profiles in the cluster and the mean distance of the profiles in the cluster from the center profile. The cluster with the most profiles and smallest mean distance from the center profile was first in this sorted file while individual profiles not belonging to any cluster were last.

These sorted clusters were then re-evaluated to maximize the number of profiles in a cluster and to ensure no profile was used in more than one cluster. Beginning 
with the first cluster in the sorted file, each profile in the cluster was chosen as a candidate cluster center. The cluster containing the greatest number of profiles was chosen, and all profiles in this cluster were flagged so that they would not be used in another cluster. All profiles in the next cluster in the sorted file not already belonging to a cluster were tested as candidate cluster centers, the cluster with the greatest number of profiles identified, and the profiles in this cluster flagged. This process continued until all profiles in the sorted file have been used.

The climatological values were determined from the weighted mean of all clusters and other independent profiles not falling within a cluster. The estimated error of the cluster mean was used as the weighting factor for the weighted mean.

$$
\bar{X}=\frac{\sum_{i=1}^{N} \frac{x_{i}}{\sigma_{i}^{2}}}{\sum_{i=1}^{N} \frac{1}{\sigma_{i}^{2}}}
$$

where $x_{i}$ is the value of the observation, in this case the cluster mean, $\sigma_{i}$ is the estimated error of the observation, and $\mathrm{N}$ is the number of clusters. The uncertainty of the weighted mean $\left(\sigma_{\bar{X}}^{2}\right)$ is then given by:

$$
\frac{1}{\sigma_{\bar{X}}^{2}}=\sum_{i=1}^{N} \frac{1}{\sigma_{i}^{2}}
$$

In order to estimate error for the cluster means, the variance within a group of XBT, Station, and CTD profiles was split into the variability within a cluster of correlated profiles (i.e., within the decorrelation time and space scales), and the variability between decorrelated and therefore independent samples. In addition, the variability within the clusters of correlated profiles will have a contribution from the geophysical variability within the cluster as well as from random measurement error. Therefore, the variance of a group of profiles can be split into 
three components:

1. the random error associated with the measurement technique (XBT, Hydrographic Station, CTD), $\sigma_{\text {inst }}$. For example, measurements from 100 XBT's deployed simultaneously will differ due to electronic noise within the data collection system. Because these errors are random, the magnitude of the measurement uncertainty decreases as the number of observations averaged together increases.

2. the geophysical variability at scales less than the approximate decorrelation time and space scales (10 days, $75 \mathrm{~km}$ ). For example, measurements from 100 XBT's deployed over a short period of time ( $<10$ days) will differ even if they have zero instrument error due to the geophysical variability in the region over which they were deployed. This will be called the small scale geophysical variability, $\sigma_{s m a l l}$.

3. the geophysical variability at scales larger than the approximate decorrelation scales. For example, the variance of 100 error free XBT measurements made at different locations and in different years. This will be called the large scale geophysical variability, $\sigma_{\text {large }}$.

If the small scale geophysical variability is much larger than the instrument uncertainty in the XBT, CTD, and Station profiles, then each independent observation should have an equal weighting. However, if the instrument uncertainty in the XBT, CTD, and Station profiles is greater than the small scale geophysical variability and differs from one instrument to another, then each independent ob- 
servation should have a different weight which is dependent on its measurement uncertainty. Therefore, in order to weight each cluster of mixed instrument types appropriately, each of these variances must be estimated.

Using this notation, all profiles with the same instrument error in a cluster belong to a population with a variance $\left(\sigma_{i}\right)$ about the true cluster mean of:

$$
\sigma_{i}^{2}=\sigma_{\text {small }}^{2}+\sigma_{\text {inst }}^{2} \quad, \quad,
$$

where $\left(\sigma_{\text {small }}^{2}\right)$ is the small scale geophysical variance and $\sigma_{\text {inst }}^{2}$ is the instrument uncertainty. Therefore, the most probable value for a cluster of M profiles is found using Equation 2.6 with Equation 2.8 for the weighting factor $\sigma_{i}^{2}$ of each profile in the cluster. If all profiles in the cluster were the same instrument type, each profile would be equally weighted. Conversely, if the profiles were different instrument types, the profiles with the smallest instrument uncertainty would have a slightly larger weight. Using Equation 2.7, the variance of the cluster weighted mean is

$$
\frac{1}{\sigma_{M}^{2}}=\sum_{i=1}^{M} \frac{1}{\sigma_{\text {small }}^{2}+\sigma_{\text {inst }}^{2}} \text {. }
$$

Similarly, the variance of $\mathrm{N}$ cluster means about their mean $\left(\sigma_{\text {clust }}^{2}\right)$ is the sum of the large scale geophysical ( $\left.\sigma_{\text {large }}^{2}\right)$ and cluster weighted mean $\left(\sigma_{M}^{2}\right)$ variances:

$$
\sigma_{\text {clust }}^{2}=\sigma_{\text {large }}^{2}+\sigma_{M}^{2}
$$

Therefore, the climatological values were found from the weighted mean of $\mathrm{N}$ independent observations (clusters and remaining individual profiles) in a region using Equation 2.6 with Equation 2.10 for the weighting factor. Individual profiles not part of any cluster must be appropriately weighted when averaging them 
with the clusters. Using Equation 2.10, the weighting factor for individual profiles will be slightly smaller than that of neighboring clusters due to their larger measurement uncertainty.

Using Equation 2.7, the uncertainty of these weighted means $\left(\sigma_{N}^{2}\right)$ is

$$
\frac{1}{\sigma_{N}^{2}}=\sum_{j=1}^{N} \frac{1}{\sigma_{\text {clust }}^{2}}=\sum_{j=1}^{N} \frac{1}{\sigma_{\text {large }}^{2}+\sigma_{M_{j}}^{2}}
$$

The measurement uncertainty was determined by clustering XBT, Station, and CTD profiles seperately using the $75 \mathrm{~km}$ and 10 day criteria. For XBT and Station clusters, the measurement uncertainty was chosen as the median of the cluster standard deviations for clusters with a mean distance from the center profile less than $10 \mathrm{~km}$. While the cluster standard deviations tended to be scattered, the standard deviations of XBT and Station clusters with mean distances from center less than $10 \mathrm{~km}$ were typically smaller than the standard deviations of clusters with larger mean distances from center. The variablity between profiles at these small time and space scales will be due more to measurement uncertainty than geophysical variability. Because the CTD data were the most heavily clustered data set, there were not sufficient clusters with mean distances from the center profile less than $10 \mathrm{~km}$ to determine a representative measurement uncertainty. Since the CTD cluster standard deviations tended to vary less with the cluster mean distance from the center profile than the XBT or Bottle clusters, the CTD measurement uncertainty was chosen as the median of all CTD cluster standard deviations. The measurement uncertainties for each type of data are shown in Table 2.6. Only clusters containing four or more profiles were included in these 
Table 2.6: Measurement uncertainties (given as standard deviations) for each instrument type.

\begin{tabular}{lccc}
\hline Parameter & XBT & Station & CTD \\
\hline STMW Top Depth $(\mathrm{m})$ & 27 & 33 & 24 \\
STMW Bottom Depth $(\mathrm{m})$ & 25 & 30 & 45 \\
Top Temperature $\left({ }^{\circ} \mathrm{C}\right)$ & 0.27 & 0.21 & 0.15 \\
Bottom Temperature $\left({ }^{\circ} \mathrm{C}\right)$ & 0.25 & 0.23, & 0.20 \\
STMW $\frac{\Delta T}{\Delta z}\left({ }^{\circ} \mathrm{C}\right.$ per $\left.100 \mathrm{~m}\right)$ & 0.083 & 0.070 & 0.081 \\
Mixed Layer Depth $(\mathrm{m})$ & 7 & 5, & 5 \\
Mixed Layer Temperature $\left({ }^{\circ} \mathrm{C}\right)$ & 0.17 & 0.10 & 0.21 \\
\hline
\end{tabular}

distributions. In addition, only profiles with maximum depths greater than $600 \mathrm{~m}$ were clustered for the STMW bottom depth and temperature.

The small and large scale geophysical variabilities were determined by first finding clusters of all profiles (XBT, CTD, and Station) which were within $75 \mathrm{~km}$ and 10 days of each other. Each profile in a cluster was de-meaned by subtracting the cluster mean from the profile's value. The small scale geophysical variability was estimated by subtracting the mean measurement variance from the variance of the distribution of de-meaned profiles:

$$
\sigma_{\text {small }}^{2}=\sigma_{\text {de-meaned }}^{2}-\frac{1}{N} \sum_{j=1}^{N} \sigma_{\text {inst }}^{2} .
$$

Again, only clusters containing four or more profiles were included in this distribution. The large scale geophysical variability was estimated by subtracting the mean variance between profiles within the clusters (i.e., the sum of the measurement and small scale geophysical variances) from the total variance of the cluster averages:

$$
\sigma_{\text {large }}^{2}=\sigma_{N}^{2}-\frac{1}{N} \sum_{i=1}^{N} \frac{\sigma_{M_{i}}^{2}}{M_{i}}
$$


The small and large scale geophysical variances for each type of data and STMW property are shown in Tables 2.7 and 2.8. The large scale geophysical variances are generally larger than the small scale geophysical or measurement variances. The large and small scale geophysical variances do vary with time of year and location. They are generally larger north of $30^{\circ} \mathrm{N}$ and east of $75^{\circ} \mathrm{W}$, and tend to be larger in winter and spring (November through April) than late summer (August through October). 
Table 2.7: Small Scale Geophysical Variances (given as Standard Deviations) for each Parameter.

\begin{tabular}{lcccc|c}
\hline \multicolumn{7}{c}{$\begin{array}{c}\text { Feb- } \\
\text { Apr }\end{array}$} & $\begin{array}{c}\text { May- } \\
\text { Jul }\end{array}$ & $\begin{array}{c}\text { Aug- } \\
\text { Oct }\end{array}$ & $\begin{array}{c}\text { Nov- } \\
\text { Jan }\end{array}$ & $\begin{array}{c}\text { Jan- } \\
\text { Dec }\end{array}$ \\
\hline STMW Top Depth (m) & & & & \\
$20-35^{\circ} \mathrm{N}, 80-75^{\circ} \mathrm{W}$ & 30 & 26 & 14 & 25 & \\
$30-40^{\circ} \mathrm{N}, 75-60^{\circ} \mathrm{W}$ & 74 & 32 & 19 & 32 & \\
$30-40^{\circ} \mathrm{N}, 60-40^{\circ} \mathrm{W}$ & 76 & 48 & 14 & 38 & \\
$20-30^{\circ} \mathrm{N}, 75-40^{\circ} \mathrm{W}$ & 31 & 21 & 14 & 17 & \\
Entire Region & 61 & 30 & 17 & 28 & \\
\hline STMW Bottom Depth (m) & & & \\
$20-35^{\circ} \mathrm{N}, 80-75^{\circ} \mathrm{W}$ & 25 & 18 & 8 & 8 & \\
$30-40^{\circ} \mathrm{N}, 75-60^{\circ} \mathrm{W}$ & 45 & 48 & 27 & 38 & \\
$30-40^{\circ} \mathrm{N}, 60-40^{\circ} \mathrm{W}$ & 50 & 32 & 27 & 39 & \\
$20-30^{\circ} \mathrm{N}, 75-40^{\circ} \mathrm{W}$ & 30 & 17 & 0 & 24 & \\
Entire Region & 40 & 35 & 23 & 31 & \\
\hline STMW Top Temperature $\left.{ }^{\circ} \mathrm{C}\right)$ & & \\
$20-35^{\circ} \mathrm{N}, 80-75^{\circ} \mathrm{W}$ & 0.27 & 0.21 & 0.20 & 0.26 & \\
$30-40^{\circ} \mathrm{N}, 75-60^{\circ} \mathrm{W}$ & 0.29 & 0.23 & 0.18 & 0.26 & \\
$30-40^{\circ} \mathrm{N}, 60-40^{\circ} \mathrm{W}$ & 0.31 & 0.13 & 0.16 & 0.32 & \\
$20-30^{\circ} \mathrm{N}, 75-40^{\circ} \mathrm{W}$ & 0.26 & 0.17 & 0.12 & 0.18 & \\
Entire Region & 0.28 & 0.20 & 0.17 & 0.24 & \\
\hline STMW Bottom Temperature $\left({ }^{\circ} \mathrm{C}\right)$ & & \\
$20-35^{\circ} \mathrm{N}, 80-75^{\circ} \mathrm{W}$ & 0.28 & 0.19 & 0.20 & 0.14 & \\
$30-40^{\circ} \mathrm{N}, 75-60^{\circ} \mathrm{W}$ & 0.31 & 0.26 & 0.14 & 0.28 & \\
$30-40^{\circ} \mathrm{N}, 60-40^{\circ} \mathrm{W}$ & 0.39 & 0.15 & 0.22 & 0.40 & \\
$20-30^{\circ} \mathrm{N}, 75-40^{\circ} \mathrm{W}$ & 0.26 & 0.16 & 0.05 & 0.23 & \\
Entire Region & 0.30 & 0.21 & 0.13 & 0.27 & \\
\hline STMW Mean Temperature Gradient $\left({ }^{\circ} \mathrm{C}\right.$ per & $100 \mathrm{~m})$ \\
$20-35^{\circ} \mathrm{N}, 80-75^{\circ} \mathrm{W}$ & 0.11 & 0.09 & 0.09 & 0.08 & \\
$30-40^{\circ} \mathrm{N}, 75-60^{\circ} \mathrm{W}$ & 0.14 & 0.06 & 0.06 & 0.09 & \\
$30-40^{\circ} \mathrm{N}, 60-40^{\circ} \mathrm{W}$ & 0.24 & 0.08 & 0.06 & 0.10 & \\
$20-30^{\circ} \mathrm{N}, 75-40^{\circ} \mathrm{W}$ & 0.06 & 0.06 & 0.05 & 0.07 & \\
Entire Region & 0.13 & 0.07 & 0.06 & 0.08 & \\
\hline
\end{tabular}


Table 2.8: Large Scale Geophysical Variances (given as Standard Deviations) for each Parameter.

\begin{tabular}{|c|c|c|c|c|c|}
\hline & $\begin{array}{l}\text { Feb- } \\
\text { Apr }\end{array}$ & $\begin{array}{c}\text { May- } \\
\text { Jul }\end{array}$ & $\begin{array}{l}\text { Aug- } \\
\text { Oct }\end{array}$ & $\begin{array}{l}\text { Nov- } \\
\text { Jan }\end{array}$ & $\begin{array}{l}\text { Jan- } \\
\text { Dec }\end{array}$ \\
\hline \multicolumn{5}{|c|}{ STMW Top Depth (m) } & \\
\hline $20-35^{\circ} \mathrm{N}, 80-75^{\circ} \mathrm{W}$ & 58 & 69 & 40 & $41^{\circ}$ & \\
\hline $30-40^{\circ} \mathrm{N}, 75-60^{\circ} \mathrm{W}$ & 72 & 51 & 43 । & 45 & \\
\hline $30-40^{\circ} \mathrm{N}, 60-40^{\circ} \mathrm{W}$ & 51 & 48 & 43 & 57 & \\
\hline $20-30^{\circ} \mathrm{N}, 75-40^{\circ} \mathrm{W}$ & 49 & 49 & 34 & 36 & \\
\hline Entire Region & 73 & 64 & 45 & 45 & \\
\hline \multicolumn{6}{|c|}{ STMW Bottom Depth (m) } \\
\hline $20-35^{\circ} \mathrm{N}, 80-75^{\circ} \mathrm{W}$ & 70 & 56 & 30 & 29 & \\
\hline $30-40^{\circ} \mathrm{N}, 75-60^{\circ} \mathrm{W}$ & 70 & 54 & 67 & 54 & \\
\hline $30-40^{\circ} \mathrm{N}, 60-40^{\circ} \mathrm{W}$ & 81 & 76 & 53 & 78 & \\
\hline $20-30^{\circ} \mathrm{N}, 75-40^{\circ} \mathrm{W}$ & 38 & 40 & 30 & 47 & \\
\hline Entire Region & 70 & 56 & 58 & 59 & \\
\hline \multicolumn{6}{|c|}{ STMW Top Temperature $\left({ }^{\circ} \mathrm{C}\right)$} \\
\hline $20-35^{\circ} \mathrm{N}, 80-75^{\circ} \mathrm{W}$ & 0.38 & 0.33 & 0.33 & 0.38 & \\
\hline $30-40^{\circ} \mathrm{N}, 75-60^{\circ} \mathrm{W}$ & 0.42 & 0.38 & 0.32 & 0.36 & \\
\hline $30-40^{\circ} \mathrm{N}, 60-40^{\circ} \mathrm{W}$ & 0.63 & 0.57 & 0.65 & 0.47 & \\
\hline $20-30^{\circ} \mathrm{N}, 75-40^{\circ} \mathrm{W}$ & 0.42 & 0.32 & 0.33 & 0.27 & \\
\hline Entire Region & 0.46 & 0.39 & 0.36 & 0.35 & \\
\hline \multicolumn{6}{|c|}{ STMW Bottom Temperature $\left({ }^{\circ} \mathrm{C}\right)$} \\
\hline $20-35^{\circ} \mathrm{N}, 80-75^{\circ} \mathrm{W}$ & 0.42 & 0.31 & 0.30 & 0.35 & \\
\hline $30-40^{\circ} \mathrm{N}, 75-60^{\circ} \mathrm{W}$ & 0.35 & 0.29 & 0.38 & 0.39 & \\
\hline $30-40^{\circ} \mathrm{N}, 60-40^{\circ} \mathrm{W}$ & 0.35 & 0.44 & 0.53 & 0.38 & \\
\hline $20-30^{\circ} \mathrm{N}, 75-40^{\circ} \mathrm{W}$ & 0.34 & 0.35 & 0.38 & 0.32 & \\
\hline Entire Region & 0.37 & 0.35 & 0.40 & 0.40 & \\
\hline \multicolumn{6}{|c|}{ STMW Mean Temperature Gradient $\left({ }^{\circ} \mathrm{C}\right.$ per $\left.100 \mathrm{~m}\right)$} \\
\hline $20-35^{\circ} \mathrm{N}, 80-75^{\circ} \mathrm{W}$ & 0.12 & 0.13 & 0.15 & 0.10 & \\
\hline $30-40^{\circ} \mathrm{N}, 75-60^{\circ} \mathrm{W}$ & 0.15 & 0.12 & 0.12 & 0.13 & \\
\hline $30-40^{\circ} \mathrm{N}, 60-40^{\circ} \mathrm{W}$ & 0.23 & 0.12 & 0.13 & 0.15 & \\
\hline $20-30^{\circ} \mathrm{N}, 75-40^{\circ} \mathrm{W}$ & 0.11 & 0.12 & 0.14 & 0.10 & \\
\hline Entire Region & 0.16 & 0.15 & 0.13 & 0.13 & \\
\hline
\end{tabular}




\section{Chapter 3}

\section{Characterizing STMW Rénewal Events}

In this chapter, the interannual and spatial variations in the degree of STMW renewal are characterized for the years 1968-1988. These years were chosen based on data availability. The beginning of this interval was defined by the rapid increase in the use of XBT probes for data collection (Figure 2.6), while its end was defined by the fall off of XBT data available from the NODC, due to the time lag between data collection and submission to the NODC for archival. The STMW renewal events will be characterized using three criteria. The first two involve comparing the late winter (February-April) mixed layer depths and temperatures to the depths and temperatures at the top of the STMW layer in the previous fall, prior to its exposure to direct atmospheric cooling. The differences in temperature and depth of the mixed layer and the top of the STMW layer will indicate the degree to which winter convective mixing penetrated the STMW layer. If the late winter mixed layers were colder/deeper than the top of the STMW layer in the previous fall, the winter mixed layers likely penetrated into the STMW layer, and the STMW layer 
experienced some degree of convective mixing during that winter. Conversely, if the late winter mixed layers were warmer/shallower than the top of the pre-existing STMW layer and thus did not penetrate into the STMW layer, then the STMW layer experienced little or no convective mixing that winter. The third criterion is based on the temperature gradient through the STMW layer in spring, just after the return of the seasonal stratification. If the mean temperature gradient in spring is less than it was in the previous fall, it will be assumed that this decrease was the result of STMW formation which resulted in a thicker and/or more vertically homogeneous STMW layer. Conversely, a mean temperature gradient in spring which is equal or greater than its mean value in the previous fall most likely means the STMW layer has become thinner and/or more stratified and was therefore not exposed to direct atmospheric cooling in winter.

Because the hydrographic data are unevenly distributed in space and time, scatter plots of the winter and spring profile positions were first generated to visualize the data distribution from one year to the next. The symbols used to indicate the profile positions in these diagrams were plotted with a gray/color scale to indicate the character of the mixed layer each winter and the STMW layer each spring. The gray scale in Figures 3.1 and 3.2 indicates the depth and temperature differences between the plotted late winter (February-April) mixed layers and the top of the STMW layer the previous fall (November-January), before the STMW layer is exposed to direct atmospheric cooling. In Figure 3.1, the mixed layer depths of profiles plotted in light gray were shallower than the top of the previous year's STMW layer, and therefore did not penetrate into the pre-existing STMW layer. 
The mixed layers of profiles plotted in dark gray penetrated less than $100 \mathrm{~m}$ into the previous year's STMW layer, while those plotted in black penetrated more than $100 \mathrm{~m}$ into the STMW layer. Similarly, profiles plotted in light gray in Figure $3.2 \mathrm{had}$ mixed layer temperatures which were warmer than the temperature at the top of the previous year's STMW layer. Those profiles plotted with dark gray had mixed layer temperatures up to $0.5^{\circ} \mathrm{C}$ colder than the temperature at the top of the pre-existing STMW layer, while those plotted in black were more than $0.5^{\circ} \mathrm{C}$ colder than the STMW layer top temperature. Finally, the gray scale in Figure 3.3 indicates the mean temperature gradient through the STMW layer. STMW layers of profiles plotted in light gray were the most stratified, having temperature gradients greater than $0.6{ }^{\circ} \mathrm{C}$ per $100 \mathrm{~m}$, while STMW layers of profiles plotted in black were the most vertically homogeneous, having temperature gradients less than $0.3^{\circ} \mathrm{C}$ per $100 \mathrm{~m}$.

The data in the winter and spring of 1968 are sparse, but it appears from Figures 3.1 and 3.2 that the mixed layer penetrated into the STMW layer, and there are several profiles the following spring with small temperature gradients (Figure 3.3). Therefore, it appears the STMW layer experienced some degree of convective mixing in 1968. The STMW layer underwent large-scale convective mixing and renewal of its vertical homogeneity in the 1969 and 1970 winters, as is evident from the large numbers of February-April profiles with cold, deep mixed layers and May-July profiles with small temperature gradients. The winters of 1971 through 1974 show less convective mixing into the STMW layer than those of 1969 and 1970. While some of the mixed layers penetrated into the STMW layer 


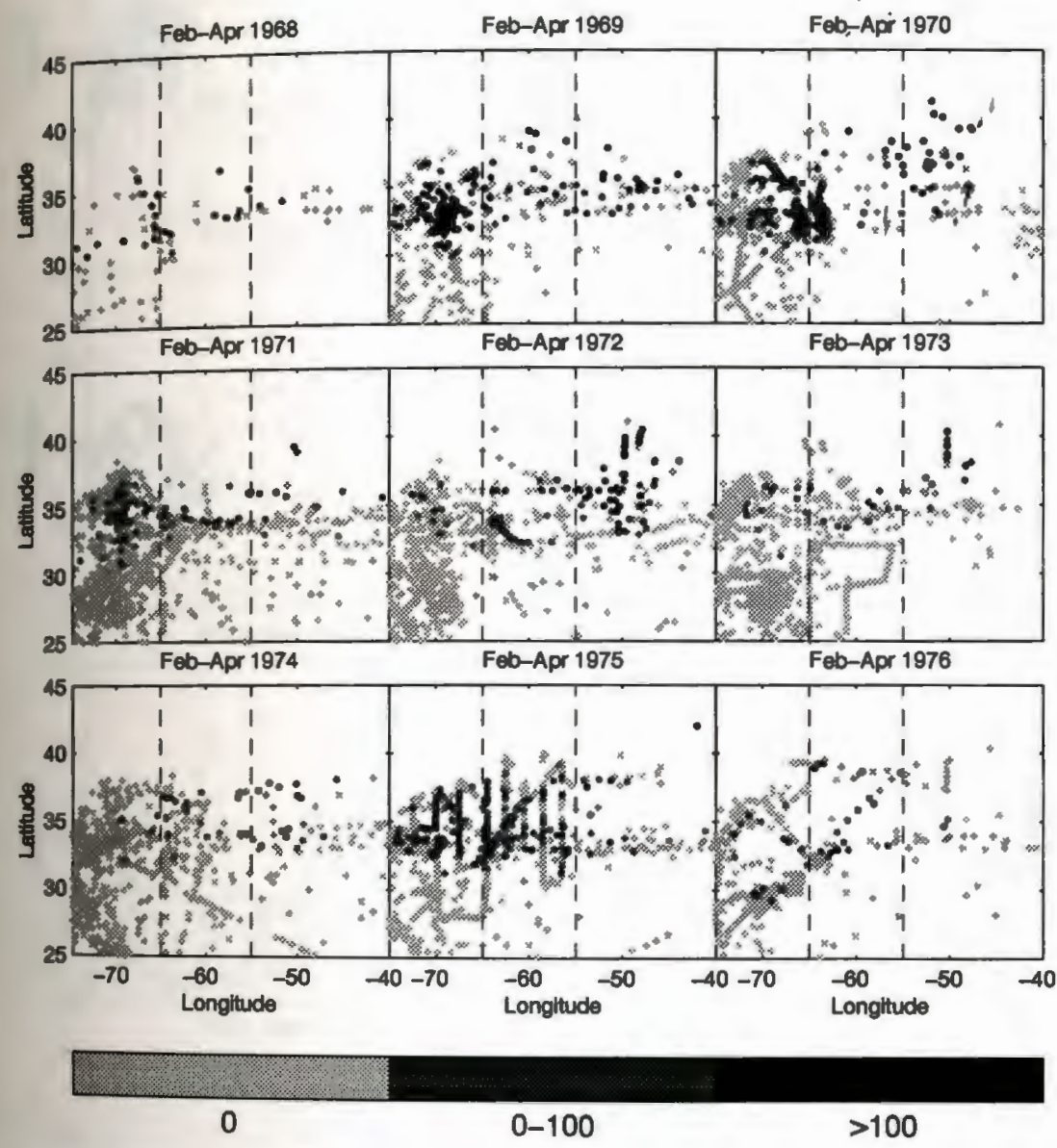

Figure 3.1: February-April profile positions, (a) 1968-1976 (b) 1977-1988. Symbol used to plot each profile position has been shaded to indicate difference between the profile's mixed layer depth and the previous year's STMW layer top depth. See text for details. 

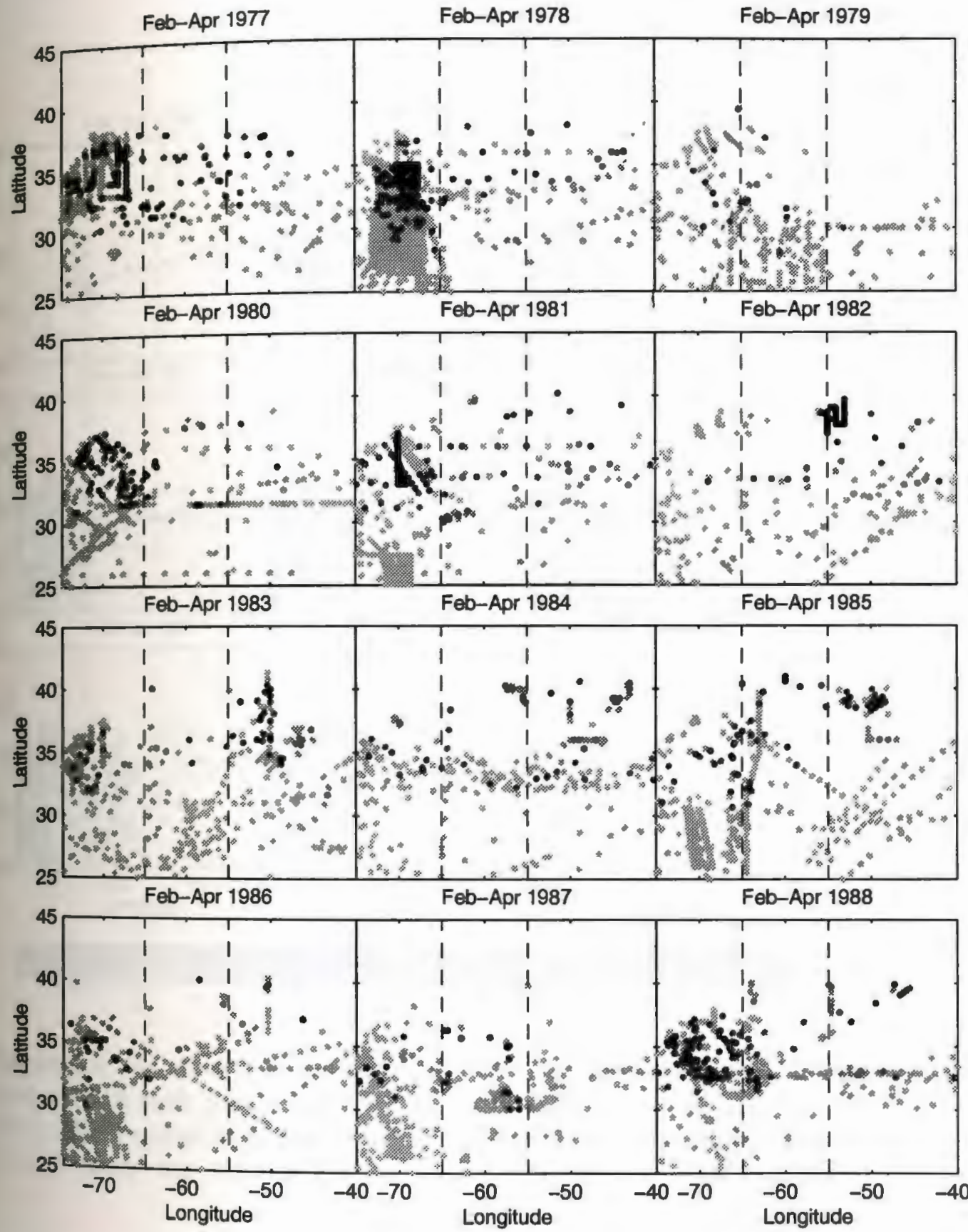

Figure 3.1(b): February-April profile positions, 1977-1988. 


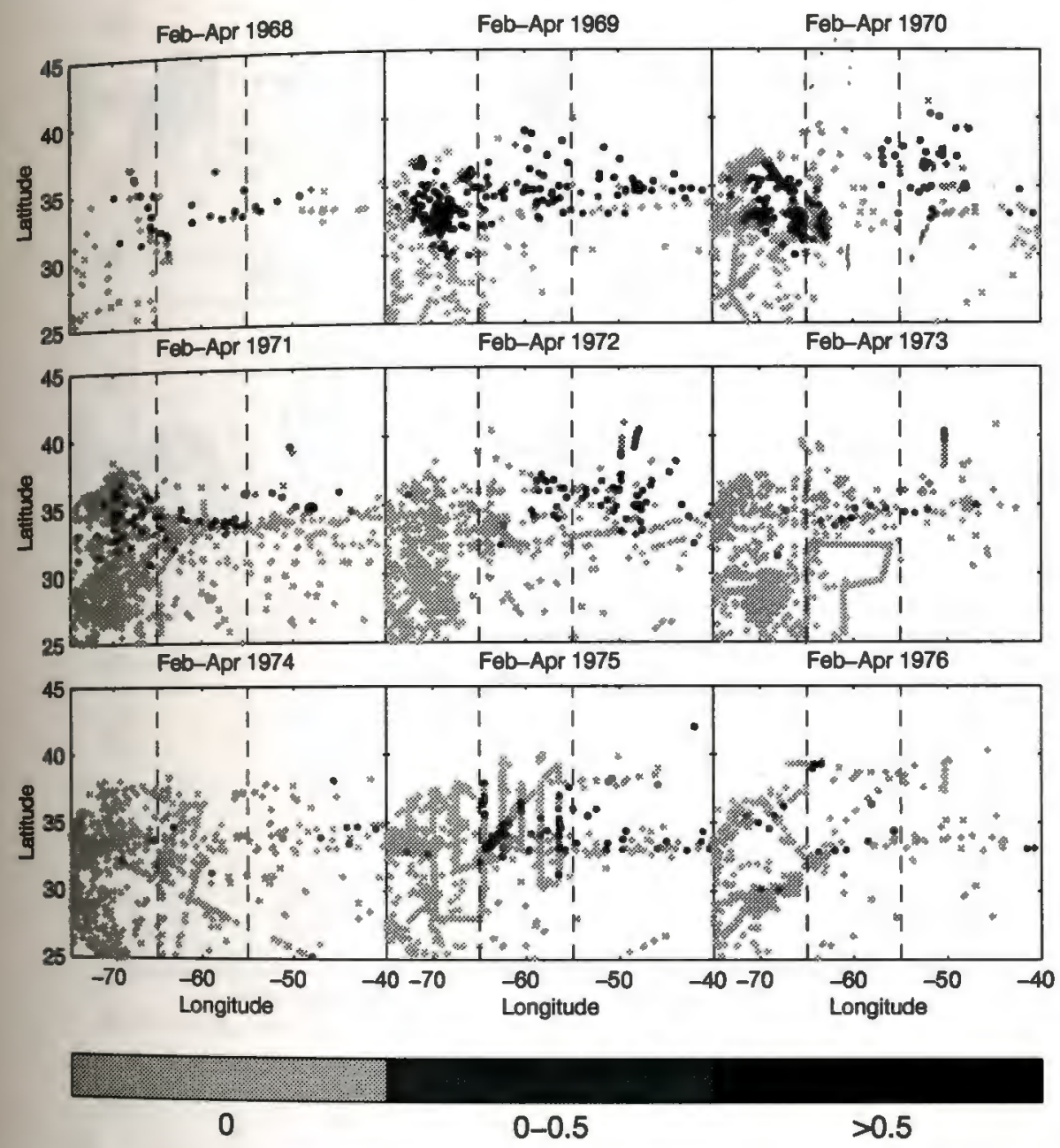

Figure 3.2: February-April profile positions, (a) 1968-1976 (b) 1977-1988. Symbol used to plot each profile position has been shaded to indicate difference between the profile's mixed layer temperature and temperature at top of the previous year's STMW layer. See text for details. 


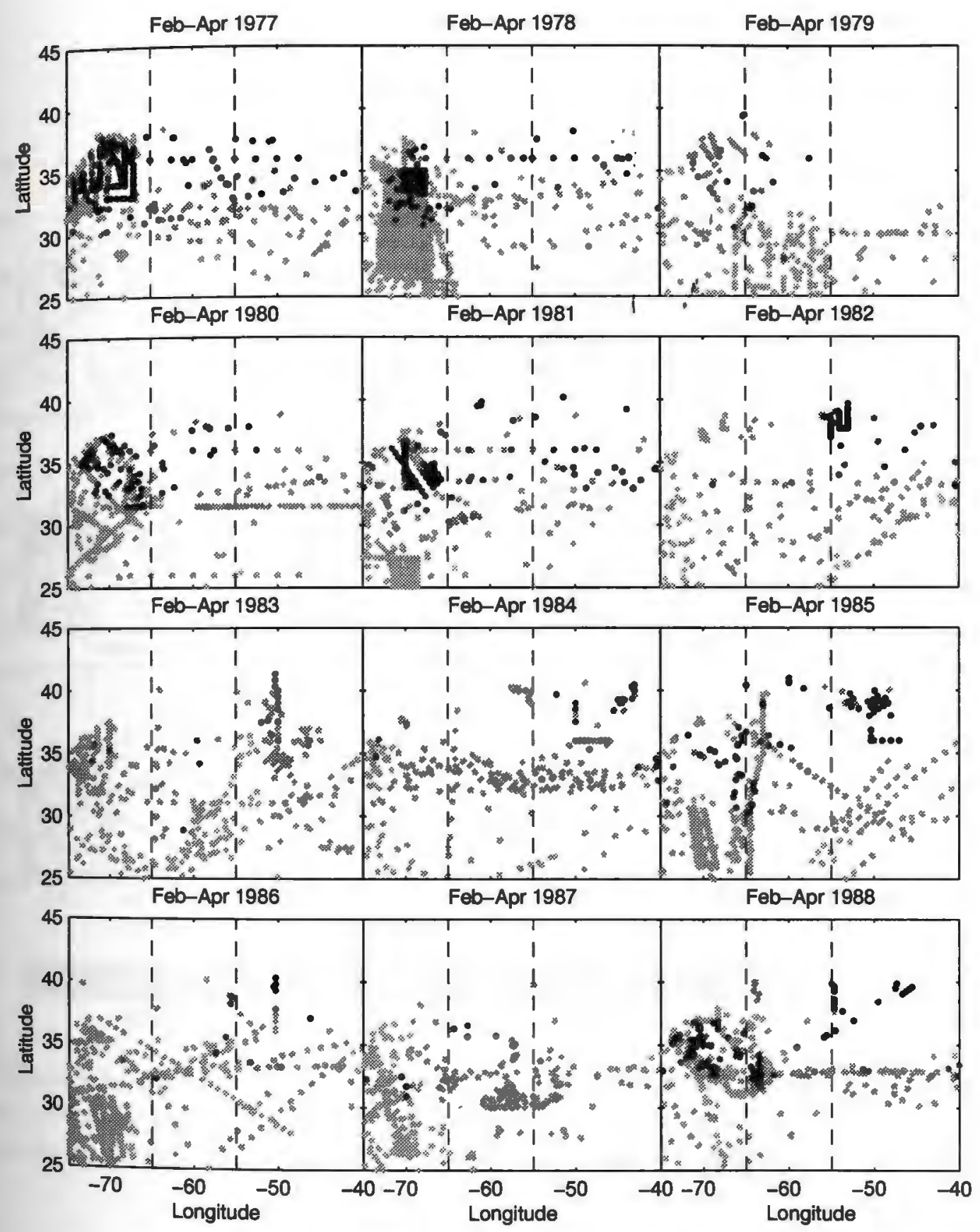

Figure 3.2(b): February-April profile positions, 1977-1988. 


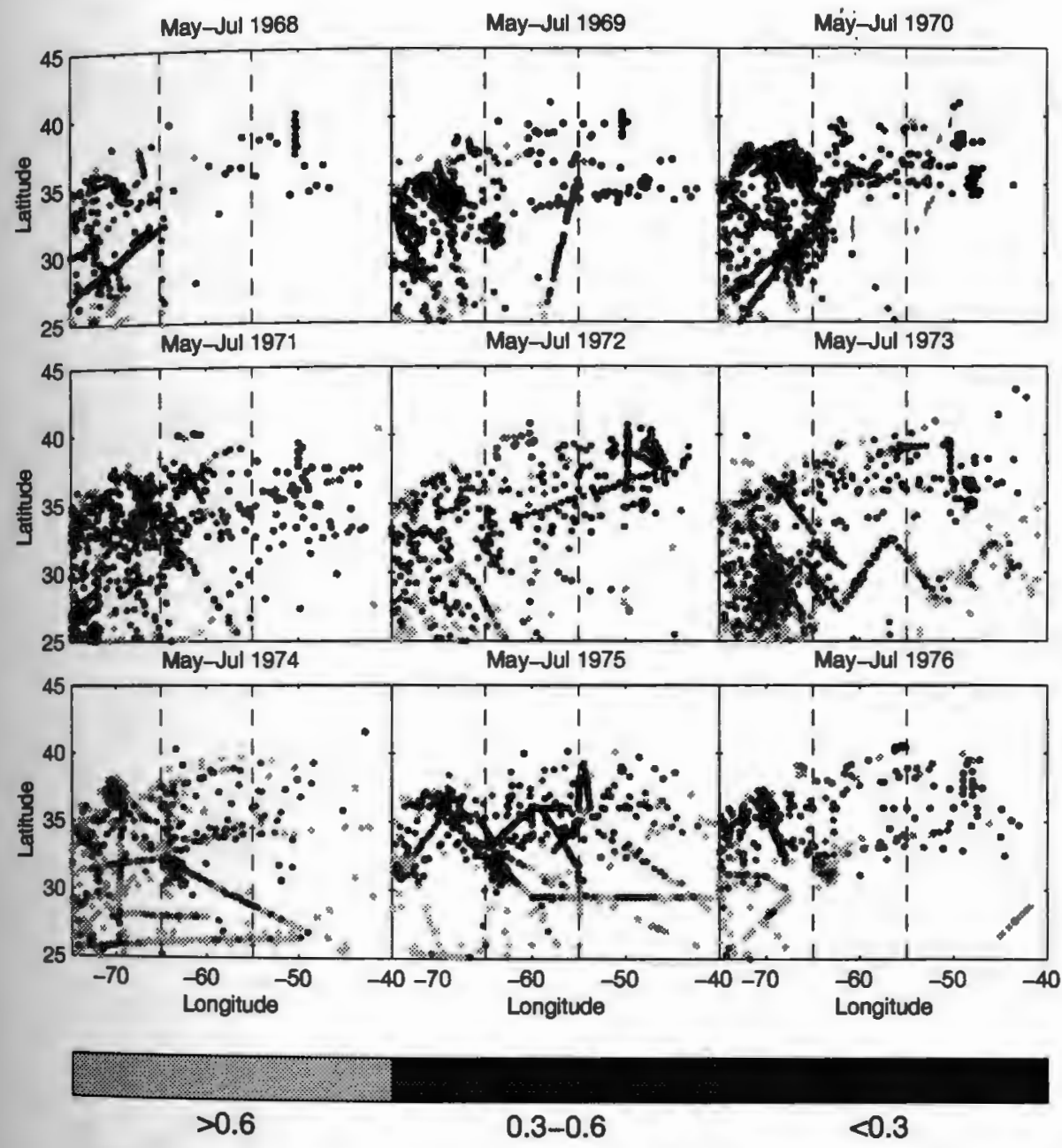

Figure 3.3: May-July profile positions, (a) 1968-1976 (b) 1977-1988. Symbol used to plot each profile position has been shaded to indicate the mean temperature gradient through the profile's STMW layer. See text for details. 

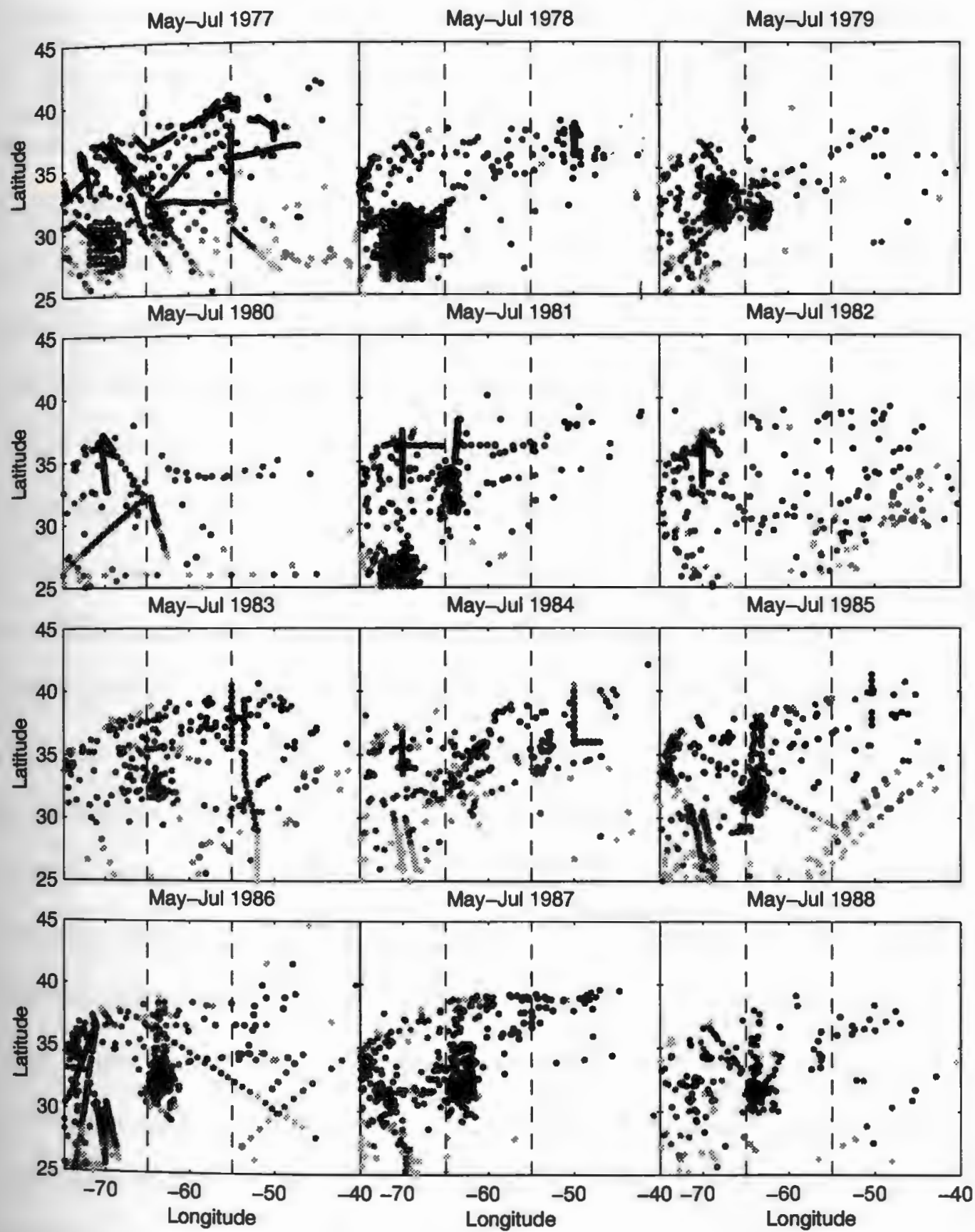

Figure 3.3(b): May-July profile positions, 1977-1988. 
during these winters, particularly to the east, all of these winters are characterized by warm February-April mixed layers relative to the STMW layer top temperature. The May-July temperature gradients also reflect the lack of renewal during these winters. While there are a number of profiles with small temperature gradients in 1971 and to the east in 1972 and 1973, there are overall fewer profiles with small temperature gradients than in 1969 or 1970 . The number of profiles with small temperature gradients appears to decrease each year, reaching a minimum in 1974. Some of the mixed layers in 1975 and 1976 appear to penetrate into the STMW layer, but most of the mixed layers in these winters were warmer than the STMW top temperature. The number of profiles in spring with small temperature gradients also increased in 1975 and 1976 from 1971-1974. Large-scale renewal of the STMW layer appears to return in the 1977 and 1978 winters with cold mixed layers penetrating into the STMW layer and a dramatically increased number of profiles in May-July with small temperature gradients. The 1979 winter data in the STMW formation region are sparse, especially east of $55^{\circ} \mathrm{W}$, but there are a number of profiles in the spring with small temperature gradients, indicating that some renewal of the STMW layer most likely occurred in 1979. While the 1980 and 1981 winters had some penetration into the STMW layer and some cold mixed layers, the rest of the 1980's appear to be characterized by little penetration and warm mixed layers. However, except for 1986, it is difficult to discern any appreciable change in the number of profiles in spring with small temperature gradients. 


\subsection{Winter Mixed Layer Characterizations}

To further assess the degree of STMW layer renewal each winter, time series of the temperature and depth at the top of the STMW layer each fall and the depth and temperature of late winter mixed layers were constructed. Again, care must be taken in the averaging used to construct these time series due to the uneven data distribution. Although the clustering of profiles closel in space and time done here (Section 2.6) will reduce some of the bias towards regions and times with large data densities, it is evident from Figures 3.1-3.3 that any averaging will be biased towards the west. Therefore, the STMW formation region north of $30^{\circ} \mathrm{N}$ will be divided into three regions indicated by dashed lines in Figures $3.1-3.3,75-65^{\circ} \mathrm{W}$, $65-55^{\circ} \mathrm{W}$, and $55-40^{\circ} \mathrm{W}$. These regions are large enough to allow for sufficient numbers of observations each year for a meaningful average, while at the same time minimizing the east-west bias in the means.

The thin line in Figure 3.4 is the mean depth of the deepest $25 \%$ of the February-April mixed layers from 1968 through 1988, while the heavy line depicts the mean depth of the top of the STMW layer in the previous fall (November 1967-January 1968 through November 1987-January 1988). Figure 3.5 shows the mean temperature of the coldest $25 \%$ of the February-April 1968-1988 mixed layers (thin line) relative to the mean temperature at the top of the STMW layer in the previous (1967-1987) fall (heavy line). The mean depths and temperatures are the weighted means of clusters of profiles and remaining individual profiles, using Equation 2.6. The error bars on each mean are the standard deviation of 
75 to $65^{\circ} \mathrm{W}$
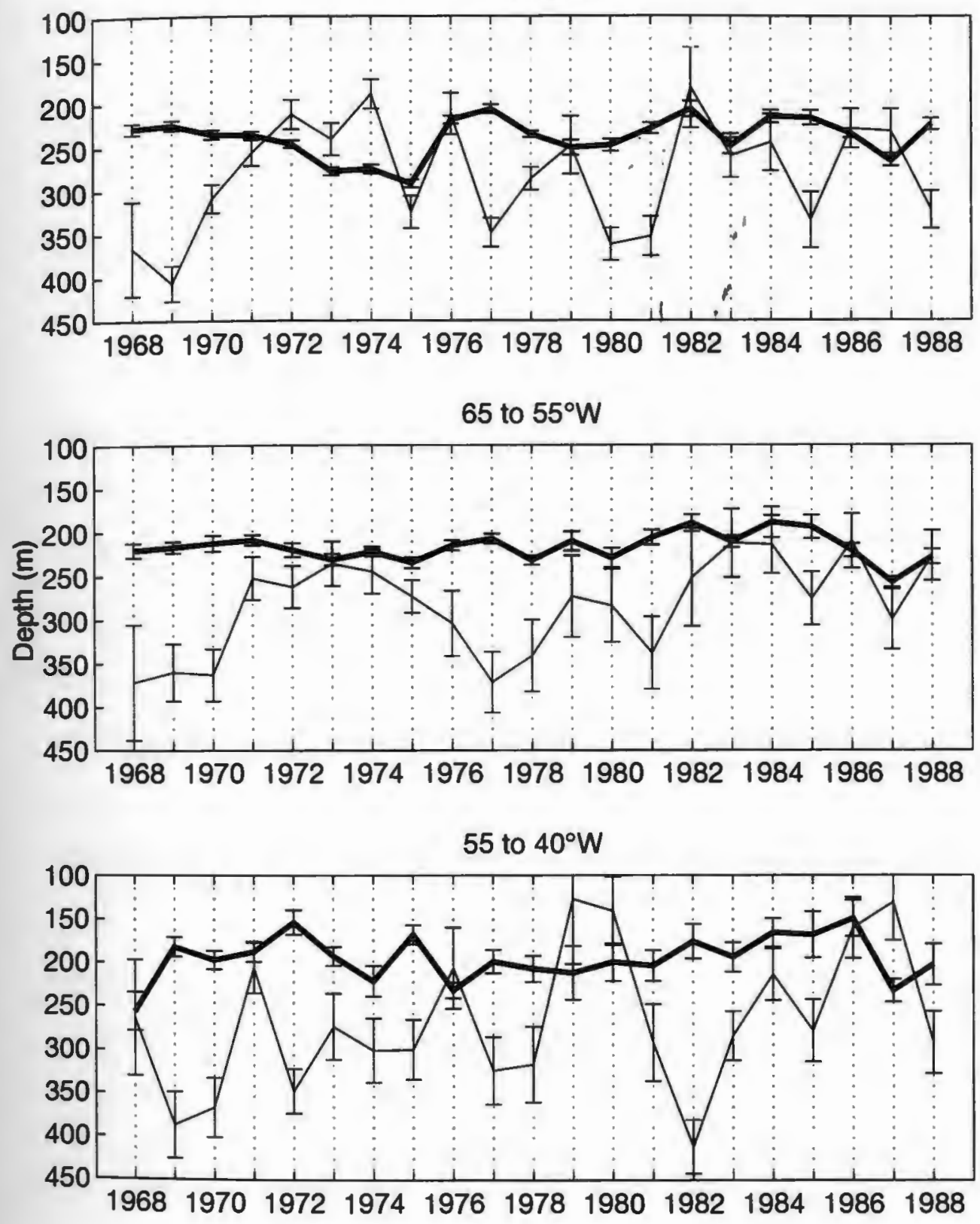

Figure 3.4: Mixed Layer and STMW Top Depth Time Series, 1968-1988. The thin line represents the mean depth of the deepest $25 \%$ of the February-April mixed layers, while the heavy line represents the mean depth of the top of the NovemberJanuary STMW layer. See text for details. 
75 to $65^{\circ} \mathrm{W}$

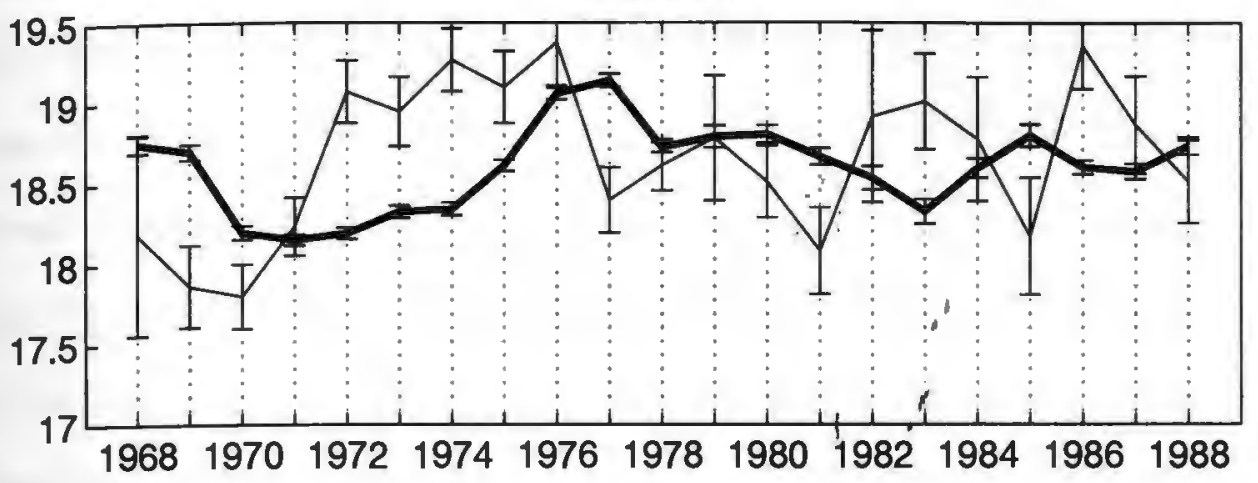

65 to $55^{\circ} \mathrm{W}$

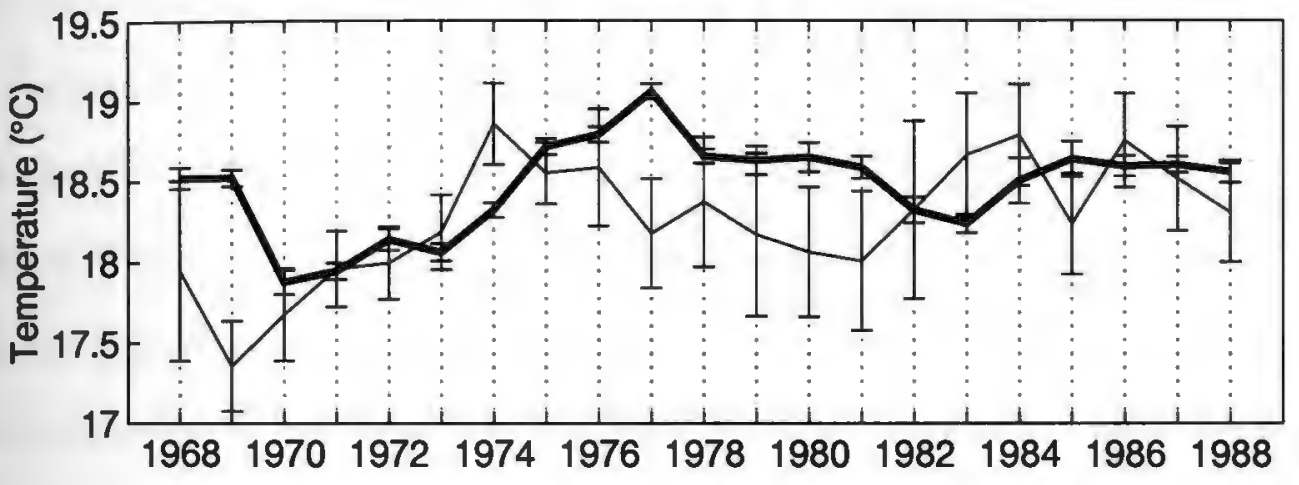

55 to $40^{\circ} \mathrm{W}$

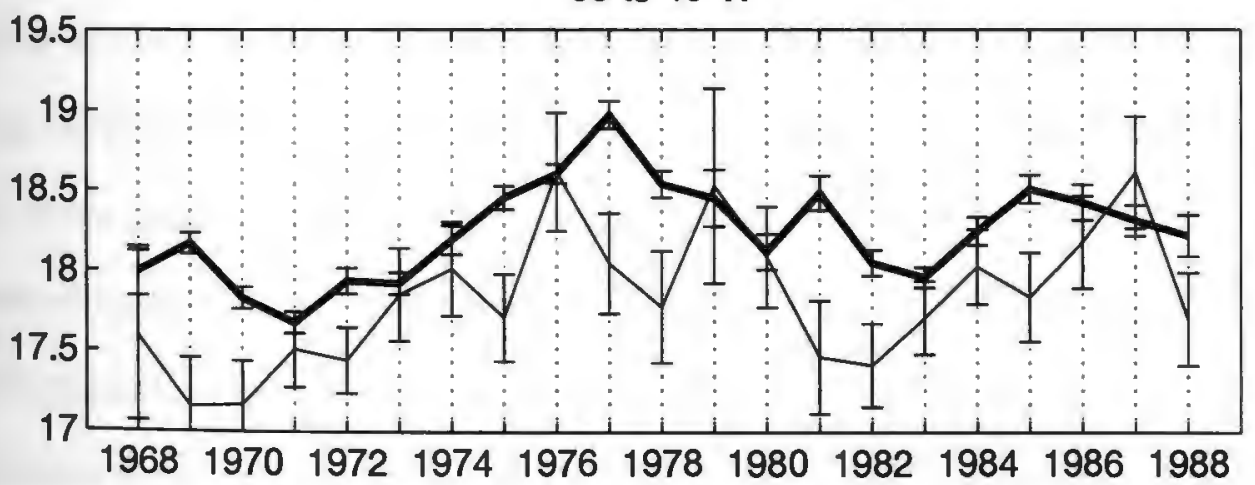

Figure 3.5: Mixed Layer and STMW Top Temperature Time Series, 1968-1988. The thin line represents the mean temperature of the coldest $25 \%$ of the FebruaryApril mixed layers, while the heavy line represents the mean temperature at the top of the November-January STMW layer. See text for details. 
the weighted means found using Equation 2.7.

From Figures 3.4 and 3.5, the 1968, 1969, and 1970 winters in all three regions are characterized by cold mixed layers penetrating into the STMW layer. During these years of annual renewal of the STMW layer, the November-January mean temperature at the top of the STMW layer (Figure 3.5) also decreased from one year to the next. The degree of renewal varied considerably from one region to the next and from one year to the next during the $1971-1976$ winters. West of $65^{\circ} \mathrm{W}$ in 1972-1974, the deepest mixed layers did not reach the top of the STMW layer and the coldest mixed layers were considerably warmer than the top of the STMW layer. In 1975 and 1976 in this region, the deepest mixed layers did reach the top of the STMW layer (Figure 3.4), but the coldest mixed layers were still much warmer than the top of the STMW layer (Figure 3.5). East of $55^{\circ} \mathrm{W}$, cold, deep mixed layers continued to penetrate into the STMW layer from 1972 to 1975 , with little or no penetration in 1971 and 1976 . The region from $65-55^{\circ} \mathrm{W}$ is an intermediate case with the deepest mixed layers reaching the top or slightly penetrating the top of the STMW layer in most winters, but not to the degree found farther east. During these years of little or no renewal of the STMW layer (1971-1976), the November-January mean temperature at the top of the STMW layer increased in all three regions. Wide-spread renewal of the STMW layer resumed in the 1977 and 1978 winters in all three regions, and the November-January mean temperature at the top of the STMW layer again decreased as it did following the 1969 and 1970 renewal events. The degree of STMW renewal varied considerably once again from 1980 through 1985. Cold mixed layers again penetrated into the STMW layer in 
1980 and 1981 , except for east of $55^{\circ} \mathrm{W}$ in 1980 . West of $65^{\circ} \mathrm{W}$ in 1982,1983 , and 1984, the deepest mixed layers reached the top of the STMW layer, but the coldest mixed layers were considerably warmer than the STMW layer top temperature. East of $55^{\circ} \mathrm{W}$, however, cold mixed layers continued to penetrate into the STMW layer during these winters. Wide-spread renewal of the STMW layer resumed in 1985 with deep, cold mixed layers existing in all three regions. There appears to have been little or no renewal of the STMW layer in 1986 or 1987. The deepest mixed layers rarely penetrated the top of the STMW layer, and the coldest mixed layers were typically warmer than the STMW top temperature. Cold mixed layers again penetrated into the STMW layer in 1988 west of $65^{\circ} \mathrm{W}$ and east of $55^{\circ} \mathrm{W}$.

\subsection{STMW Layer Temperature Gradient Characterization}

The third characterization of STMW renewal involves comparing the mean temperature gradient through the STMW layer in fall, before it is exposed to direct atmospheric cooling, to the mean temperature gradient in late spring, after the return of the seasonal stratification has isolated the STMW layer from the atmosphere. The 3-monthly mean temperature gradients for each year and the three regions north of $30^{\circ} \mathrm{N}$ are plotted in Figure 3.6. The first mean in each year is the May- July mean, followed by August-October, and finally November-January. These 3-monthly means are the weighted means of clusters of profiles and remaining individual profiles, using Equation 2.6. The error bars on each mean are the standard deviation of the weighted means found using Equation 2.7. 
Since the temperature gradients in the spring of 1969 and 1970 were less than the previous fall in all three regions, there appears to have been wide-spread convective mixing and a thickening/homogenizing of the STMW layer during these two winters, in aggreement with the mixed layer characterization. The temperature gradients west of $65^{\circ} \mathrm{W}$ consistently increased from 1971 through 1974, indicating no renewal of the STMW layer in this region during these years. East of $55^{\circ} \mathrm{W}$, however, STMW renewal appears to have continued during these winters. The temperature gradients decreased from fall to spring in all three regions from 1975 through 1981. West of $55^{\circ} \mathrm{W}$, the temperature gradients increased from fall to spring in 1982, 1983, and 1986, while they decreased during each of these springs east of $55^{\circ} \mathrm{W}$.

\subsection{Comparison of Characterizations}

The results from the characterizations seem to be in general agreement. They show large-scale renewal of the STMW layer in 1969, 1970, 1977, 1978, and 1985, no renewal west of $65^{\circ} \mathrm{W}$ from 1971-1974, and renewal occurring more often east of $55^{\circ} \mathrm{W}$ than west of $65^{\circ} \mathrm{W}$. To assess the agreement of these characterizations more carefully, two time series combining the different characterizations were constructed. In the first time series (Figure 3.7), the difference between the 3-monthly mean temperature gradients is plotted with the depth difference between the mean lovember-January STMW layer top and the mean depth of the deepest $25 \%$ of the February-April mixed layers. The difference in the 3-monthly mean temperature gradients is again plotted in the second time series (Figure 3.8), but now with the 
75 to $65^{\circ} \mathrm{W}$
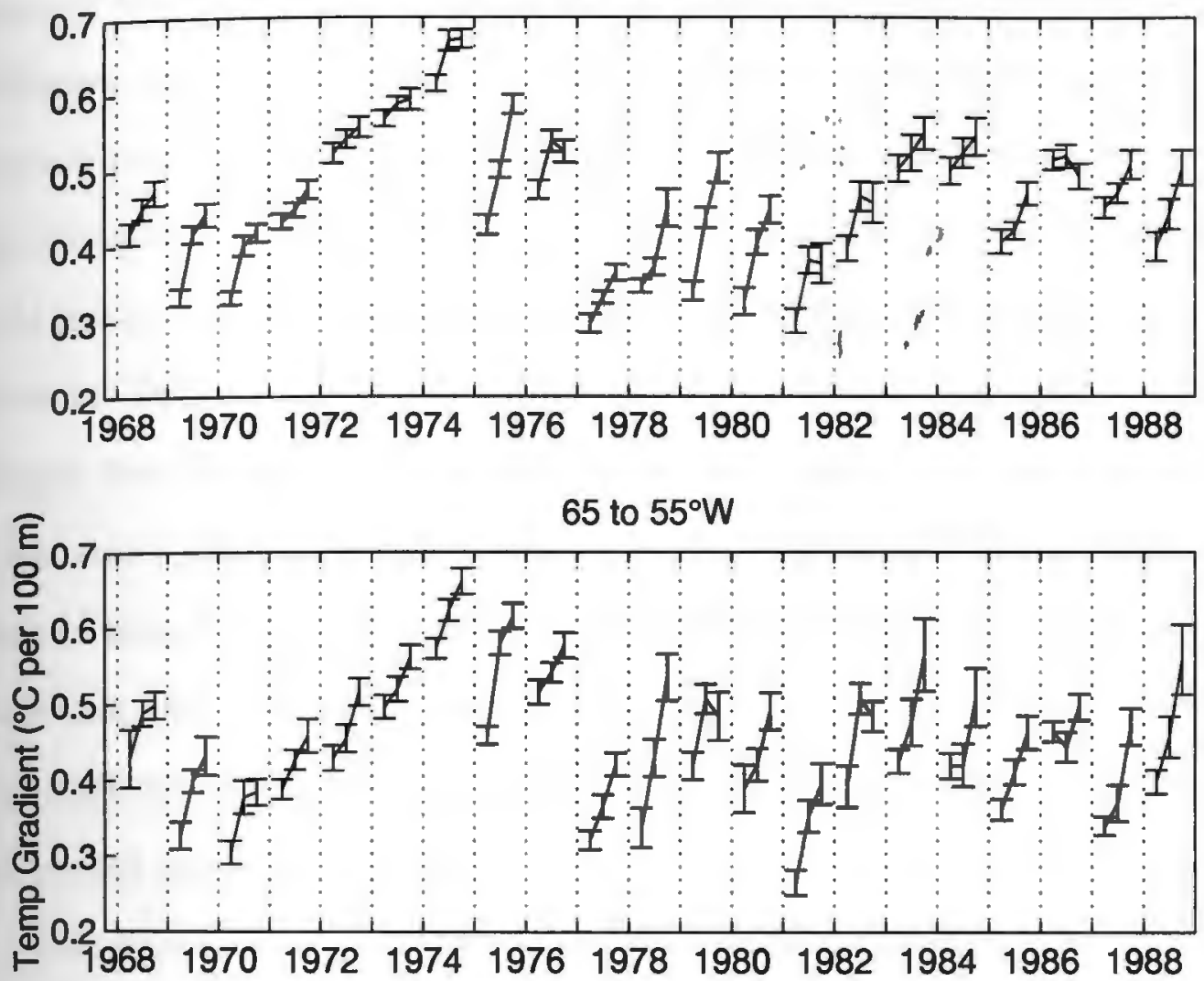

55 to $40^{\circ} \mathrm{W}$

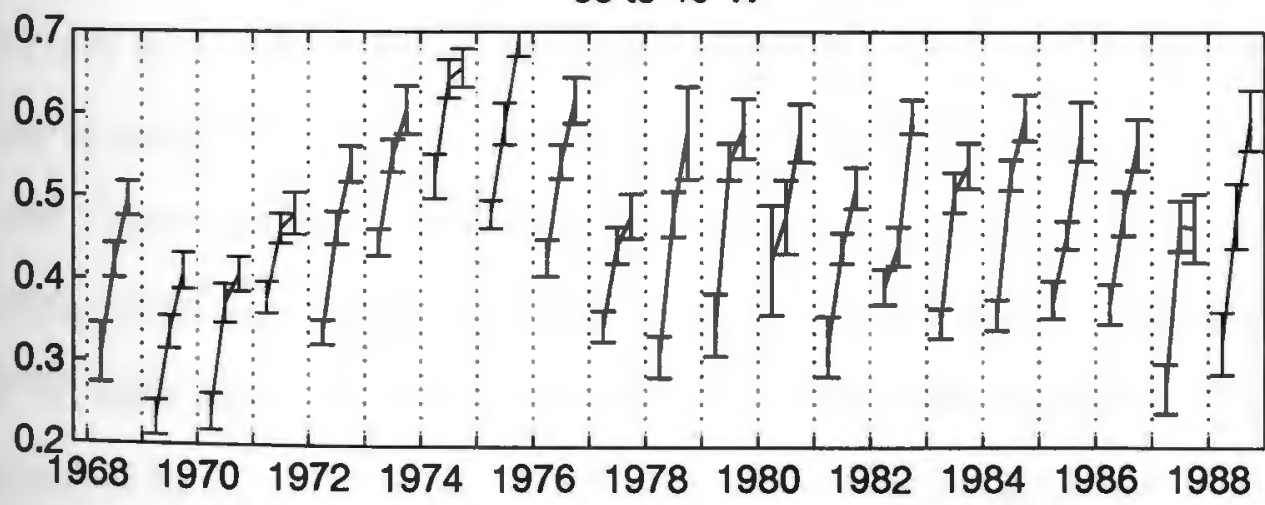

Figure 3.6: 3-Monthly (May-July, August-Oct, and November-January) Mean Temperature Gradient Time Series, 1968-1988. See text for details. 
temperature difference between the mean November-January STMW top and the mean of the coldest $25 \%$ of the February-April mixed layers. This temperature difference has been converted to a depth difference using the mean NovemberJanuary temperature gradient through the STMW layer. In both of these figures, the spring-fall temperature gradient differences are plotted with open circles. The solid line in each figure represents no change in the 3-monthly mean temperature gradient. Points above this line represent those temperature gradients which increased from the previous 3-monthly mean, while those below the line represent temperature gradients which decreased from the previous 3-monthly mean. In both of these figures, the mixed layer-STMW layer differences are plotted using large dots, with their corresponding axis to the right. Years where the mixed layer was shallower or warmer than the top of the STMW layer were set to zero, and are plotted along the solid line.

Both figures show good agreement between the characterizations. Generally, when the winter mixed layers penetrated into the STMW layer more than $50 \mathrm{~m}$ into the STMW (Figure 3.7), the temperature gradients through the STMW layer were smaller in spring than they were in the previous fall. There are some exceptions, however. There are large decreases in the temperature gradient with little corresponding winter penetration into the STMW layer in 1975, 1976, and 1979 west of $65^{\circ} \mathrm{W} ; 1975,1984$, and 1987 from 65 to $55^{\circ} \mathrm{W}$; and $1976,1979,1980,1986$, and 1987 east of $55^{\circ} \mathrm{W}$. In addition, the mixed layers penetrated more than $50 \mathrm{~m}$ into the STMW layer, but the temperature gradients through the STMW layer were not reduced in the springs of 1978 west of $65^{\circ} \mathrm{W}$ and 1982 in the $65-55^{\circ} \mathrm{W}$ region. 
75 to $65^{\circ} \mathrm{W}$
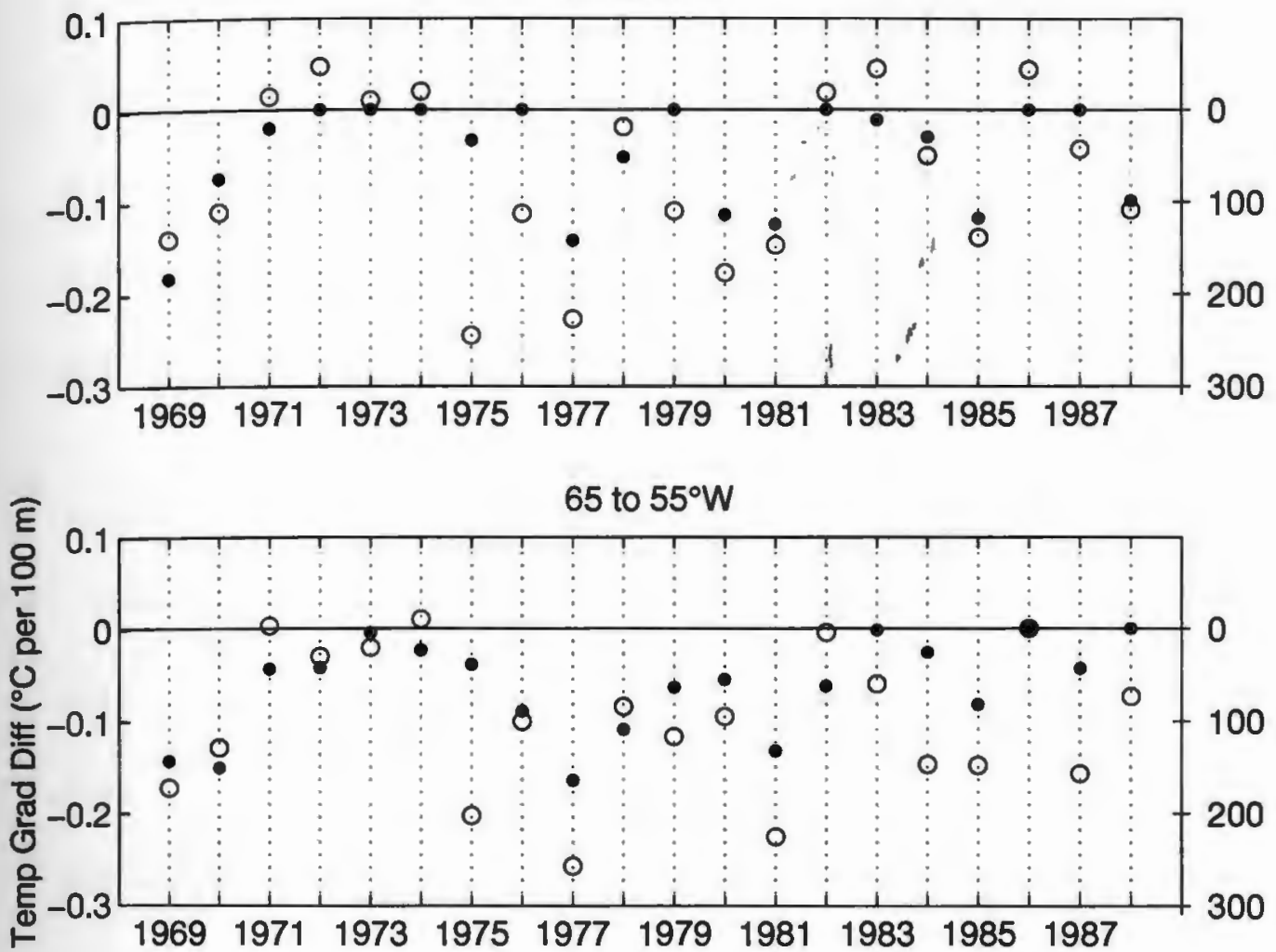

55 to $40^{\circ} \mathrm{W}$

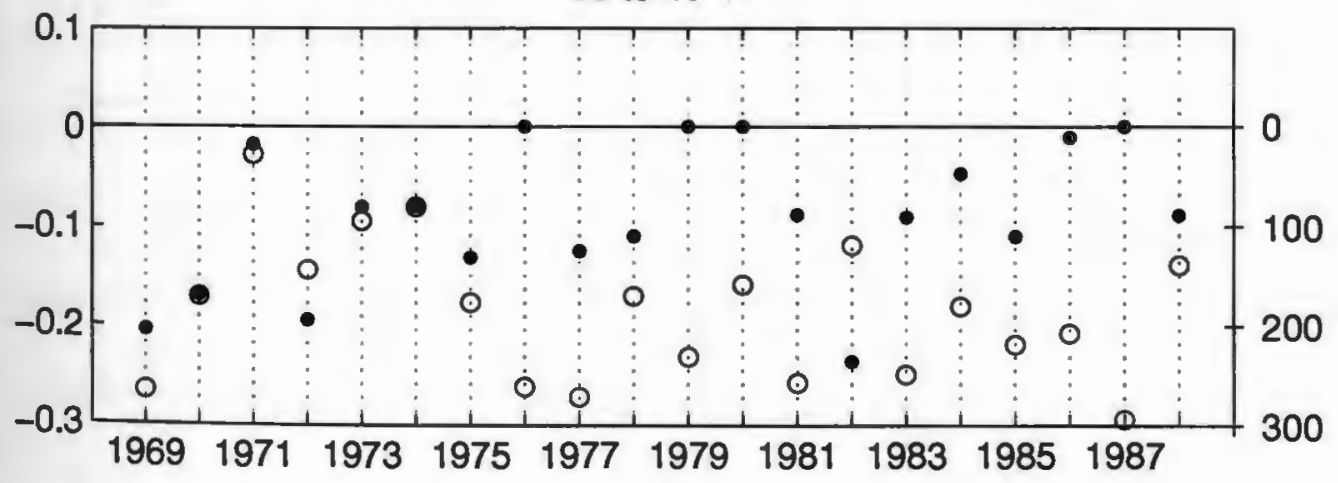

Figure 3.7: Temperature Gradient and Mixed Layer-STMW Top Depth Difference, 1968- 1988. The open circles represent the spring-fall difference in the 3-monthly mean temperature gradients shown in Figure 3.6. The dots represent the difference between the mixed layer and STMW top depths shown in Figure 3.4. 
75 to $65^{\circ} \mathrm{W}$
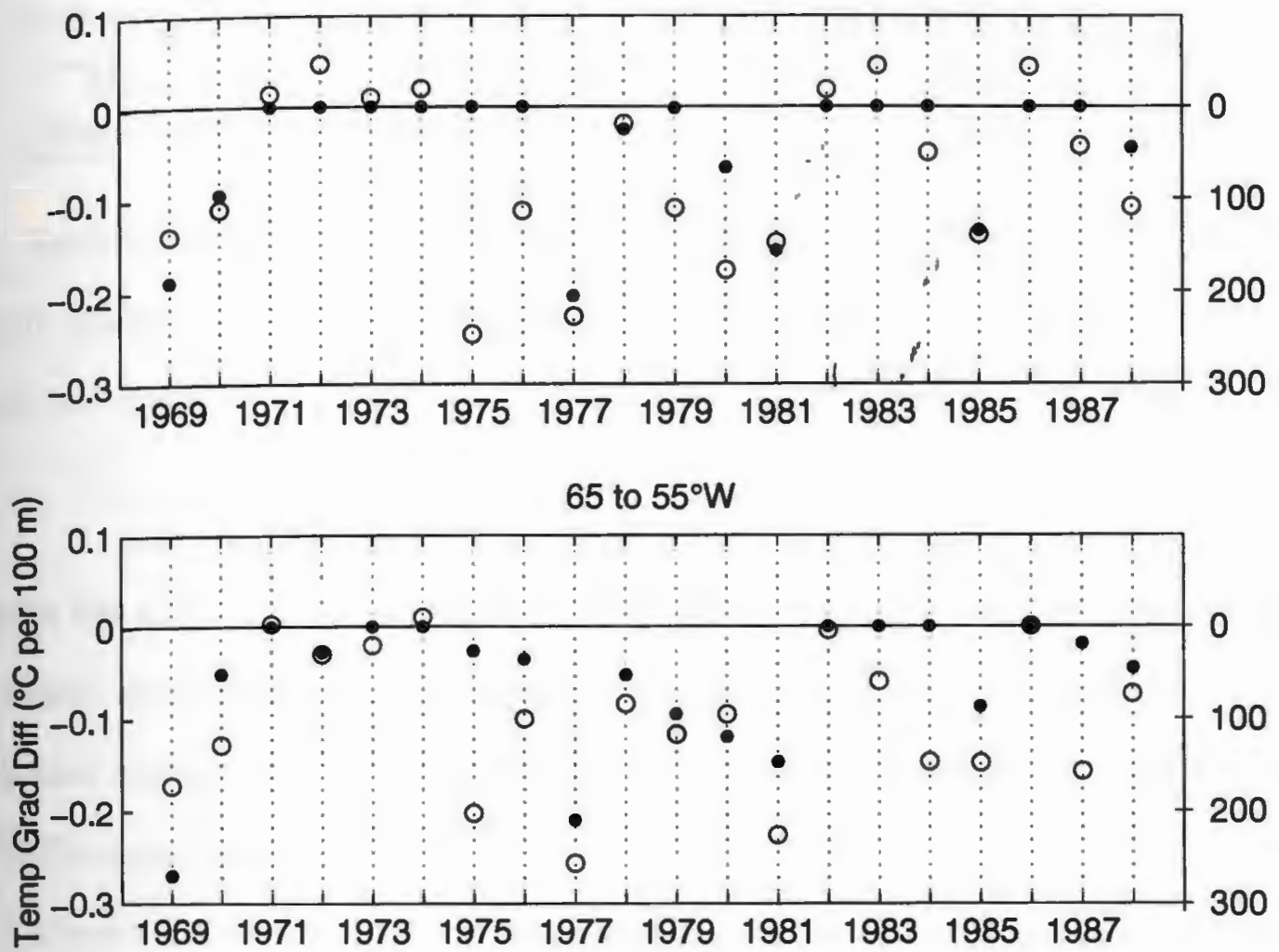

55 to $40^{\circ} \mathrm{W}$

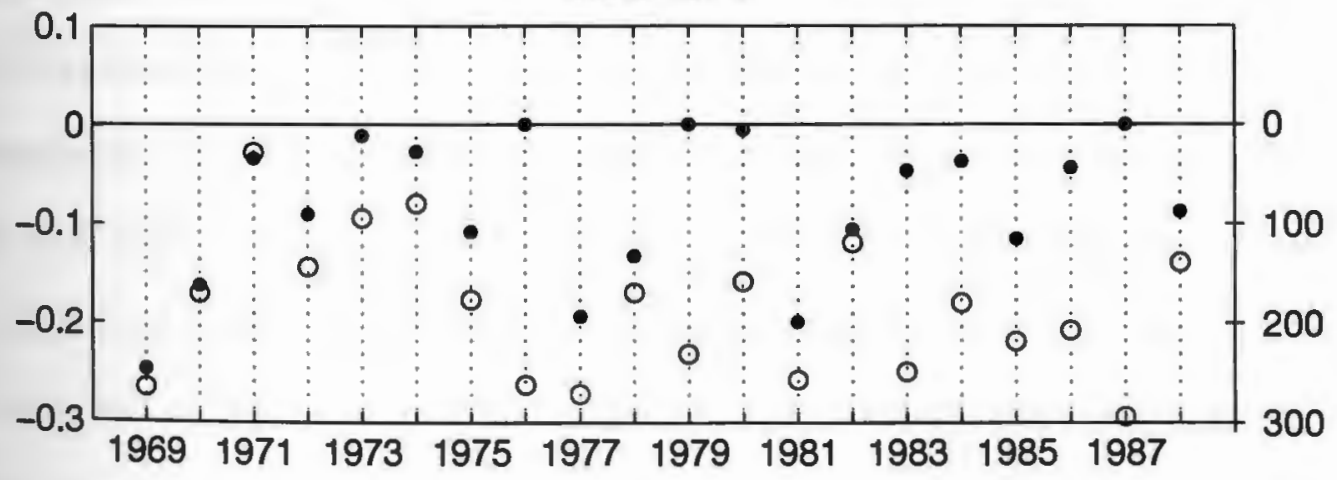

Figure 3.8: Temperature Gradient and Mixed Layer-STMW Top Temperature Difference, 1968-1988. The open circles represent the spring-fall difference in the 3-monthly mean temperature gradients shown in Figure 3.6. The dots represent the difference between the mixed layer and STMW top temperatures shown in Figure 3.5. 
Table 3.1: Correlation Coefficients Between Charaterizations

\begin{tabular}{cccc}
\hline & $75-65^{\circ} \mathrm{W}$ & $65-55^{\circ} \mathrm{W}$ & $55-40^{\circ} \mathrm{W}$ \\
\hline Mixed Layer Depths (Figure 3.7) & 0.80 & 0.86 & 0.71 \\
Mixed Layer Temperatures (Figure 3.8) & 0.75 & 0.81 & 0.76 \\
\hline
\end{tabular}

Table 3.1 lists the correlation coefficients between the mixed layer and temperature gradient characterizations for each region. Based on testing the hypothesis that the characterizations were not correlated $\left(\rho_{x y}=\delta\right)$ using the statistic

$$
t=\frac{r_{x y} \sqrt{N-2}}{\sqrt{1-r_{x y}^{2}}}
$$

which has a Student's distribution (Spiegel 1961), the mixed layer and temperature gradient characterizations are significantly correlated at the $95 \%$ confidence level, whether comparing mixed layer depths or temperatures converted to depths to the STMW temperature gradients.

There are several possible reasons for the discrepancies between the three characterizations. First, the data sampling in February through April could have been such that the periods/locations with the deepest mixed layers were missed or undersampled. Figures 3.1 and 3.9 suggest that this may have been the case in 1982 and 1987 in the $65-55^{\circ} \mathrm{W}$ region, and 1976,1979 , and 1987 east of $55^{\circ} \mathrm{W}$. The month of March in particular was undersampled in these regions/years, and in some, two of the three late winter months (February through April, when the mixed layers would be their deepest) were undersampled. Poor sampling, then, may explain why the two characterizations do not agree in five of the 14 cases.

Another possible explanation may be that profiles with small temperature gradients were formed to the west in winter and advected into the regions the following 
75 to $65^{\circ} \mathrm{W}$

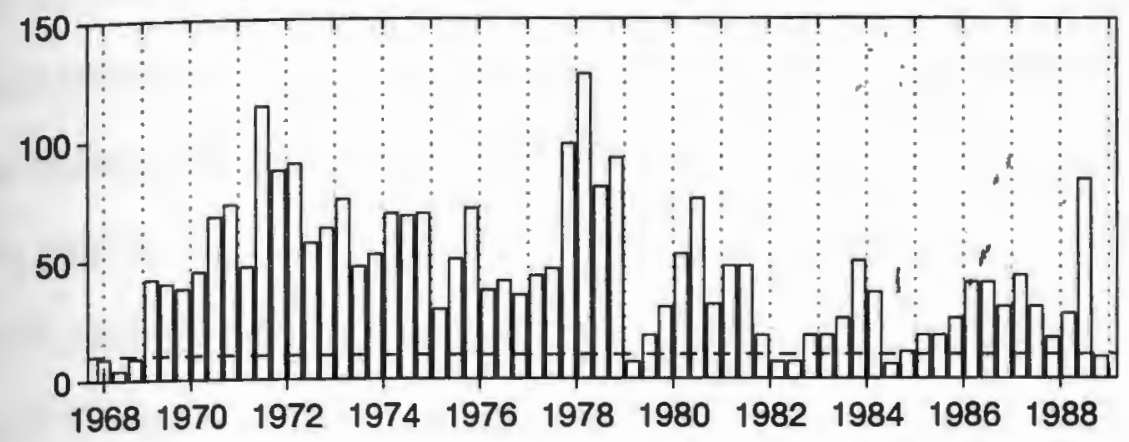

65 to $55^{\circ} \mathrm{W}$
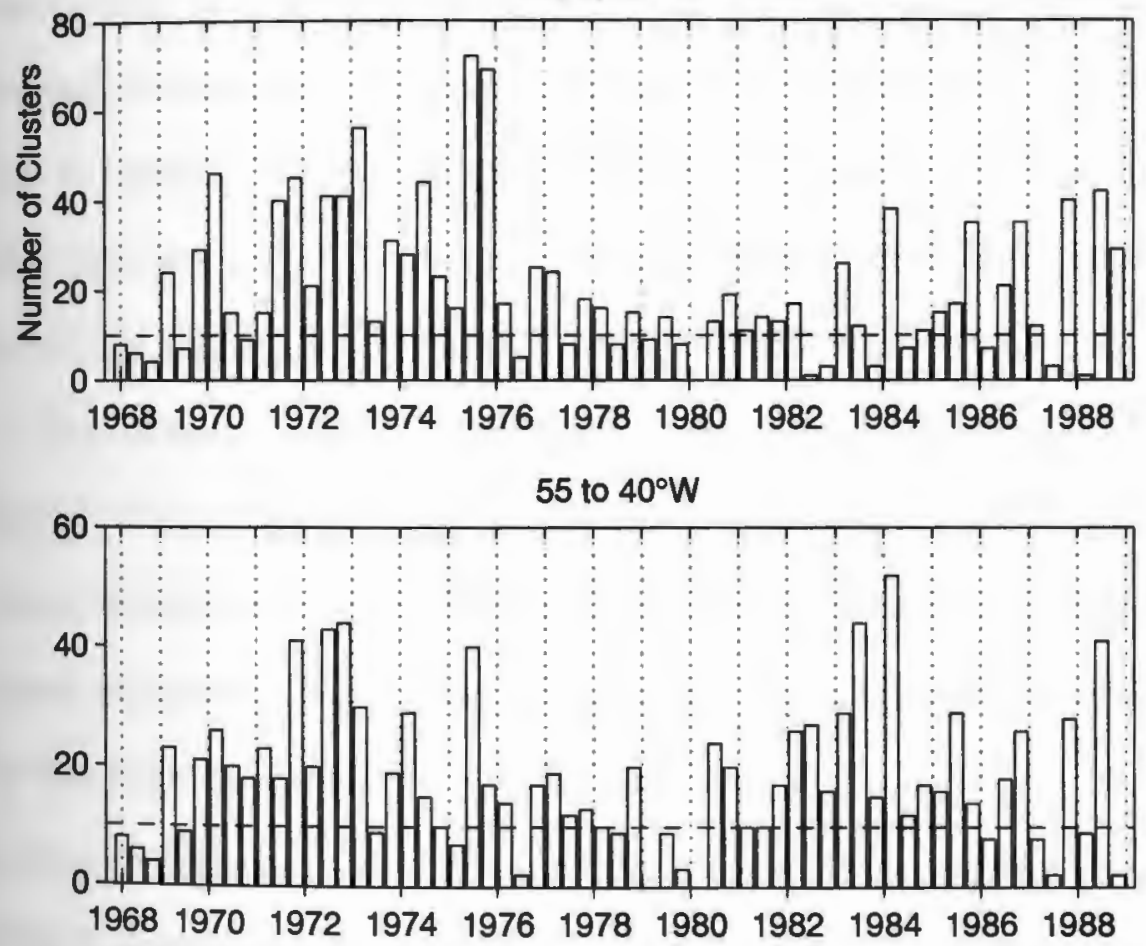

Figure 3.9: Number of Clusters in February, March, and April of Each Year, 19681988. For reference, dotted line represents ten clusters. 
spring, resulting in reduced temperature gradients in spring without substantial penetration in the winter. This argument cannot be applied to the westernmost region, but could explain the differences in the other two regions. However, for the years where the two characterizations do not agree in the 65 to $55^{\circ} \mathrm{W}$ region, there was penetration into the STMW layer west of $65^{\circ} \mathrm{W}$ only in 1975 . In fact, in 1984 and 1987 both characterizations showed no renewal of the STMW layer west of $65^{\circ} \mathrm{W}$, and yet the temperature gradients were reduced from fall to spring in the 65 to $55^{\circ} \mathrm{W}$ region in these years. Advection can be ruled out east of $55^{\circ} \mathrm{W}$ in 1976 , 1980,1986 , and 1987 as well. In each of these years, either the characterizations showed no renewal to the west (1986 and 1987), or the STMW layer in this region was too cold to have been advected from the west (1976 and 1980). Therefore, advection is a possible explanation for the large decrease in temperature gradient in 1975 in the 65 to $55^{\circ} \mathrm{W}$ region and 1979 in the 55 to $40^{\circ} \mathrm{W}$ region.

The characterizations also would not agree if the spring STMW layer was thicker than the fall STMW layer, but no convective mixing (i.e., no deep, cold mixed layers) occurred in the winter. This could occur in those years when the mixed layers are deep enough to reach the top or even penetrate into the STMW by less than $50 \mathrm{~m}$, but the mixed layer temperatures are warmer than the temperatures previously at the top of the STMW layer. In this case, a thin, warm STMW layer could form on the upper part of the older, pre-existing STMW layer. Although this dual STMW layer will have a relatively large change in temperature from top to bottom and little renewal of the pre-existing STMW layer, its large thickness will result in a reduced temperature gradient. 
The formation of these thick, dual-layer STMW layers is a possible explanation for the discrepancies between the characterizations in 1975 in both of the westernmost regions, and 1976 and 1979 west of $65^{\circ} \mathrm{W}$. In these years, warm mixed layers did reach and slightly penetrate the top of the STMW:layer. For example, in 1975, the mean depth of the deepest $25 \%$ of the mixed layers west of $65^{\circ} \mathrm{W}$ was $360 \mathrm{~m}$, $70 \mathrm{~m}$ deeper than the top of the STMW layer in the preyious fall, but the mean of the coldest $25 \%$ of the mixed layers was $0.4^{\circ} \mathrm{C}$ warmer than the temperature at the top of the STMW layer. Also, the temperature at the top of the STMW layer warmed by $0.5^{\circ} \mathrm{C}$ from fall to spring in 1975 .

In these dual-layer STMW layer cases, the RMS difference between the best-fit line through the STMW layer (consisting of both the new and old layer) would be large (Section 2.5). The mean RMS difference was the largest in 1975, 1976, and 1979 west of $65^{\circ} \mathrm{W}$; and in 1975 and 1984 in the $65-55^{\circ} \mathrm{W}$ region. Figure 3.10 is an example of these dual-layer STMW layers. The method used here (Section2.3) identified a STMW layer from $\sim 250$ to $\sim 575 \mathrm{~m}$. The temperature profile has an inflection point within this layer, however, with smaller temperature gradients above $\sim 450 \mathrm{~m}$ than below.

Forming a new STMW layer near the top of a pre-existing one is not the only explanation for thick STMW layers with large RMS, however. STMW layers containing temperature inversions or noise would also be thick and have a large RMS. Therefore, although the results from 1975, 1976, and 1979 point to a plausible geophysical explanation for the discrepancies between the two methods, it is difficult to establish the relative importance of the formation of multiple-layer STMW 
36.13 N, 59.65 W, Day 276 of 1976

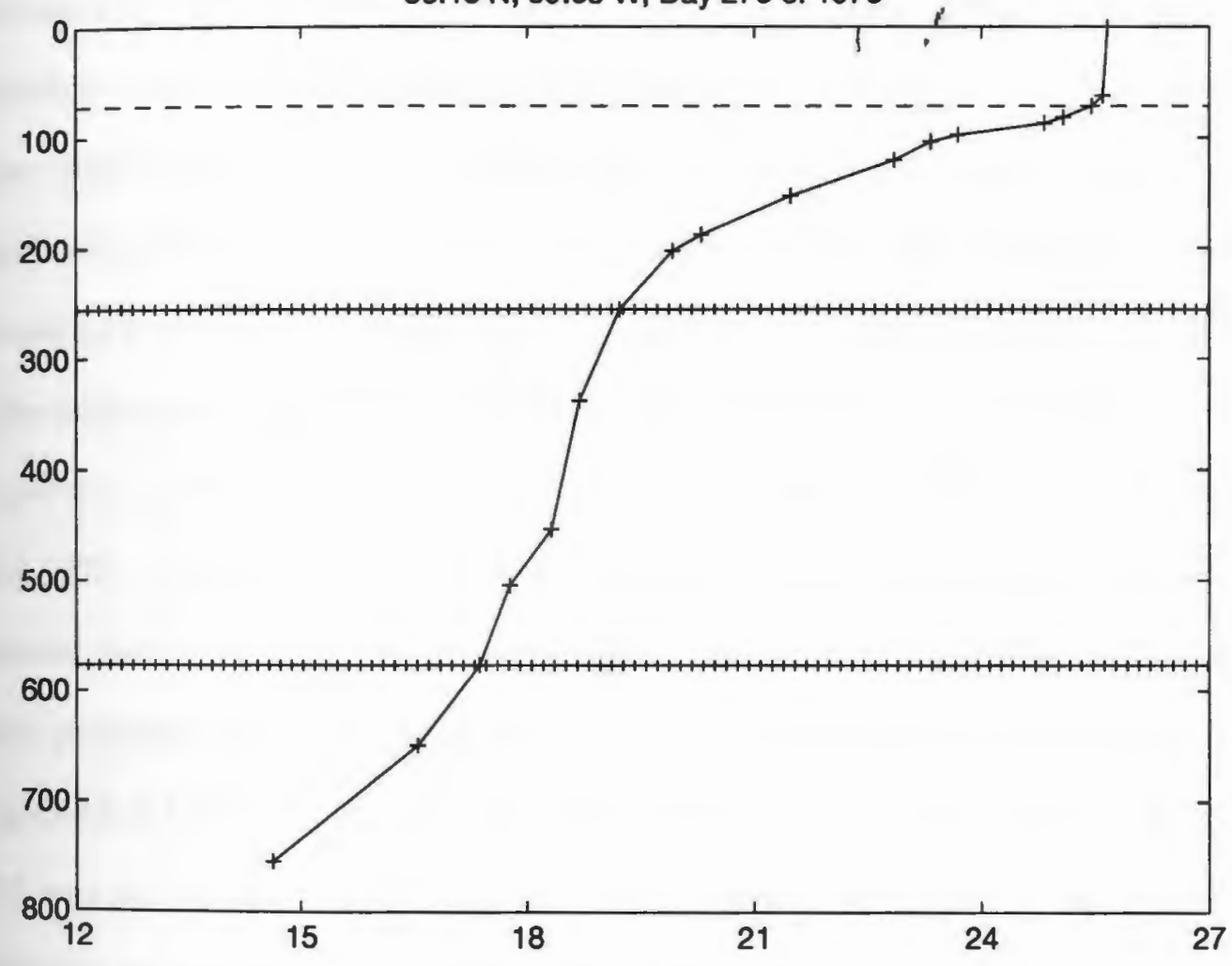

Figure 3.10: XBT Profile with a Multiple Layer STMW Layer. 
layers to random errors creating thick STMW layers without penetration of winter mixed layers.

\subsection{Comparison with Other Observations of STMW Renewal}

The observations of STMW renewal by Talley and Raymer, (1982), Jenkins (1982), Cornillon et al. (1987), and Klein and Hogg (1996) coincide at various times with these time series of STMW renewal (Figures 3.4-3.6) and therefore can be compared with these results. Talley and Raymer (1982) and Jenkins (1982) used the Panulirus hydrographic station data to estimate the degree of large-scale renewal of the subtropical gyre. Talley and Raymer (1982) examined variations in STMW properties at the potential vorticity (potential density gradient) minimum from 1954-1978. They found the STMW arriving at Bermuda in 1969-1971 had been renewed each year, and the temperatures at the potential vorticity minimum became progressively colder each year. Both of these trends are seen here as well (Figures 3.4-3.5). They argued that the STMW arriving at Bermuda from 1972 to 1975 was not renewed, and they found the temperatures at the potential vorticity minimum increased as well. This agrees with the observations seen here west of $55^{\circ} \mathrm{W}$. STMW formed east of $55^{\circ} \mathrm{W}$ in these years would either have been advected south of Bermuda by the subtropical gyre recirculation or to the east and never incorporated into the subtropical gyre, as was observed by Klein and Hogg (1996) in 1988. Talley and Raymer (1982) found newly formed STMW formation arriving at Bermuda again in 1975 or 1976, but the temperatures and densities of 
this STMW were anomalously warm and low, respectively. This agrees with the warm, thick dual-layer STMW layers observed here in these years. They found the STMW arriving at Bermuda in 1977 and 1978 had recently been renewed, and the temperatures at the potential vorticity minimum decreased in these years as well, in agreement with the results shown in Figures 3.4-3.5. :

Jenkins (1982) characterized the degree of renewal of the subtropical gyre using salinity on isopycnals, radioactive tracers, and oxygen data, all at the Panulirus hydrographic station near Bermuda. He argued that increased salinity on isopycnals is indicative of a high latent heat flux in winter and therefore ventilation. From oxygen, salinity, and radioactive tracer data, he also estimated the water mass renewal rate on isopycnals. From these data, he found

1. high salinities on isopycnals in 1969 and 1970 , indicating large-scale renewal of the subtropical gyre in these winters.

2. decreasing salinities and water mass renewal rates on isopycnals from 19691976, indicating less large-scale renewal in these years.

3. increasing salinities and water mass renewal rates on isopycnals from 19761980.

4. from radioactive tracer data alone, there was less ventilation of the subtropical gyre in 1974 and 1975 than 1977 and 1978.

Although it is difficult to compare Jenkins (1982)'s conclusions based on data at a single point to all three regions used here, there is good general agreement 
between his results and those found here, i.e., large-scale renewal in 1969 and 1970, no renewal in 1971-1976, and increased renewal in 1977 through 1980.

Cornillon et al. (1987) used satellite observations to construct sea surface temperature time series in $215 \mathrm{~km}$ x $215 \mathrm{~km}$ squares for January through May 1983. Based on their results, it appears convective mixing 'and renewal occurred in a limited region of the subtropical gyre in 1983, i.e., fast of $63^{\circ} \mathrm{W}$ and north of $32.5^{\circ} \mathrm{N}$. The characterizations of STMW renewal used here also found renewal in the eastern portion of the subtropical gyre with no renewal to the west in 1983 (Figures 3.4-3.6).

Finally, Klein and Hogg (1996) used current meter data near $55^{\circ} \mathrm{W}$, Panulirus hydrographic data, and XBT data to examine STMW formation in 1987, 1988, and 1989. They found warm $\left(>17.8^{\circ} \mathrm{C}\right) \mathrm{STMW}$ formed between 65 and $57^{\circ} \mathrm{W}$, and no formation west of $65^{\circ} \mathrm{W}$ or east of $57^{\circ} \mathrm{W}$, in 1987 ; and warm $\left(>18.1^{\circ} \mathrm{C}\right)$ STMW formed west of $63^{\circ} \mathrm{W}$ and cold STMW $\left(\sim 17.6^{\circ} \mathrm{C}\right)$ formed east of $59^{\circ} \mathrm{W}$ in 1988 . They concluded that the cold STMW east of $59^{\circ} \mathrm{W}$ in 1988 was advected east, out of the subtropical gyre, and was therefore not incorporated into the gyre. The formation of warm STMW layers from $65-57^{\circ} \mathrm{W}$ in 1987 agrees with Figures 3.43.5 which showed warm mixed layers penetrating to the top of the STMW layer in winter in the $65-55^{\circ} \mathrm{W}$ region and reduced temperature gradients in spring, i.e., formation of a warm, thick dual-layer STMW layer. Figure 3.4 shows the winter mixed layers do not penetrate to the top of the STMW layer west of 65 or east of $55^{\circ} \mathrm{W}$ in 1987 . Therefore, there was no STMW formation/renewal in these two regions, which agrees with Klein and Hogg (1996)'s results. These figures also show 
penetration of cold mixed layers into the STMW layer west of $65^{\circ} \mathrm{W}$ and east of $55^{\circ} \mathrm{W}$ in 1988 , and less penetration in the $65-55^{\circ} \mathrm{W}$ region, again in agreement with Klein and Hogg (1996).

\subsection{Comparison with North Atlantic Oscillation Index}

Dickson et al. (1996) present hydrographic and other proxy data to suggest the long-term convective activity in the Greenland, Labrador, and Sargasso Seas are coordinated by the North Atlantic Oscillation (NAO). The NAO is a large-scale alteration of the North Atlantic's subpolar low (i.e., the Icelandic Low) and subtropical high (the Azores High) pressure patterns. It is the dominant mode of atmospheric variability in the North Atlantic, particularly in winter (Cayan 1992b, Hurrell 1995). The index of NAO variability is typically taken as the pressure difference between Iceland and the Azores Islands, but Hurrell's (1995) index based on the Lisbon, Portugal to Stykkisholmur, Iceland pressure difference will be used here (Figure 3.11). A positive index indicates a stronger (lower) than normal Icelandic Low and a stronger (higher) than normal Azores high, while a negative index indicates a smaller pressure difference between the two pressure centers (Dickson et al. 1996). In the mid-latitudes of the western North Atlantic, winters with a negative NAO index are characterized by stronger than normal westerly winds, larger ocean-to-atmospheric heat fluxes, and negative sea surface temperature anomalies, while the opposite conditions exist for winters with a positive NAO index (Cayan 1992a, Cayan 1992b). 
Dickson et al. (1996) base their argument on the NAO controlling the convective activity in the Sargasso Sea primarily on the connection between the strong convection and STMW formation which occurred in the late 1960's, when the NAO was strongly negative (Figure 3.11), and the weak convective activity in the 1990's when the NAO was positive. Comparing Figure 3.11 to Figures 3.7 and 3.8, there is some agreement between the NAO Index and STMW renewal by deep penetration of cold mixed layers. Generally, winters in which the NAO was negative $(1969,1970,1977,1979,1985$, and 1987) are winters of stronger STMW renewal. Conversely, winters in which the NAO was positive (1972-1974, 1982-1984, 1986) are characterized by less STMW renewal. However, differences from these generalizations can be seen in the two records. For example, the NAO was negative in 1971, but there was no renewal of the STMW layer. Conversely, it was positive in 1981, when all three characterizations indicated renewal.

To quantitatively compare the NAO as a measure of STMW renewal with the three measures introduced earlier in this chapter, the correlation coefficients between the NAO Index in Figure 3.11 and the three characterizations of STMW renewal in Figures 3.7 and 3.8 were calculated (Table 3.2). Based on testing the hypothesis that STMW renewal and the NAO are not correlated $\left(\rho_{x y}=0\right)$ using Equation 3.1, the correlations between STMW renewal using the mixed layer characterizations and the NAO are statistically significant at the $95 \%$ confidence level west of $55^{\circ} \mathrm{W}$, while they are not significant at this confidence level east of $55^{\circ} \mathrm{W}$. The correlations between STMW renewal using the temperature gradient characterization and the NAO are not significant at the $95 \%$ confidence interval. The 
stronger correlations between the two winter mixed layer characterizations and the NAO Index are likely the result of the strong connection between the NAO and the winter sea surface temperature anomalies (Cayan 1992a). The formation of thick, dual-layer STMW layers in certain winters by some process other than convective mixing in winter (such as advection) may explain the weaker'correlations between the NAO Index and the temperature gradient characterization. The weaker correlations east of $55^{\circ} \mathrm{W}$ are consistent with the results from Sections 3.1-3.3 which indicated frequent renewal of the STMW layer in this region, i.e. the STMW layer is renewed almost every year east of $55^{\circ} \mathrm{W}$, regardless of the phase of the NAO.

Therefore, the correlation between the NAO and STMW renewal is strongest to the west, and for winters where the NAO is either strongly positive (weak or no STMW renewal) or strongly negative (STMW renewal). The NAO seems to control STMW renewal during extreme winters (positive or negative) when much of the STMW gyre will be affected. STMW formation does not seem to be as strongly controlled by the NAO in more moderate winters. It seems, then that the NAO controls STMW renewal on large scales when large areas occupying outcrop areas for many isopycnals will be affected (Jenkins 1982), but other processes seem to have more of an influence on STMW renewal on other scales when the NAO is not the dominant forcing mechanism.

\subsection{Mean Annual Timing of Renewal Events}

The spring mixed layer-fall STMW layer comparisons may also be used to determine what time of year on average the STMW layer is exposed to direct atmo- 


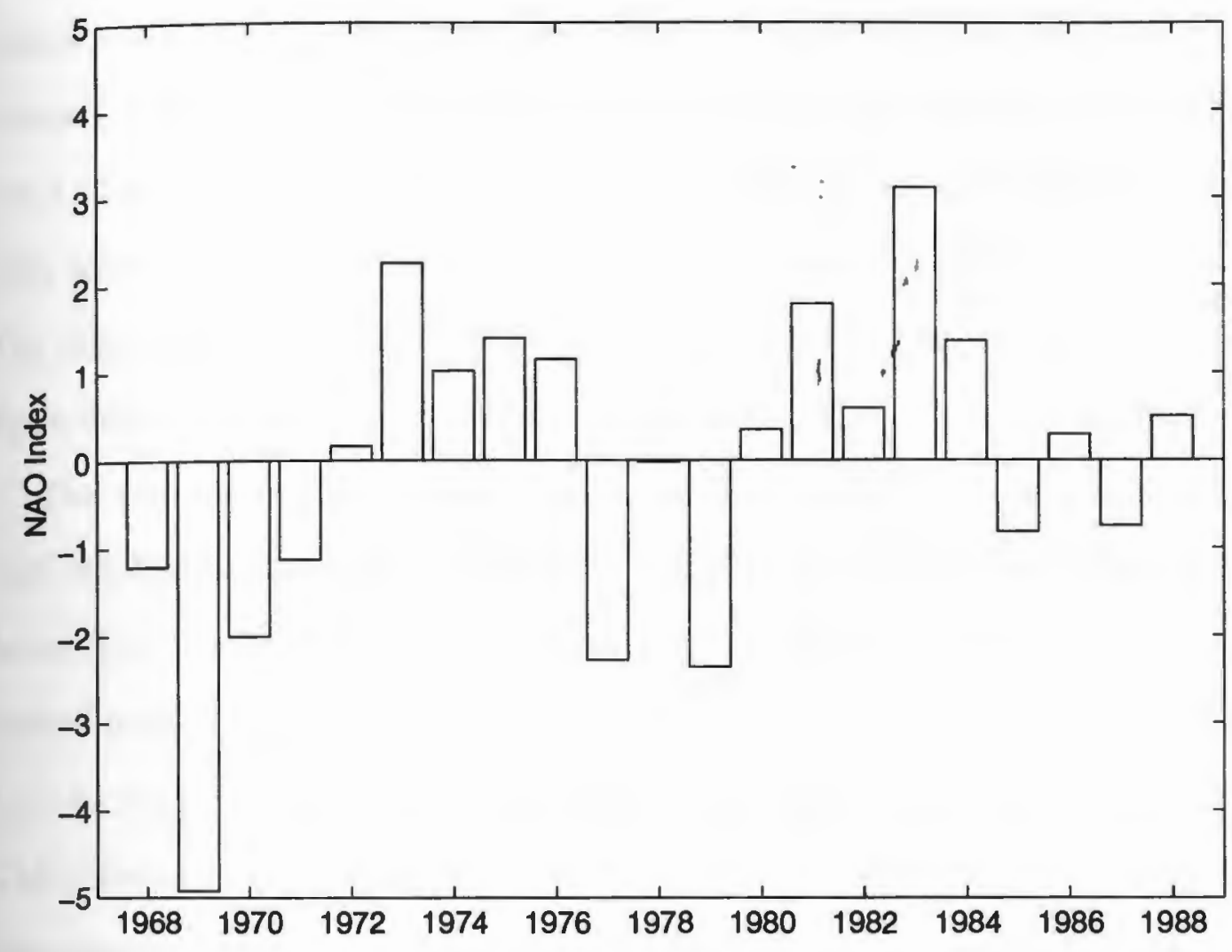

Figure 3.11: The North Atlantic Oscillation Index, 1968-1988, from Hurrell (1995). The NAO Index shown here is based on the difference in normalized DecemberMarch pressures between Lisbon, Portugal and Stykkisholmur, Iceland.

Table 3.2: Correlation Coefficients Between Characterizations of STMW Renewal and NAO Index

\begin{tabular}{lccc}
\hline & $75-65^{\circ} \mathrm{W}$ & $65-55^{\circ} \mathrm{W}$ & $55-40^{\circ} \mathrm{W}$ \\
\hline Iixed Layer Depths (Figure 3.7) & -0.42 & -0.39 & -0.08 \\
Mixed Layer Temperatures (Figure 3.8) & +0.60 & +0.63 & +0.18 \\
gemperature Gradient (Figures 3.7 and 3.8) & -0.27 & -0.20 & -0.09 \\
\hline
\end{tabular}


spheric cooling. Figure 3.12 shows the percentage of clusters/individual profiles in January through May with mixed layers which were deeper than the NovemberJanuary weighted mean STMW top for each region and every ten days, while Figure 3.13 shows the percentage in January through May with mixed layers which were colder than the November-January weighted mean STMW top temperature. The differences in the shape of the histograms in the twor figures are most likely again due to the presence of deep, but warm mixed layers in certain winters.

The distributions for all three regions in both figures are relatively uniform, with the distribution in the westernmost region (west of $65^{\circ} \mathrm{W}$ ) tending to be less broad (i.e., over fewer days) than in the other two regions. Since there is not a well defined peak in any of these distributions, they suggest that renewal of the STMW layer by convective mixing can occur over a broad range of days in a given winter. This observation is in agreement with Cornillon et al. (1987)'s satellite sea surface temperature time series in the North Atlantic subtropical gyre in the winter of 1983. They found the sea surface temperatures in a region near $35^{\circ} \mathrm{N}, 59^{\circ} \mathrm{W}$ were relatively constant at a temperature just below $18^{\circ} \mathrm{C}$ from mid-February to midApril. Therefore, this region would have been a location of convective mixing during this rather extensive time period.

\subsection{Conclusions}

Three different characterizations were used to assess the degree of renewal of the STMW layer during the 1968-1988 winters. Two characterizations are based on comparing the winter mixed layer properties to the STMW layer properties in the 
75 to $65^{\circ} \mathrm{W}$
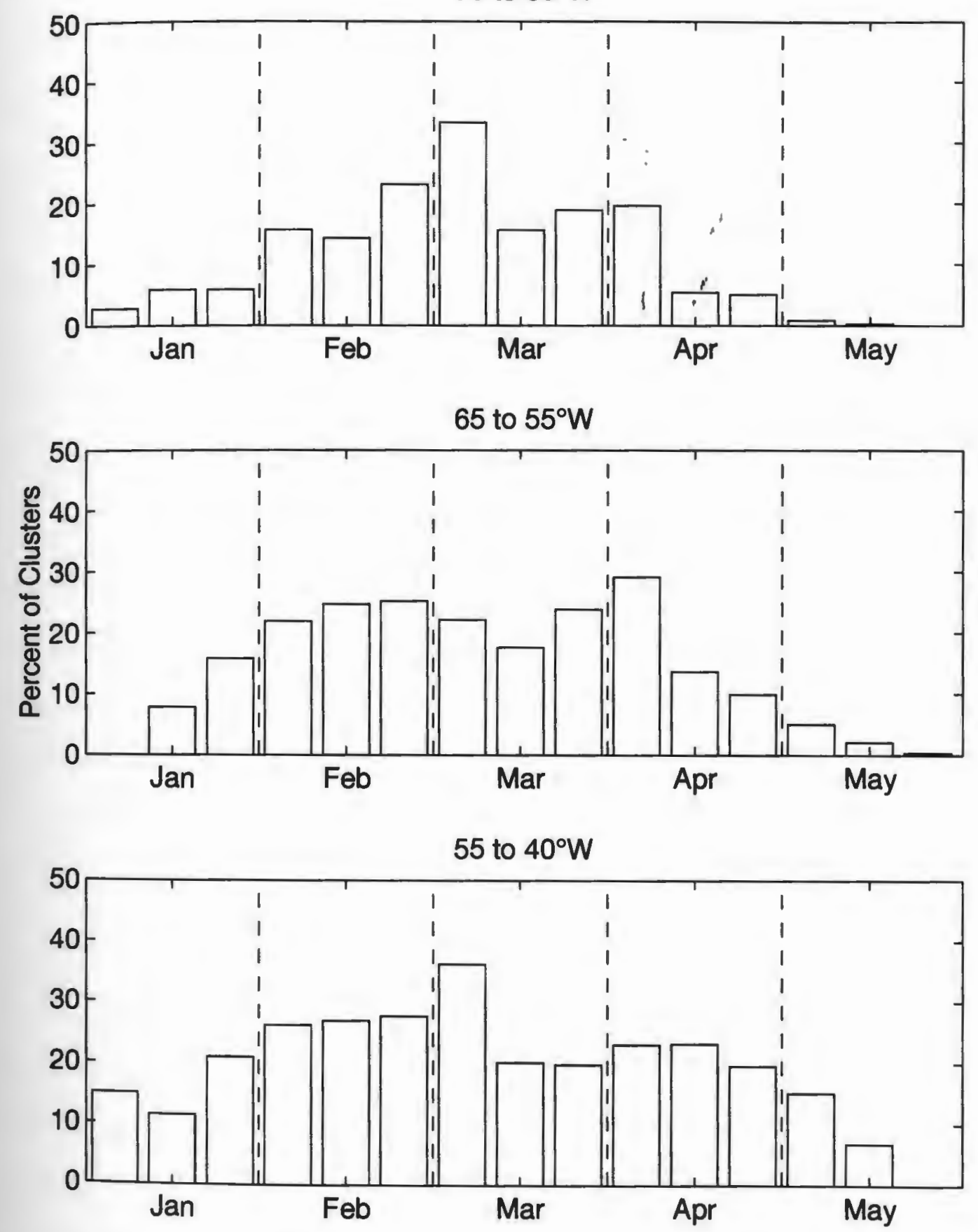

Figure 3.12: Percent of Clusters with Mixed Layers Deeper Than STMW Layer Top Every 10 Days January-May, 1968-1988. 
75 to $65^{\circ} \mathrm{W}$

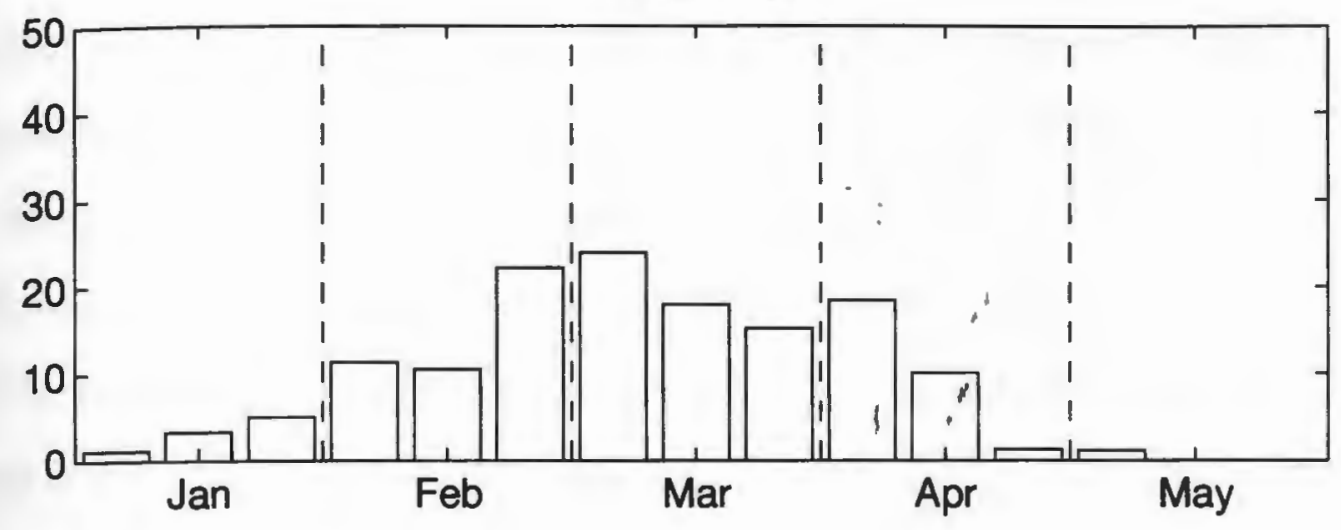

65 to $55^{\circ} \mathrm{W}$

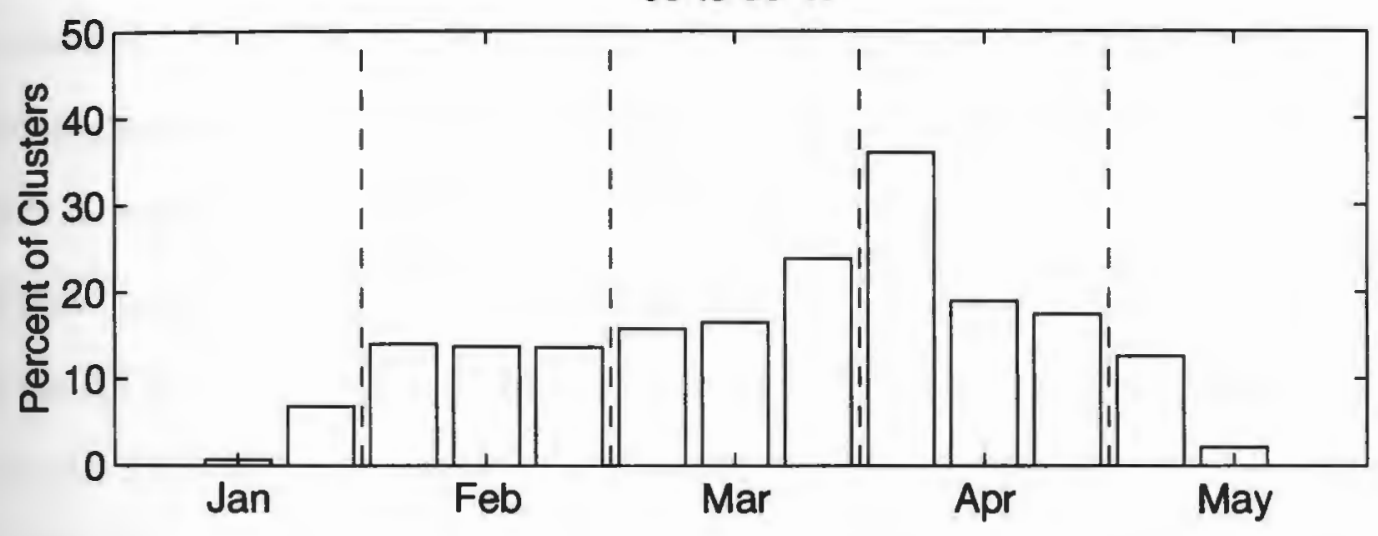

55 to $40^{\circ} \mathrm{W}$

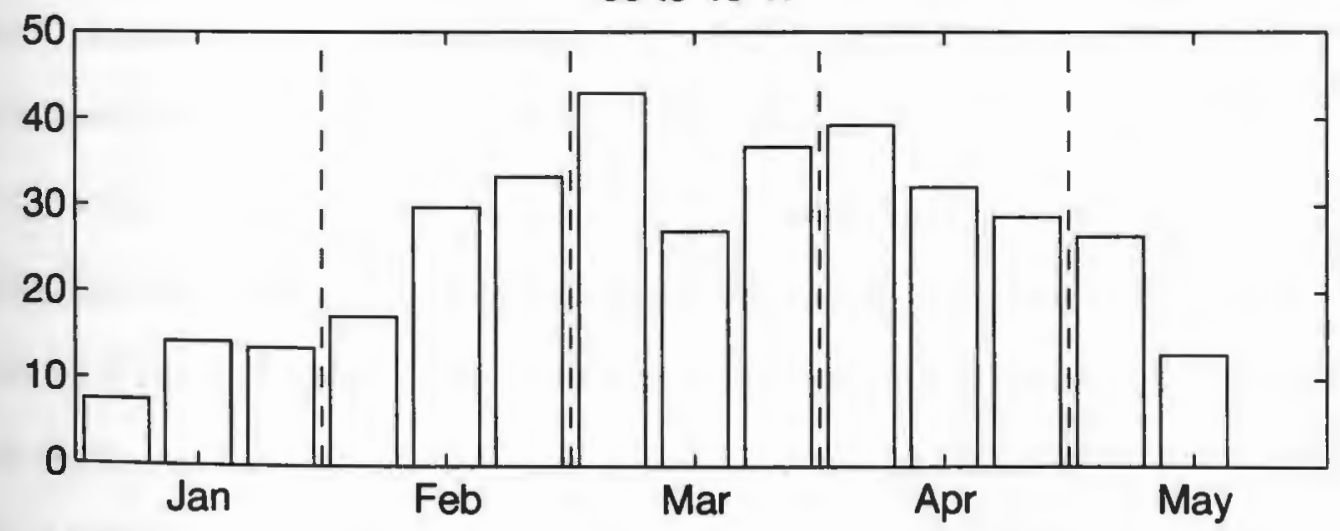

Figure 3.13: Percent of Clusters with Mixed Layers Colder Than STMW Layer Top Every 10 Days January-May, 1968-1988. 
previous fall, while the third characterization involves comparing the temperature gradient through the STMW layer in the fall before convective mixing to the temperature gradient in the spring after convective mixing. The characterizations are statistically correlated and in good agreement, with the exceptions of 1975 , 1976, and 1979 and the years of poor sampling in February, through April.

The mixed layer characterizations are dependent on sampling the deep, cold mixed layers when and where the convective mixing is taking place. The temperature gradient characterization has the advantage of being less time sensitive, but it is susceptible to advection of the profiles from the actual location of the convective mixing, making it difficult to determine whether STMW was locally renewed or not. In addition, the temperature gradient criterion is affected by the formation of dual-layer STMW layers during winters of partial renewal, indicating renewal of the STMW layer when there was little penetration of the winter mixed layers into the STMW layer.

The characterizations are in good agreement with previous studies of STMW using a variety of characterizations. These characterizations based on temperature alone, however, take advantage of the large number of XBT profiles to describe the variations in the renewal of the STMW layer in space as well as time. The results found here do show significant spatial as well as temporal variations in the degree of STMW renewal. The mixed layer seems to penetrate the STMW layer more often and typically for a longer period each year east of $55^{\circ} \mathrm{W}$ than it does west of $55^{\circ} \mathrm{W}$.

Since it appears STMW can be formed without renewing the pre-existing 
STMW layer, a distinction should be made between STMW formation and renewal of the STMW layer. For example, Talley and Raymer (1982)'s potential vorticity characterization indicated newly formed STMW arrived at Bermuda in 1975 , but it was a warmer and less dense variety of STMW. Based on these results, it appears that this newly formed STMW was the, remnant of the warm mixed layers which penetrated to the top of the STMW layer, but did not renew the pre-existing STMW layer. Here, STMW renewal events will be identified by the penetration of cold mixed layers more than $50 \mathrm{~m}$ into the STMW layer, and a decrease in the mean temperature gradient from fall to spring. Table 3.3 identifies the years meeting these criteria as years of STMW renewal, those years where these criteria were not satisfied as no STMW renewal, and those years where the characterizations were not consistent. 
Table 3.3: 1969-1988 STMW Renewal Events. $R=$ Renewal Event, NR = No Renewal, ? = Characterizations Do Not Agree. 1 '

\begin{tabular}{cccc}
\hline year & $75-65^{\circ} \mathrm{W}$ & $65-55^{\circ} \mathrm{W}$ & $55-40^{\circ} \mathrm{W}$ \\
\hline 1969 & $\mathrm{R}$ & $\mathrm{R}$ & $\mathrm{R}$ \\
1970 & $\mathrm{R}$ & $\mathrm{R}$ & $\mathrm{R}$ \\
1971 & $\mathrm{NR}$ & $\mathrm{NR}$ & $\mathrm{NR}$ \\
1972 & $\mathrm{NR}$ & $\mathrm{NR}$ & $\mathrm{R}$ \\
1973 & $\mathrm{NR}$ & $\mathrm{NR}$ & $\mathrm{R}$ \\
1974 & $\mathrm{NR}$ & $\mathrm{NR}$ & $\mathrm{R}$ \\
1975 & $?$ & $?$ & $\mathrm{R}$ \\
1976 & $?$ & $\mathrm{R}$ & $?$ \\
1977 & $\mathrm{R}$ & $\mathrm{R}$ & $\mathrm{R}$ \\
1978 & $?$ & $\mathrm{R}$ & $\mathrm{R}$ \\
1979 & $?$ & $\mathrm{R}$ & $?$ \\
1980 & $\mathrm{R}$ & $\mathrm{R}$ & $?$ \\
1981 & $\mathrm{R}$ & $\mathrm{R}$ & $\mathrm{R}$ \\
1982 & $\mathrm{NR}$ & $?$ & $\mathrm{R}$ \\
1983 & $\mathrm{NR}$ & $\mathrm{NR}$ & $\mathrm{R}$ \\
1984 & $\mathrm{NR}$ & $?$ & $\mathrm{R}$ \\
1985 & $\mathrm{R}$ & $\mathrm{R}$ & $\mathrm{R}$ \\
1986 & $\mathrm{NR}$ & $\mathrm{NR}$ & $?$ \\
1987 & $\mathrm{NR}$ & $?$ & $?$ \\
1988 & $\mathrm{R}$ & $?$ & $\mathrm{R}$ \\
\hline
\end{tabular}




\section{Chapter 4}

\section{Changes in the STMW: Temperature Gradient}

Perhaps the most striking features of Figure 3.6 are the annual and interannual changes in the temperature gradient through the STMW layer. In the years when the STMW layer was renewed $(1969,1970,1977,1978,1981$, and 1985), the temperature gradient increased at a relatively constant rate through the rest of the year in each of the three regions. Looking at the change in the temperature gradient from 1970 through 1974 in the two westernmost regions where there was no STMW renewal, the temperature gradient continued to increase from one year to the next, but at a smaller rate than during the years of STMW renewal. The increase in the temperature gradient with time following renewal of the STMW layer will be defined here as the "erosion" of the thermostad, and the "restratification rate" as the rate at which the temperature gradient increases.

In this chapter, the restratification rate through the year and from one year to the next is examined. The annual restratification rate is first estimated from the changes in each year's three 3-monthly mean temperature gradients in Figure 3.6. 
Next, the processes which can increase the STMW layer's temperature gradient following each winter are discussed. Finally, the interannual restratification rate is estimated by examining the changes in the temperature gradient from the time at which the STMW layer was last renewed.

\subsection{Annual Changes}

\subsubsection{Temperature Gradient}

To examine the changes in the temperature gradient through the year, the annual 3monthly mean temperature gradients in Figure 3.6 were averaged to form one mean for each 3-month period (Figure 4.1). In this averaging, each year's 3-monthly mean temperature gradient was weighted by its standard deviation, and the mean was again found using Equation 2.6. The errorbars on these means (Figure 4.1) are the standard error of the mean, found using Equation 2.7. Finding the means in this way ensures that each year has nearly the same weight and prevents the means from being biased towards those years with large numbers of profiles (Figure 2.6).

The 3-monthly mean temperature gradients for years when the STMW layer was renewed by convective mixing were determined separately from years when the STMW layer experienced no convective mixing. The years of STMW renewal were chosen as 1969, 1970,1977, 1980, 1981, and 1985. The years with no STMW renewal were chosen as $1971,1972,1973,1974,1982,1983$, and 1986 . These were the years when the two criteria discussed in Sections 3.1 and 3.2 were consistent in their assessment of either renewal or no renewal in the two westernmost regions (west of $55^{\circ} \mathrm{W}$ ). Since the two criteria indicate STMW is renewed almost every 
year east of $55^{\circ} \mathrm{W}$, the easternmost region was not considered in classifying a year as one of STMW renewal or no renewal. The solid line in Figure 4.1 represents the mean change in the temperature gradient from spring to early winter during the renewal years, and the dashed line represents the change during non-renewal years.

For the two westernmost regions, both Figure 3.6 and $A .1$ suggest the restratification rate is larger (i.e., the temperature gradient is increasing faster) during renewal years than non-renewal years. Because STMW is renewed almost every winter in the easternmost region, the restratification rate is similar for both cases.

In order to quantify the restratification rate and the differences in this rate in renewal and non-renewal years, the slope of the least-squares best fit line to each year's three 3-monthly mean temperature gradients (Figure 3.6) was found. Table 4.1 lists the mean and standard errors of these annual slopes for all years, renewal years, and (for the two westernmost regions) non-renewal years for each region. From this table, two trends stand out. First, the annual restratification rates increase from west to east. Second, the rates are statistically larger for renewal years than non-renewal years.

\subsubsection{Thickness and Temperature Difference}

In order to examine some of the processes responsible for the increase in the STMW layer's temperature gradient through the year, the changes in the STMW layer's top and bottom temperature and depth, and their differences, were examined. 3monthly averages of depth and temperature of the STMW layer top and bottom, 
75 to $65^{\circ} \mathrm{W}$
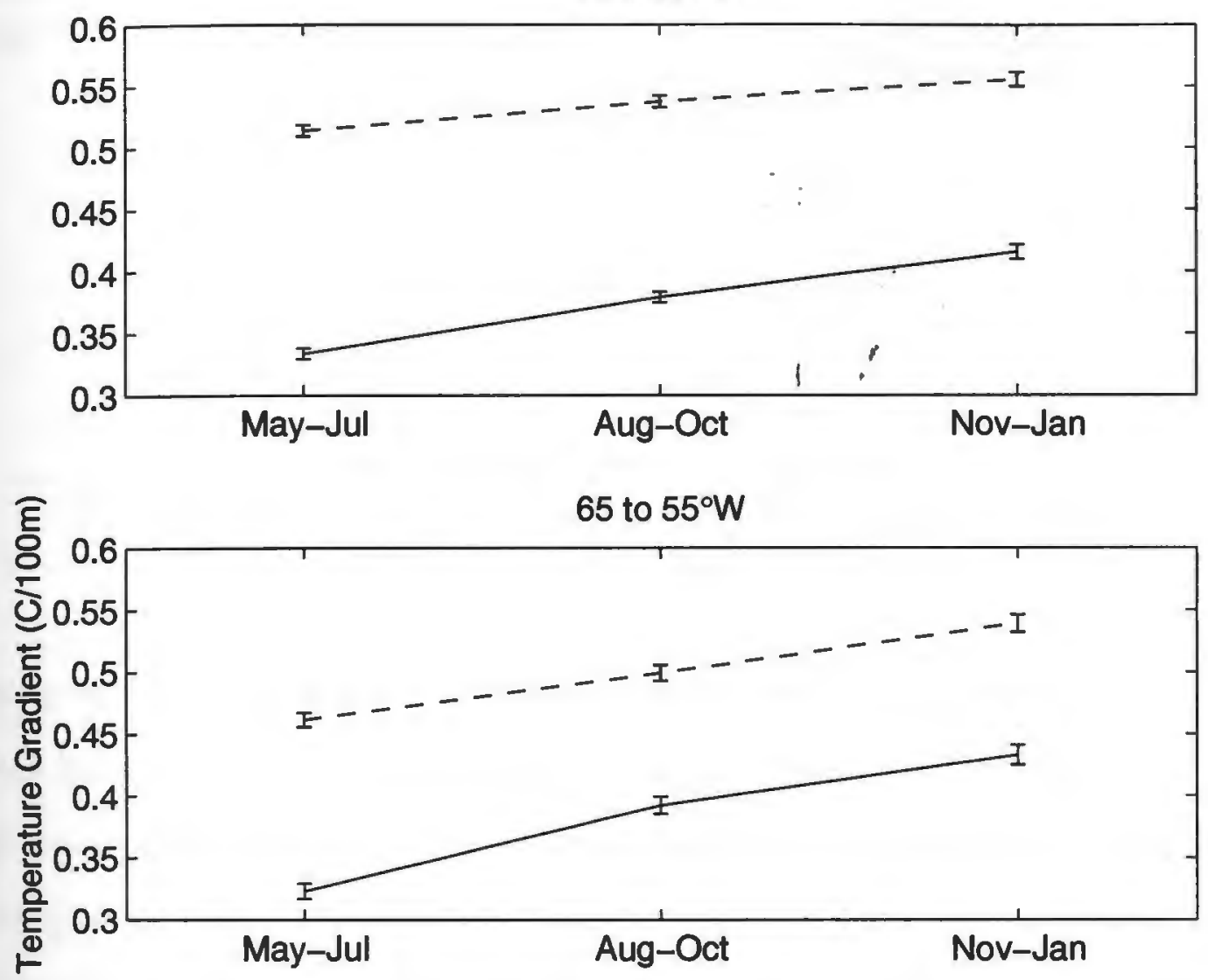

55 to $40^{\circ} \mathrm{W}$

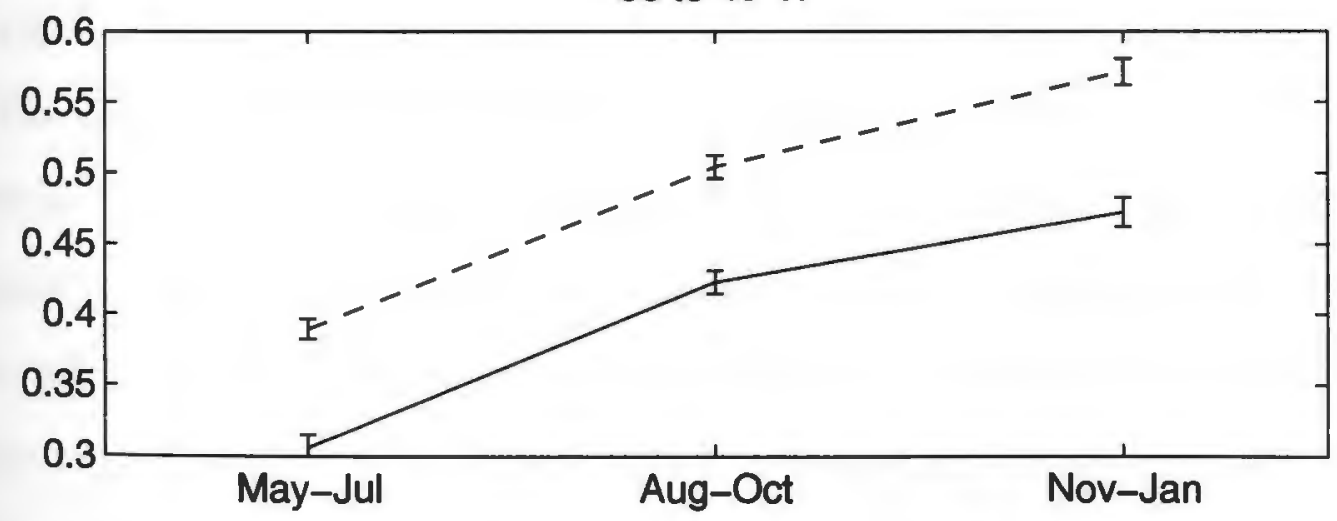

Figure 4.1: Annual Changes in 3-Monthly (May-July, August-Oct, and NovemberJanuary) Mean STMW Temperature Gradient. Solid Line = Following Years of STMW Renewal. Dashed Line = Years of No STMW Renewal. See text for details. 
Table 4.1: Annual Mean Changes in Temperature Gradient from Mean Slopes of Best-Fit Lines to Figure 3.6

\begin{tabular}{ccc}
\hline & Mean & Standard Error of the Mean $(\sigma / \sqrt{n})$ \\
\hline & All Years $\left({ }^{\circ} \mathrm{C} / 100 \mathrm{~m} /\right.$ day $)$ \\
$75-65^{\circ} \mathrm{W}$ & $3.9 \times 10^{-4}$ & $0.5 \times 10^{-4}$ \\
$65-55^{\circ} \mathrm{W}$ & $5.5 \times 10^{-4}$ & $0.5 \times 10^{-4}$ \\
$55-40^{\circ} \mathrm{W}$ & $10.3 \times 10^{-4}$ & $0.5 \times 10^{-4}$ \\
& Renewal Years $\left({ }^{\circ} \mathrm{C} / 100 \mathrm{~m} /\right.$ day $) \cdot$ \\
$75-65^{\circ} \mathrm{W}$ & $4.7 \times 10^{-4}$ & $0.5 \times 10^{-4}$ \\
$65-55^{\circ} \mathrm{W}$ & $6.0 \times 10^{-4}$ & $0.8 \times 10^{-4}{ }^{\prime}$ \\
$55-40^{\circ} \mathrm{W}$ & $10.9 \times 10^{-4}$ & $0.6 \times 10^{-4}$ \\
& Non-Renewal Years $\left({ }^{\circ} \mathrm{C} / 100 \mathrm{~m} /\right.$ day $)$ \\
$75-65^{\circ} \mathrm{W}$ & $2.4 \times 10^{-4}$ & $0.5 \times 10^{-4}$ \\
$65-55^{\circ} \mathrm{W}$ & $4.5 \times 10^{-4}$ & $0.5 \times 10^{-4}$ \\
\hline
\end{tabular}

along with the STMW layer thickness and temperature change through the layer, were calculated by again first finding the average of each year, then the mean of all years using Equation 2.6. The solid line in Figures 4.2-4.5 represent the mean change from spring to early winter during the renewal years, and the dashed line represents the change during non-renewal years. The errorbars in Figures 4.2-4.5 are the standard error of the means found using Equation 2.7.

The depths of the STMW layer top and bottom in renewal and non-renewal years are within $50 \mathrm{~m}$ of each other (Figure 4.2). Also, their annual rate of change through the year is similar. The temperatures at the top and bottom of the STMW layer exhibit a different behavior, however (Figure 4.3). While the temperatures at the top of the STMW layer are similar in renewal and non-renewal years, the temperatures at the bottom of the STMW layer are considerably warmer in the renewal years than the non-renewal years, particularly west of $65^{\circ} \mathrm{W}$. This indicates 
that STMW formation is actually a warming of the deeper waters, as has been discussed by Marsh and New (1996). Also, the temperatures at the top and bottom of the STMW layer east of $55^{\circ} \mathrm{W}$ are colder than those to the west. This east-west gradient in the temperature of the STMW layer (colder to the east, warmer to the west) has also been reported by McCartney et al. (1980), Talley and Raymer (1982), Ebbesmeyer and Lindstrom (1986), and Hall and Fofonoff (1993).

West of $55^{\circ} \mathrm{W}$, the temperature at the top of the STMW layer (Figure 4.3) in May-July of non-renewal years is warmer (and yet deeper) than renewal years. The temperature at the top of the STMW layer decreases from May through January of the non-renewal years, while it remains relatively constant through the renewal years., resulting in the temperature at the top of the STMW layer colder in August-October and November-January of non-renewal than renewal years. The errorbars indicate these differences, although small, are significant. These trends may be explained in part by the larger temperature gradient through the STMW layer in non-renewal years versus a more vertically homogeneous STMW layer in renewal years. As the top of the STMW layer deepens due to the deepening seasonal thermocline, the temperature will decrease in non-renewal years, while it will remain relatively constant in renewal years.

With one exception, the changes in thickness in the renewal years are similar to those in the non-renewal years (Figure 4.4). Except for the renewal years in the $65-55^{\circ} \mathrm{W}$ region, the thickness decreases by $\sim 20-30 \mathrm{~m}$ from May-July to AugustOctober, then by 10-15 m from August-October to November-January. These later changes in thickness are similar to those found by Suga et al (1989) in the 

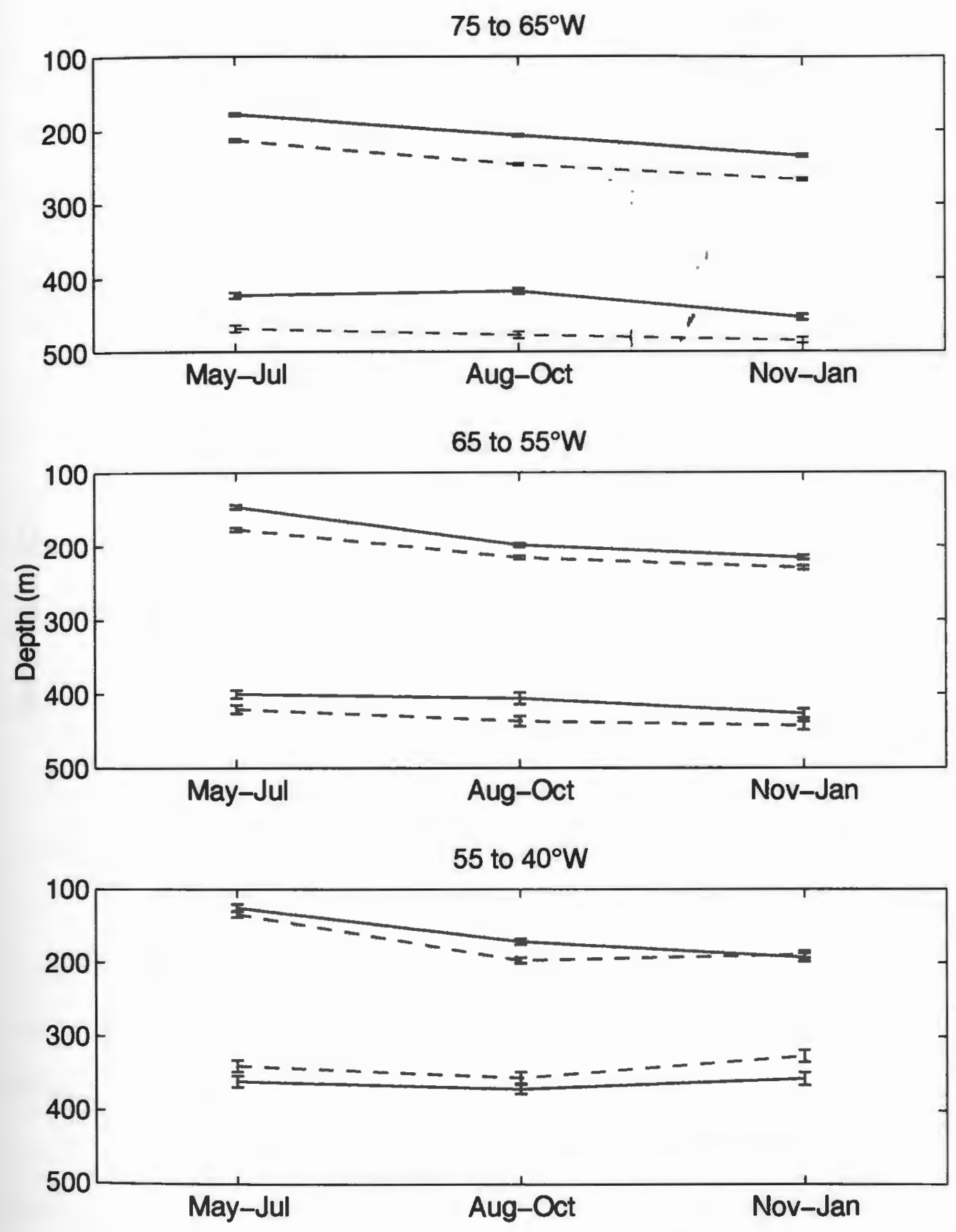

Figure 4.2: Annual Changes in 3-Monthly (May-July, August-Oct, and NovemberJanuary) Mean Depth of Top and Bottom of STMW. Solid Line = Following Years of STMW Renewal. Dashed Line = Years of No STMW Renewal. 

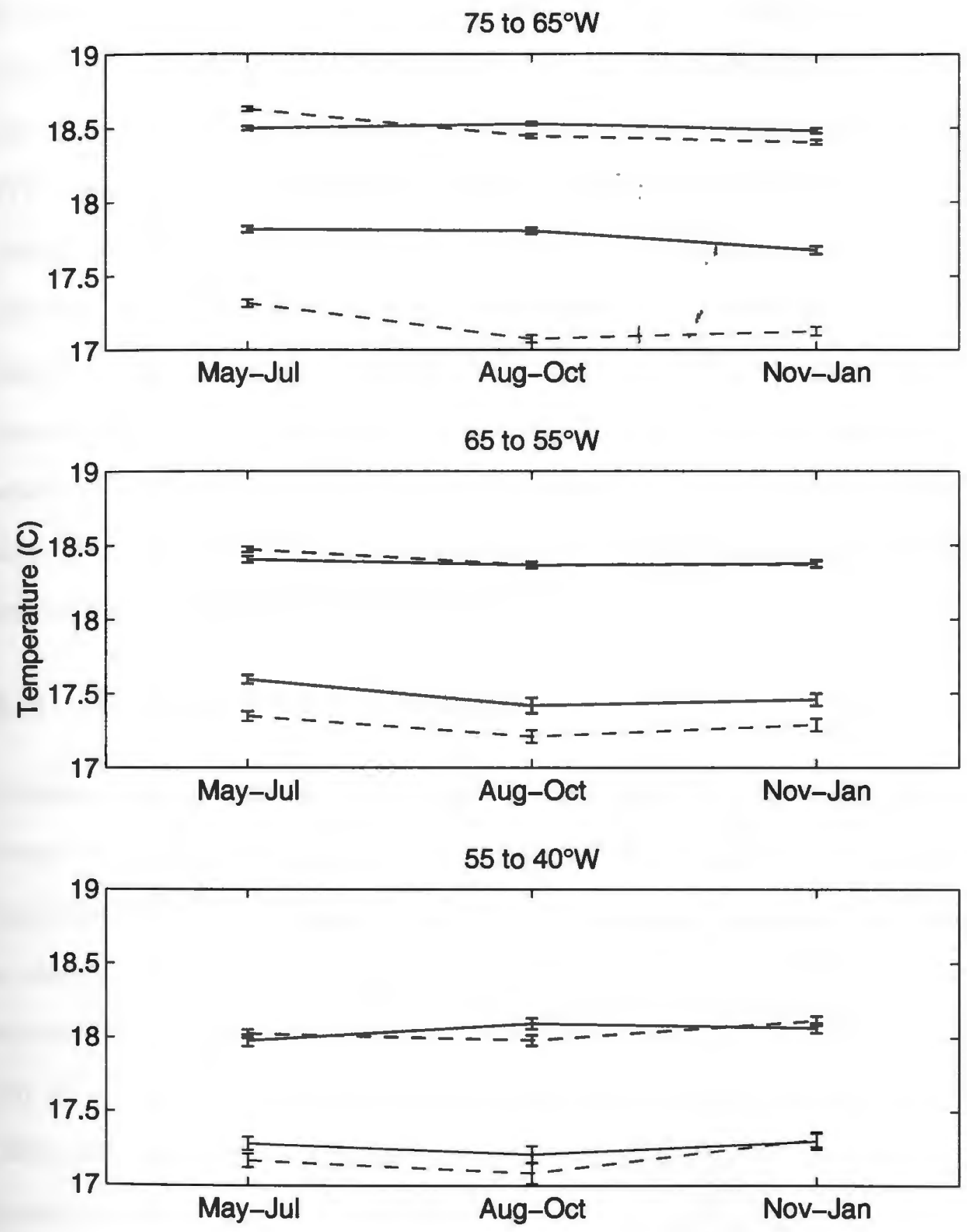

Figure 4.3: Annual Changes in 3-Monthly (May-July, August-Oct, and NovemberJanuary) Mean Temperature at Top and Bottom of STMW. Solid Line = Following Years of STMW Renewal. Dashed Line = Years of No STMW Renewal. 
North Pacific. They found the North Pacific STMW layer thinned on average by $15 \mathrm{~m}$ from late summer (six months after formation) to late winter (12 months after formation). Figure 4.5 indicates that the temperature difference through the STMW layer is increasing slightly in renewal years, while (west of $65^{\circ} \mathrm{W}$ ) it is decreasing in non-renewal years. Therefore, the annual increase in the temperature difference through the layer following renewal years acts ip concert with the thinning of the STMW layer to increase the temperature gradient, whereas the annual decrease in the temperature difference through the layer in the non-renewal years acts to decrease the temperature gradient, opposite to the thinning of the STMW layer. Thus, the annual temperature gradient restratification rate west of $55^{\circ} \mathrm{W}$ is larger for the renewal years than non-renewal years.

\subsection{Interannual Changes}

Interannual changes in the STMW layer are addressed via scatter plots of time versus the temperature gradient (Figure 4.6), and depth and temperature of the top of the STMW layer (Figures 4.7 and 4.8). Time along the $\mathrm{x}$-axis of these figures is relative to February 1st of the most recent year in which the STMW layer was renewed. The renewal years were again defined as 1969, 1970, 1977, 1980, 1981, and 1985, while the subsequent non-renewal years were 1971, 1972, 1973, 1974, 1982, 1983, and 1986. So, clusters/profiles from 1971, 1972, 1973, and 1974 are all plotted relative to February 1st of 1970.

In Figure 4.6, the wide range of temperature gradients in February-April of the renewal years (days 0-90) is indicative of the three STMW configurations dis- 
75 to $65^{\circ} \mathrm{W}$

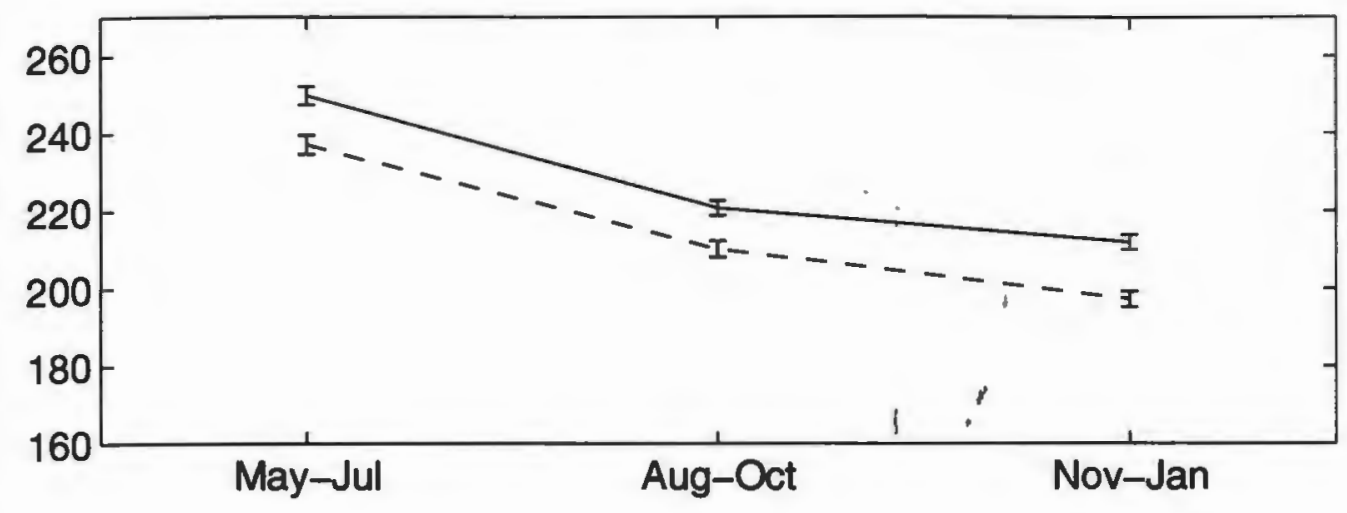

65 to $55^{\circ} \mathrm{W}$

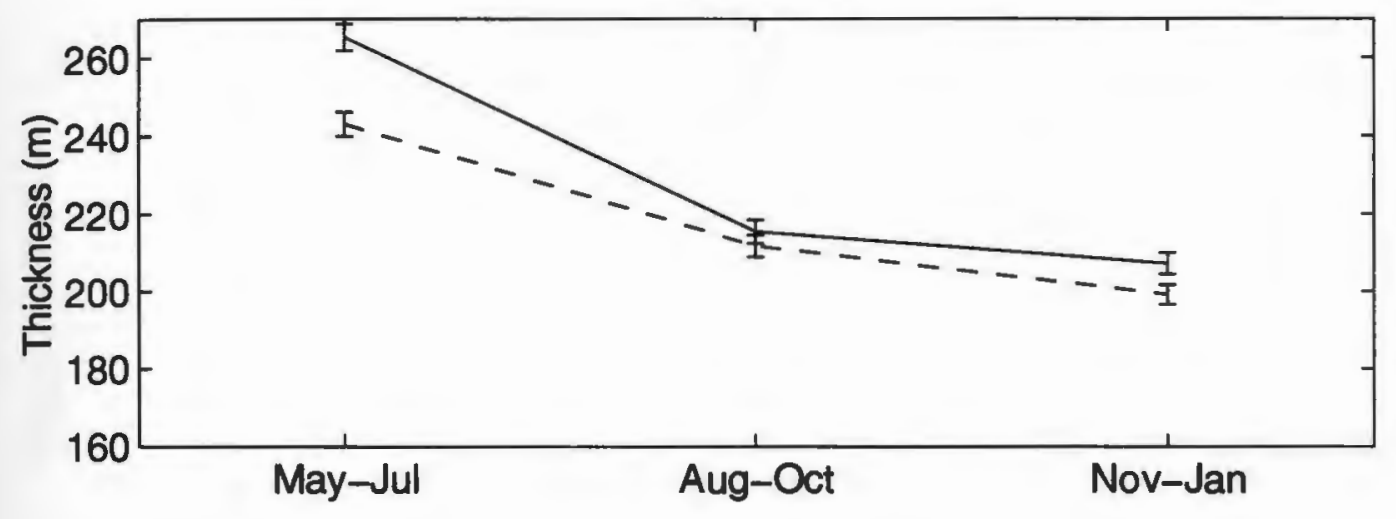

55 to $40^{\circ} \mathrm{W}$

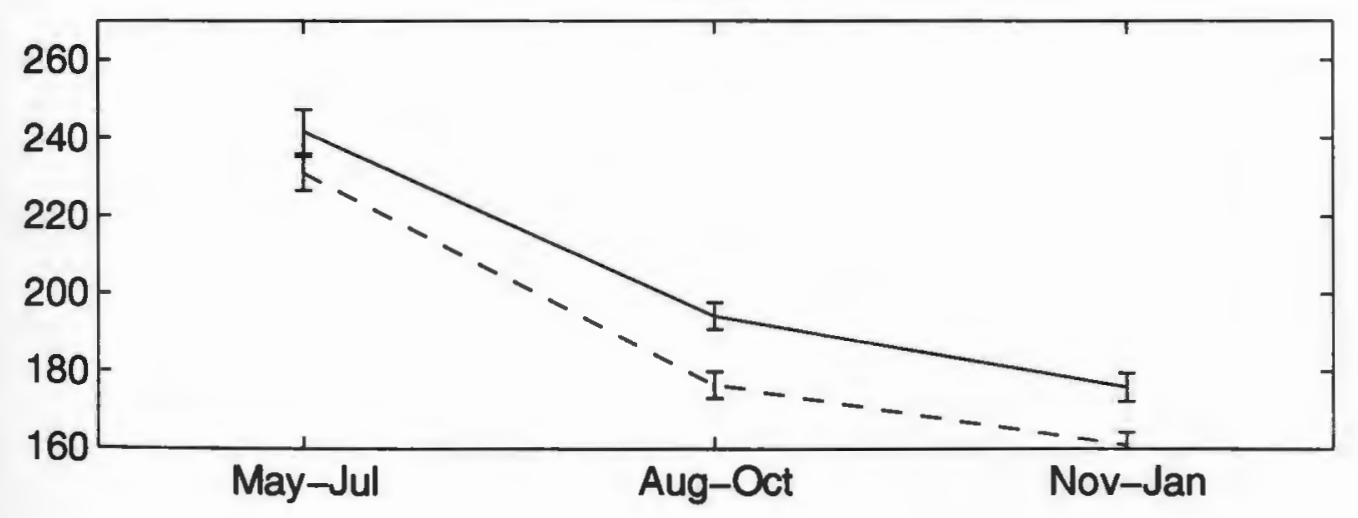

Figure 4.4: Annual Changes in 3-Monthly (May-July, August-Oct, and NovemberJanuary) Mean Thickness of STMW. Solid Line = Following Years of STMW Renewal. Dashed Line = Years of No STMW Renewal. 
75 to $65^{\circ} \mathrm{W}$
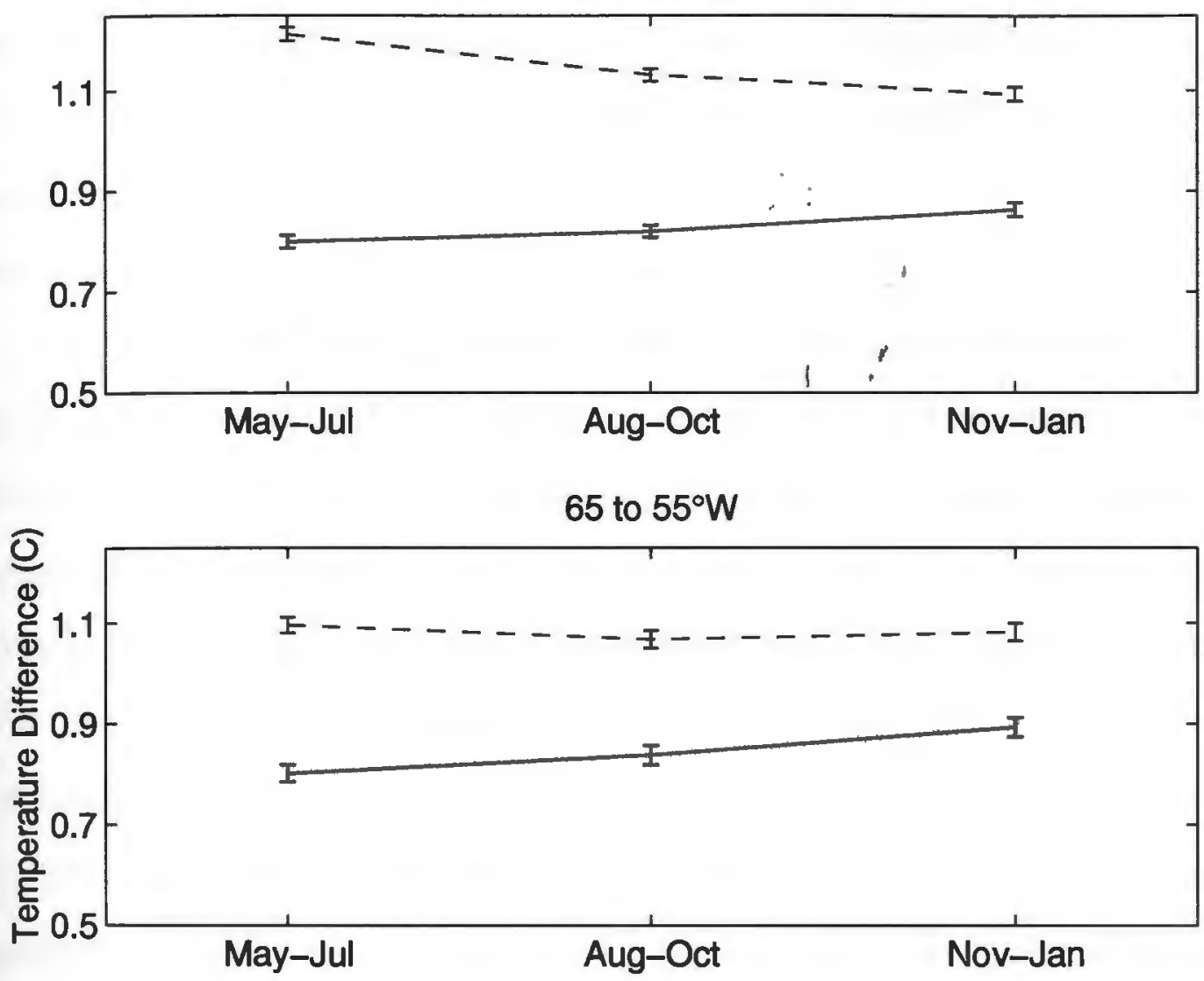

55 to $40^{\circ} \mathrm{W}$

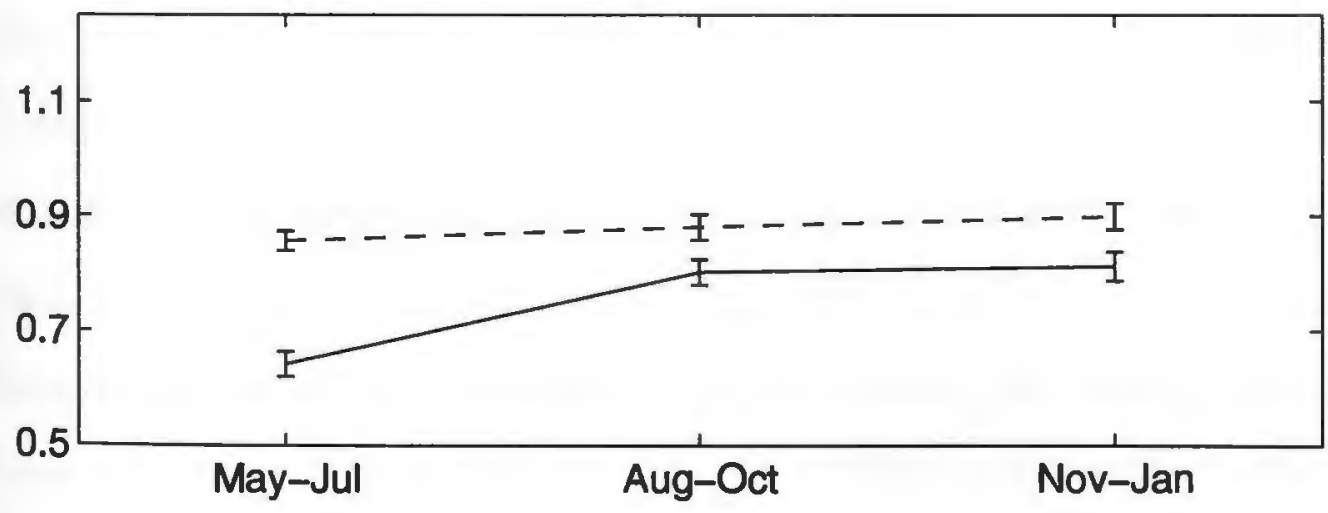

Figure 4.5: Annual Changes in 3-Monthly (May-July, August-Oct, and NovemberJanuary) Mean Temperature Difference through STMW. Solid Line $=$ Following Years of STMW Renewal. Dashed Line = Years of No STMW Renewal. 
cussed in Section 2.3. The small (e.g. $<0.3^{\circ} \mathrm{C}$ per $100 \mathrm{~m}$ ) temperature gradients are of newly formed STMW layers, while the larger temperature gradients (e.g. $>0.6^{\circ} \mathrm{C}$ per $100 \mathrm{~m}$ ) are from older STMW layers that are under the deepening winter mixed layer. In the two westernmost regions, the increase in the temperature gradient with time since the STMW layer was last renewed is evident.

Although the temperature gradient (Figure 4.6) shows a,steady increase in time for a number of years past the most recent renewal of the STMW layer, the depth of the top of the STMW layer (Figure 4.7) shows an annual shoaling to the sea surface in February-April, including the non-renewal years. This would imply the STMW layer was exposed to direct atmospheric cooling and convective mixing. However, Figure 4.8 shows several profiles with warm temperatures $\left(>19^{\circ} \mathrm{C}\right)$ at the top of the STMW layer in spring, particularly west of $65^{\circ} \mathrm{W}$ and in the fourth and fifth years (days $>1100$ ) after renewal. This, taken with the relatively few profiles with small $\left(<0.4{ }^{\circ} \mathrm{C}\right.$ per $\left.100 \mathrm{~m}\right)$ temperature gradients in these springs, suggests that multiple-layer STMW layers may have formed during these nonrenewal years, particularly west of $65^{\circ} \mathrm{W}$. These dual-layer STMW layers consist of a shallow, warm STMW layer which was locally formed in that winter on top of an older STMW layer which was formed in a previous winter, as discussed in Sections 3.3 and 4.1. Again, the method used here (Section 2.3) has difficulty distinguishing between these two layers. Therefore, both layers would be grouped into one layer, resulting in the shoaling of the top of the STMW layer in Figure 4.7, the increase in profiles with warm temperatures at their top in Figure 4.8, and the lack of corresponding profiles with small temperature gradients in Figure 4.6 (the 
temperature gradients plotted in Figure 4.6 were the slope of the best-fit line through both layers). This trend is less evident in the $65-55^{\circ} \mathrm{W}$ region than west of $65^{\circ} \mathrm{W}$, probably due to a complex mixture of locally formed deep, locally formed shallow, and advected STMW layers.

A second feature of Figure 4.7 which supports the concept of no renewal of the STMW layer and the presence of dual-layer STMW layers in the non-renewal years is the relatively smaller number of deep $(>300 \mathrm{~m}$ ) STMW layer top depths in February-April of the non-renewal years ( days $370,730,1100,1460$ ) compared with that of the renewal years (days < 90). Profiles with STMW tops deeper than $300 \mathrm{~m}$ in the winters of renewal years correspond to deep mixed layers and a STMW layer remnant underneath, thus a deep STMW top depth. (In the renewal years, there will also be large numbers of profiles where the STMW layer has completely penetrated to the bottom of the pre-existing STMW layer, and the top of this newly formed STMW layer will be at or near the surface.) In the nonrenewal years, there are fewer profiles with STMW layer tops deeper than $300 \mathrm{~m}$ in February-April, because there are reduced deep mixed layers in these years. Rather there are shallow, locally formed STMW layers in these winters.

Finally, Figures $4.6,4.7$ and 4.8 again indicate that the STMW layer in the region east of $55^{\circ} \mathrm{W}$ is renewed more often than west of $55^{\circ} \mathrm{W}$. East of $55^{\circ} \mathrm{W}$, the annual resetting of the temperature gradient to smaller values is seen in subsequent years ( days $370,730,1100,1460)$. The top of the STMW layer again shoals each spring ( days $370,730,1100,1460$ ), but there are relatively fewer profiles with warm temperatures $\left(>19^{\circ} \mathrm{C}\right)$ at the top of the STMW layer in this region each 
spring than there are in the other two regions.

In order to quantify the STMW layer temperature gradient's interannual restratification rate, the median temperature gradient in Figure 4.6, STMW layer thickness, and temperature difference through the STMW layer were found every 90 days for the two regions west of $55^{\circ} \mathrm{W}$. These 90 day running medians are shown in Figures 4.9-4.10. The interannual rate following the temperature gradient minimum in the spring (May-July) of the renewal years appears to be approximately linear (Figure 4.9).

However, an annual thickening of the STMW layer in spring and thinning to a minimum each November-January is apparent in Figure 4.10. Figure 4.11 also shows an increase in the temperature difference through the STMW layer each spring (May-July) and a decrease each fall. Again, the formation of warm, shallow STMW layers on top of the pre-existing, deeper STMW layers during the non-renewal years, followed by the re-entrainment of these warm, shallow layers into the mixed layer during the following months explain these annual changes in thickness and temperature difference.

To separate these seasonal changes of the STMW layer from the interannual changes, a least-squares line was fit to the November-January median temperature gradient, and STMW layer thickness and temperature difference values. The seasonal pynocline would be at its maximum depth, and the reversal of the buoyancy forcing would not yet have completely removed the seasonal pycnocline for the November-January period. Table 4.2 lists the interannual rates of change for the temperature gradient, thickness, and temperature difference, as determined from 

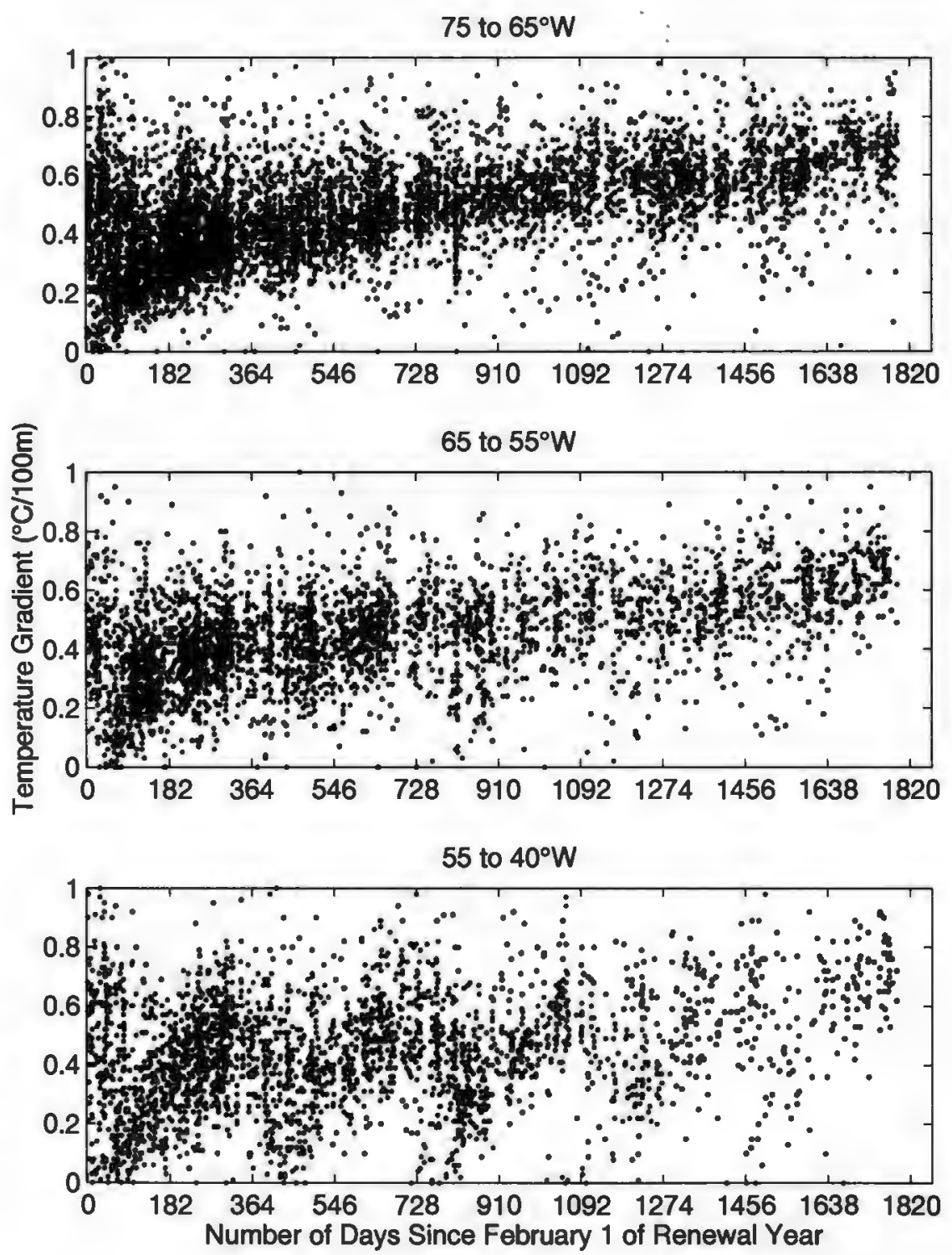

Figure 4.6: Temperature Gradient Time Series. Each cluster's mean temperature gradient through the STMW layer is plotted relative to February 1st of the year the STMW layer was last renewed. 
75 to $65^{\circ} \mathrm{W}$
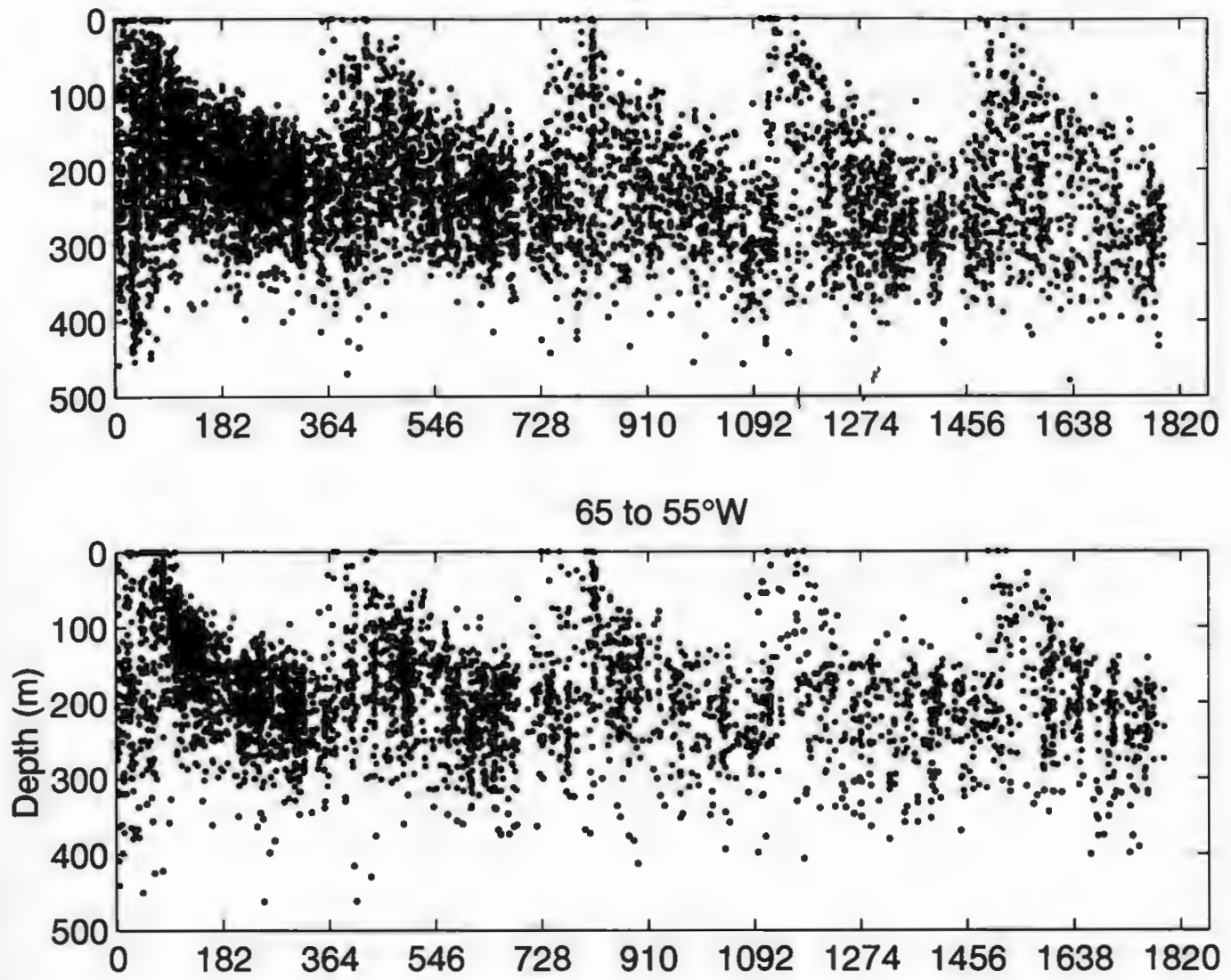

55 to $40^{\circ} \mathrm{W}$

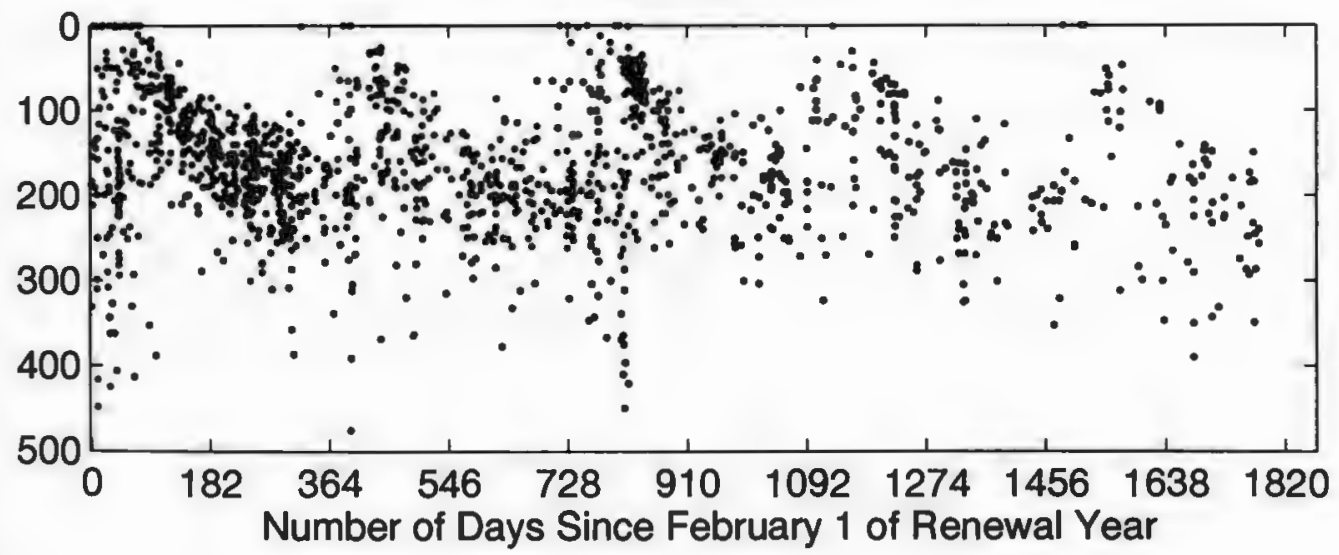

Figure 4.7: Depth of Top of STMW Layer Time Series. The depth of the top of each cluster's STMW layer is plotted relative to February 1st of the year the STMW layer was last renewed. 
75 to $65^{\circ} \mathrm{W}$

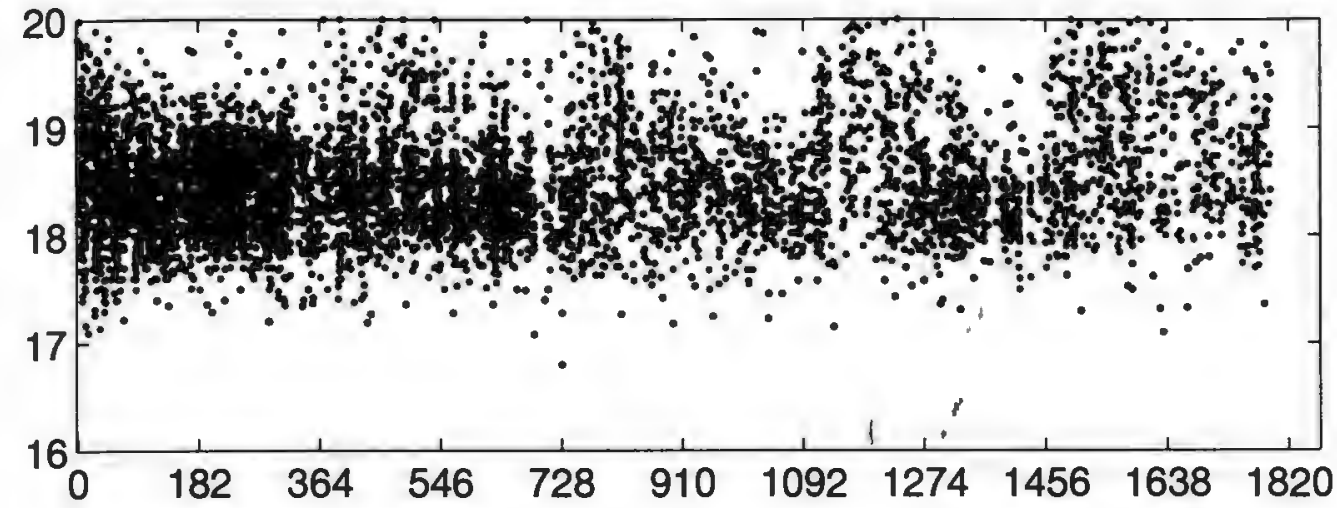

65 to $55^{\circ} \mathrm{W}$

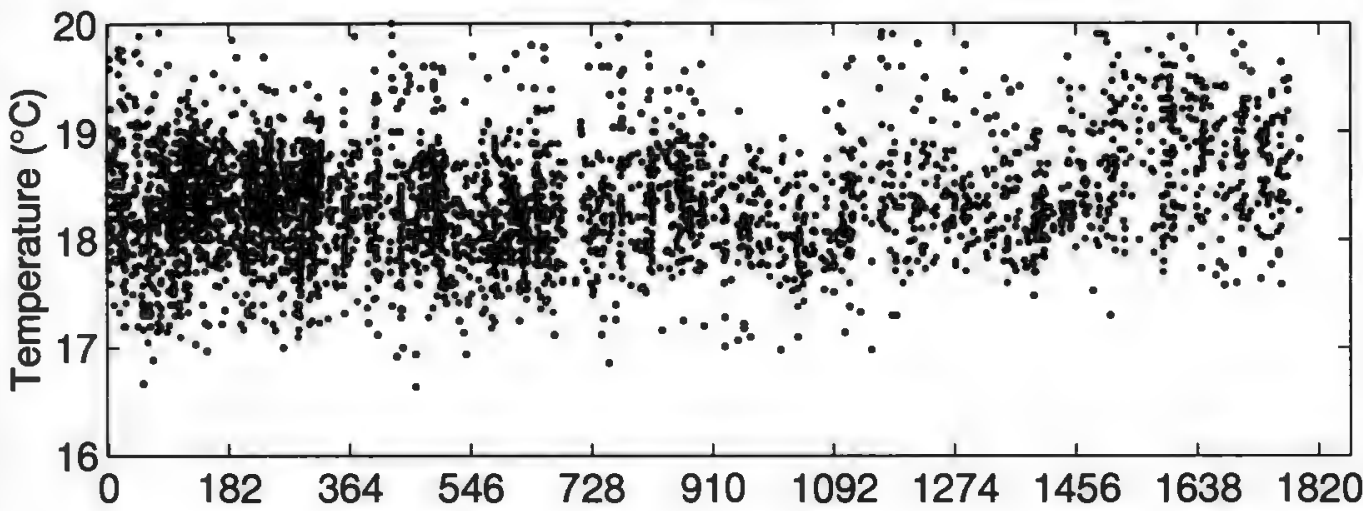

55 to $40^{\circ} \mathrm{W}$

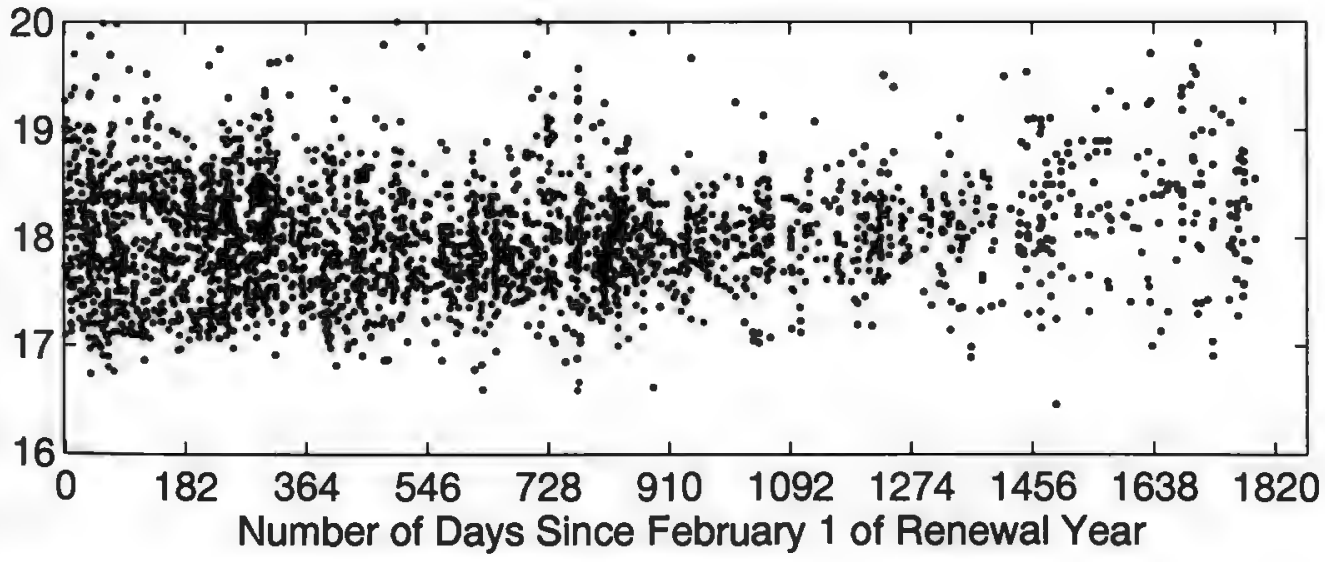

Figure 4.8: Temperature at Top of STMW Layer Time Series. The temperature at the top of each cluster's STMW layer is plotted relative to February 1st of the year the STMW layer was last renewed. 


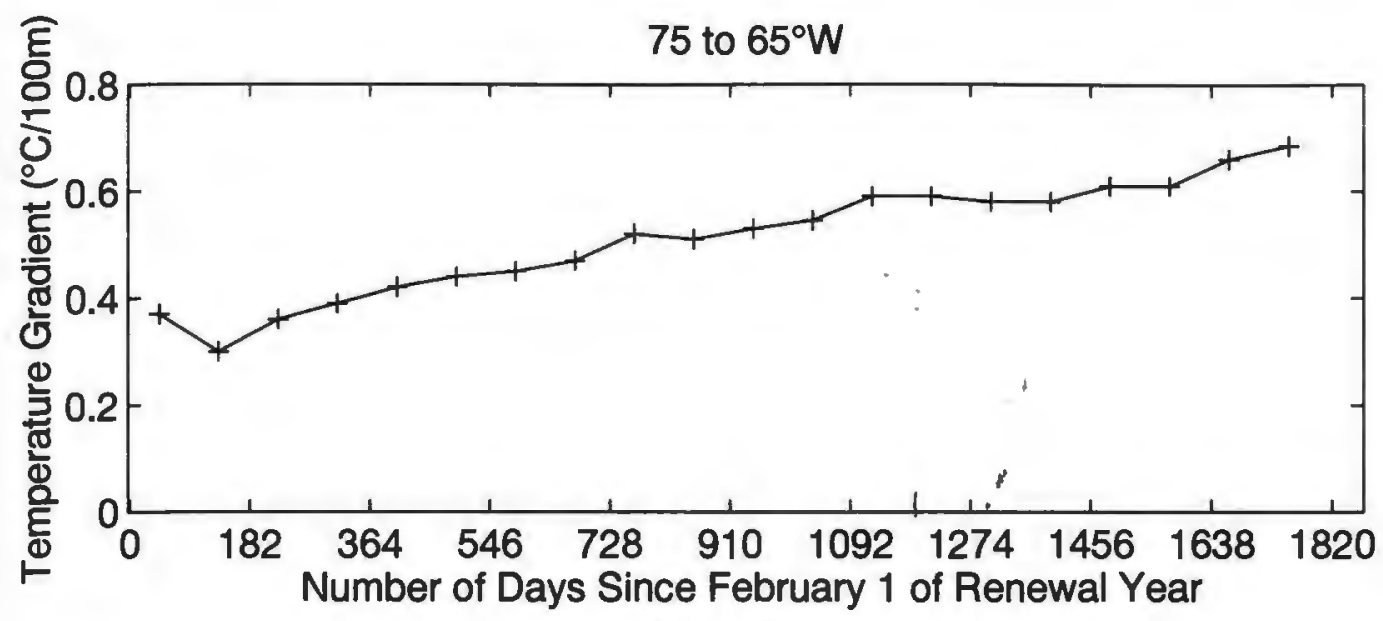

65 to $55^{\circ} \mathrm{W}$

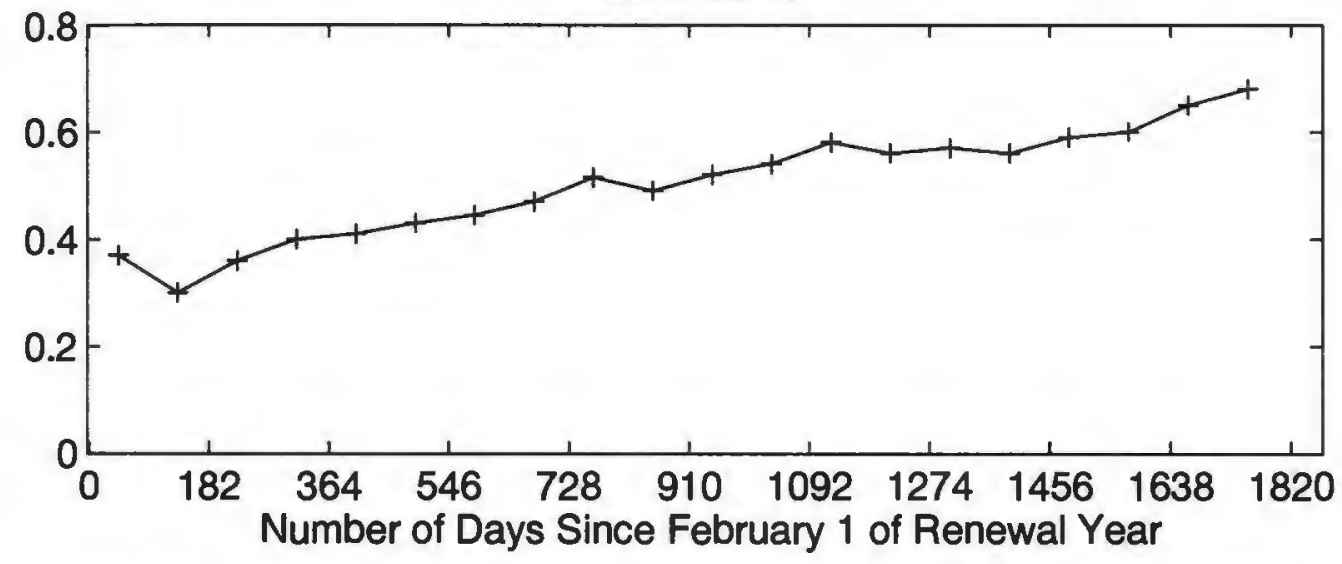

Figure 4.9: Median of mean temperature gradient through STMW layer plotted in Figure 4.6 every 90 days.

the slopes of these best-fit lines.

\subsection{Conclusions}

From Figures 4.4 and 4.5, it appears most of the annual restratification rate following winters of STMW renewal is due to annual decreases in thickness, with a slight increase in the temperature difference aiding in increasing the temperature 

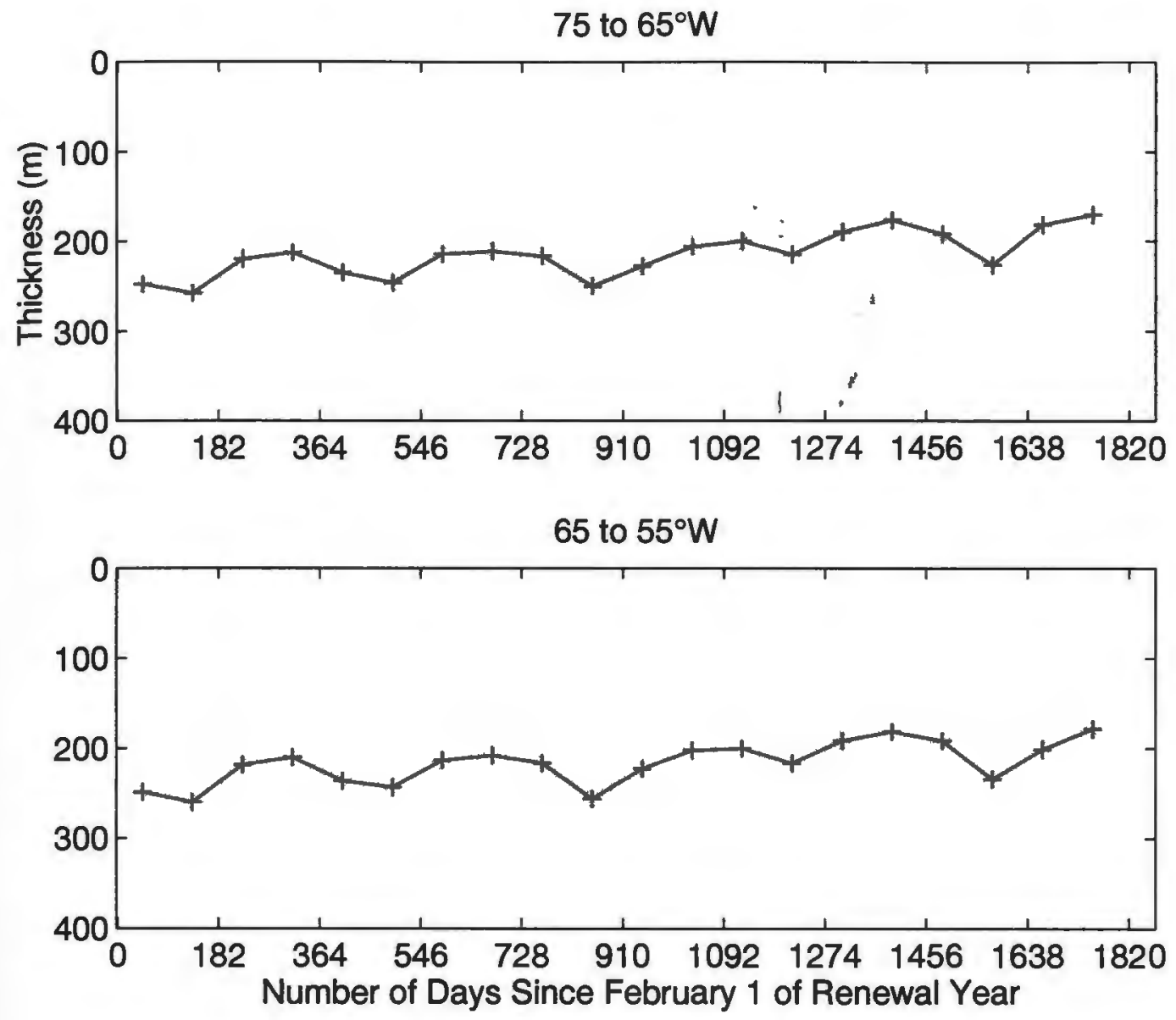

Figure 4.10: Median of STMW layer thickness every 90 days.

Table 4.2: Interannual Mean Changes in Temperature Gradient, Thickness, and Temperature Difference

\begin{tabular}{ll}
\hline \multicolumn{2}{c}{$\mathbf{7 5 - 6 5 ^ { \circ } \mathrm { W }}$} \\
Temperature Gradient & $1.9 \times 10^{-4}{ }^{\circ} \mathrm{C} / 100 \mathrm{~m} /$ day \\
Thickness & $-3.3 \times 10^{-2} \mathrm{~m} /$ day \\
Temperature Difference & $+2.2 \times 10^{-4}{ }^{\circ} \mathrm{C} /$ day \\
\multicolumn{2}{c}{$65-55^{\circ} \mathrm{W}$} \\
Temperature Gradient & $1.8 \times 10^{-4}{ }^{\circ} \mathrm{C} / 100 \mathrm{~m} /$ day \\
Thickness & $-2.5 \times 10^{-2} \mathrm{~m} /$ day \\
Temperature Difference & $+2.3 \times 10^{-4}{ }^{\circ} \mathrm{C} /$ day \\
\hline
\end{tabular}




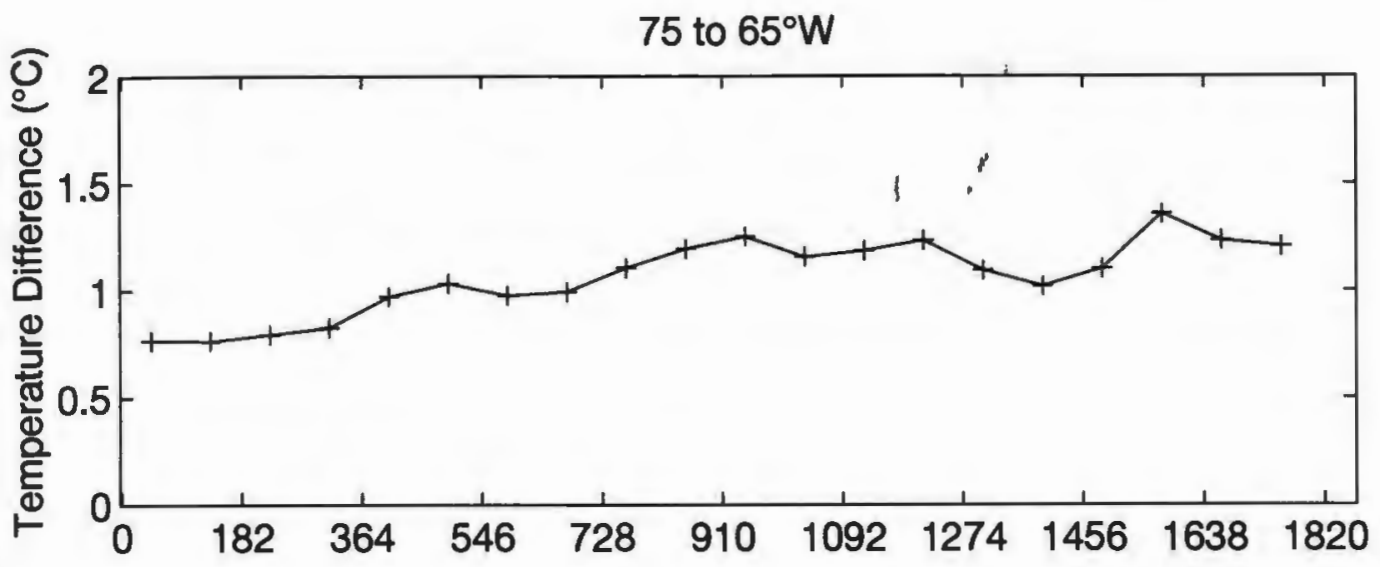

65 to $55^{\circ} \mathrm{W}$

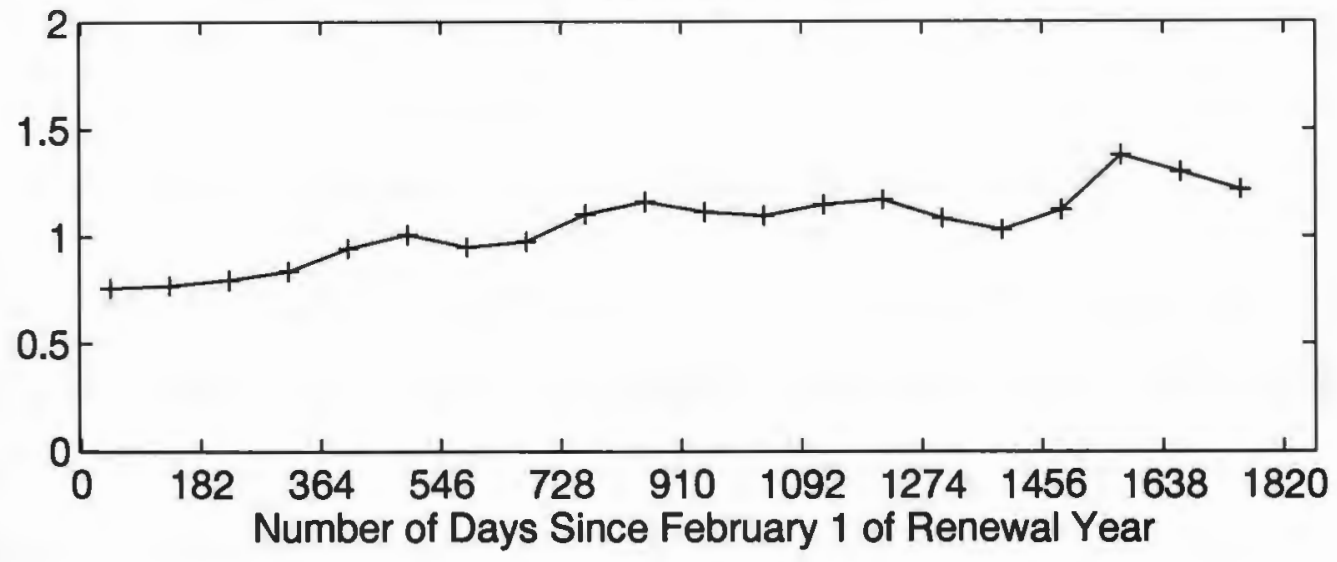

Figure 4.11: Median of temperature difference through the STMW layer every 90 days. 
gradient through the layer. Although the annual deepening of the mixed layer and re-entrainment of waters at the top of the STMW layer may explain much of the annual changes in thickness, it cannot explain the increase in the temperature difference. If the waters at the top of the STMW layer were simply re-entrained with no other processes acting on the layer, the temperature difference through the layer would decrease as the seasonal pycnocline worked its way down the STMW layer temperature gradient. However the temperature difference is increasing. This increase in the temperature difference could be due to

1. vertical mixing/diffusion of relatively warmer water down from above the layer, and/or

2. vertical mixing/diffusion of relatively cooler water up from beneath the layer, and/or

3. lateral processes bringing warmer/cooler water into the STMW layer.

The fact that the potential vorticity of the STMW layer increases as the STMW moves away from its formation region suggests that some mixing in the layer does occur (McCartney 1982). Suga et al. (1989) and Bingham (1992) suggest that the bottom of the NPSTMW layer suffers diapycnal mixing with the main thermocline. Suga and Hanawa (1995c) found indications of mixing by salt fingering at the core and bottom of the NPSTMW layer. Dewar (1986) developed a model of the STMW layer which suggests the potential vorticity structure in the layer is maintained by diabatic potential vorticity forcing during wintertime convection and lateral eddydriven mixing. McCartney (1982) suggests both lateral advection-lateral diffusion 
along isopycnal surfaces and lateral advection cross-isopycnal (double-diffusive) balances can explain the distribution of STMW properties in the subtropical gyre.

Comparing Tables 4.1 and 4.2, the interannual restratification rate is smaller than the annual restratification rate for renewal years, while the interannual restratification rate is similar to the annual restratification rate for non-renewal years west of $65^{\circ} \mathrm{W}$. From Table 4.2, it appears that changes in thickness (thinning) as well as temperature difference (increasing) cause the temperature gradient through the STMW layer to increase during years of no renewal.

Figure 4.12 shows the change in the potential vorticity of the STMW layer (calculated from hydrographic station and CTD data) with time since the STMW layer was last renewed. The solid line represents the median potential vorticity every 90 days. Although there are fewer data points and the change of potential vorticity with time is noiser than the change in temperature gradient, the trend in Figure 4.12 for potential vorticity is similar to the trend in Figures 4.6 and 4.9 for temperature gradient - the potential vorticity (i.e., density stratification) of the STMW layer increases when the STMW layer experiences no convective mixing and renewal. Talley and Raymer (1982) examined the interannual variability in the STMW arriving at the Panulirus hydrographic station near Bermuda. They also found the potential vorticity (i.e., the potential density gradient) at the potential vorticity minimum within the STMW layer increased from 1972 to 1975. They argued that this increase was because the STMW arriving at Panulirus had not been renewed since 1971, and the STMW layer was becoming thinner during the years of no annual renewal. Their Figure 4 shows the thickness between the 
isopycnals which bound the STMW layer becoming smaller from 1972 to 1975 than during the years of annual renewal.

In addition, the annual rate of increase in the temperature difference through the STMW layer in renewal years (Figure 4.5) and the interannual rate of increase in the temperature difference following winters of no renewal (Table 4.2) are of the same order. The annual rate of increase from Figure 4.5 ranges from 2.2 to $4.4 \times 10^{-4}{ }^{\circ} \mathrm{C}$ per day in the $75-65^{\circ} \mathrm{W}$ region and from 4.4 to $5.6 \times 10^{-4}{ }^{\circ} \mathrm{C}$ per day in the $65-55^{\circ} \mathrm{W}$ region, suggesting similar processes (horizontal/vertical mixing/diffusion and/or horizontal advection) are affecting the change in temperature through the STMW layer on annual and interannual scales. However, different processes appear to be affecting the decrease in the thickness of the STMW layer on annual and interannual time scales. From Figure 4.4, the thickness of the STMW layer decreases at a rate of $\sim 0.2-0.3 \mathrm{~m} /$ day from $\sim$ June to $\sim$ December following a winter in which the STMW layer experienced convective mixing and renewal. These rates are an order of magnitude larger than the interannual rates given in Table 4.2. The annual decrease in the thickness of the STMW layer is most likely dominated by the deepening of the seasonal thermocline from MayDecember. The interannual decrease in the thickness of the STMW layer (i.e., differences in November-January thickness' of the STMW layer) following winters of no STMW renewal may be due to Ekman pumping and/or subduction of the STMW layer between thinning isopycnals. These compressional processes would also be working on the STMW layer on annual (May-December) time scales, but may not be as significant as the deepening of the seasonal thermocline on these 

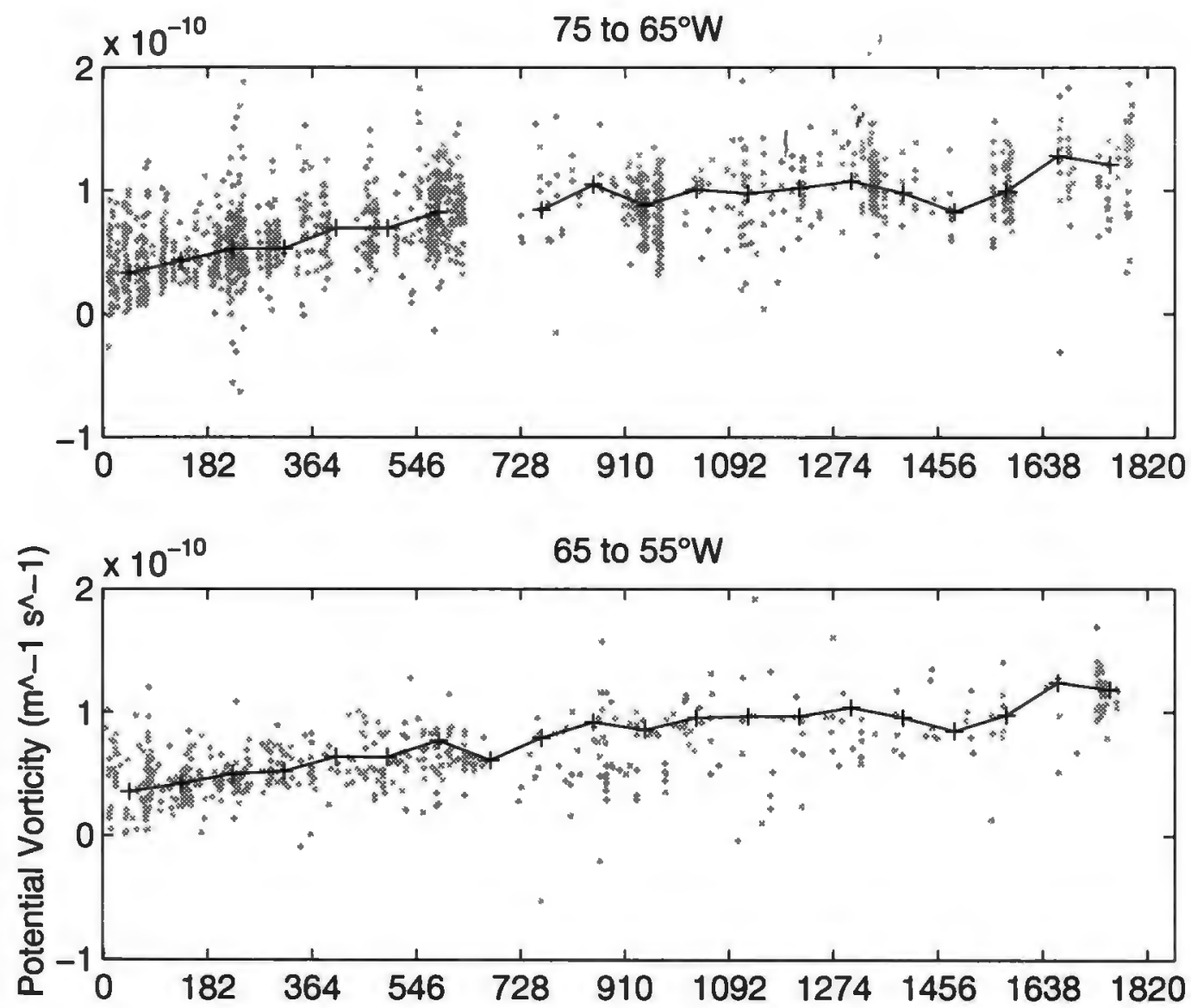

Figure 4.12: Potential Vorticity Time Series. Each cluster's mean potential vorticity through the STMW layer is plotted relative to February 1st of the year the STMW layer was last renewed. 
shorter time scales. 


\section{Chapter 5}

\section{Average STMW Layer : Characteristics}

The annual renewal of the STMW layer was discussed in Chapter 3, while the annual and interannual variations in its properties were discussed in Chapter 4. In this chapter, the average spatial distribution of its properties will be examined. The 1968-1988 average top and bottom depth and temperature, temperature gradient, and average temperature of the STMW layer will be determined every $2.5^{\circ}$ of latitude and $5.0^{\circ}$ of longitude. After contour plots of these long-term averages are presented and discussed, the spatial distribution of properties in renewal years (specifically 1969 and 1970) will be compared to the distribution of properties after several years of no renewal of the STMW layer (specifically 1971, 1972, 1973, and 1974).

To avoid the seasonal changes in the properties at the top of the STMW layer (shoaling in February-April, deepening after May, see Sections 4.1 and 4.2) affecting the long-term averages, clusters/profiles from September through December will be used here to determine the mean STMW properties. The seasonal pycnocline 
will be at its deepest during these months, therefore there will be minimal reentrainment of the waters at the top of the STMW layer back into the mixed layer. The averages presented here, then, represent the mean STMW layer which is the remnant of the previous winter's convective mixing, and is the STMW layer available for possible renewal in the next winter.

The average properties of the STMW layer were determined by first finding the weighted mean of all September-December clusters/profiles in $2.5^{\circ}$ latitude by $5^{\circ}$ longitude bins. The years used here were again 1968-1988, when the data density was the highest. The mean for each bin for each year and its standard error were first found from the weighted mean of all clusters/profiles in that bin using Equations 2.6 and 2.7, and the annual means for each bin were then averaged. In this averaging, each year's annual mean was again weighted by its standard error, and the mean and standard error for each bin were found using Equations 2.6 and 2.7. Averages were not found for bins with fewer than five annual means. Finding the STMW mean properties in this way has two advantages. First, it minimizes the bias of the means towards years with large data volumes. Second, the interannual variability in the STMW properties can be estimated from the variance of the annual means about their average.

Yasuda and Hanawa (1997) used a similar approach in constructing their two decadal climatologies of North Pacific STMW. They found annual seasonal averages in $2^{\circ}$ by $2^{\circ}$ bins, then averaged the annual means. The bin sizes chosen here are similar, and were chosen to allow for a sufficient number of observations each year to find reliable annual means. The slightly coarser grid used here was needed 
particularly for determining the mean depth and temperature of the bottom of the STMW layer as well as the average temperature of the layer since these properties were only determined from those profiles with maximum depths greater than $600 \mathrm{~m}$. This requirement reduced the number of data points available to determine the means for these properties by $\sim 75 \%$.

\subsection{Average Distribution of STMW Properties 5.1.1 Depth}

The mean depth of the top and bottom of the STMW layer are shown in Figure 5.1. Bins with either no data or data in fewer than five years are shaded gray.

From Figure 5.1, the STMW layer is deeper and thicker to the west than to the east. Thickness' range from $\sim 175 \mathrm{~m}$ in the east to $\sim 200 \mathrm{~m}$ in the west. Since the bottom depth contours are oriented primarily north-south while the top depth contours south of $30^{\circ} \mathrm{N}$ are oriented primarily east-west, deepening to the south, the STMW layer becomes thinner to the south of $30^{\circ} \mathrm{N}$. The standard deviation of the annual means of the top of the STMW layer is $\sim 30 \mathrm{~m}$, while it is $\sim 45 \mathrm{~m}$ for the bottom depths.

These results are in general agreement with previous observations of STMW in individual hydrographic sections which found the STMW arriving at Bermuda was between the depths of 150 and $450 \mathrm{~m}$ (Schroeder et al. 1959); and the STMW layer was nominally $200 \mathrm{~m}$ thick (Worthington 1959, Istoshin 1961), decreased to the south, particularly south of $32^{\circ} \mathrm{N}$ (Istoshin 1961, Suga et al. 1989), and decreased from west to east (Masuzawa 1972, Hanawa 1987). 

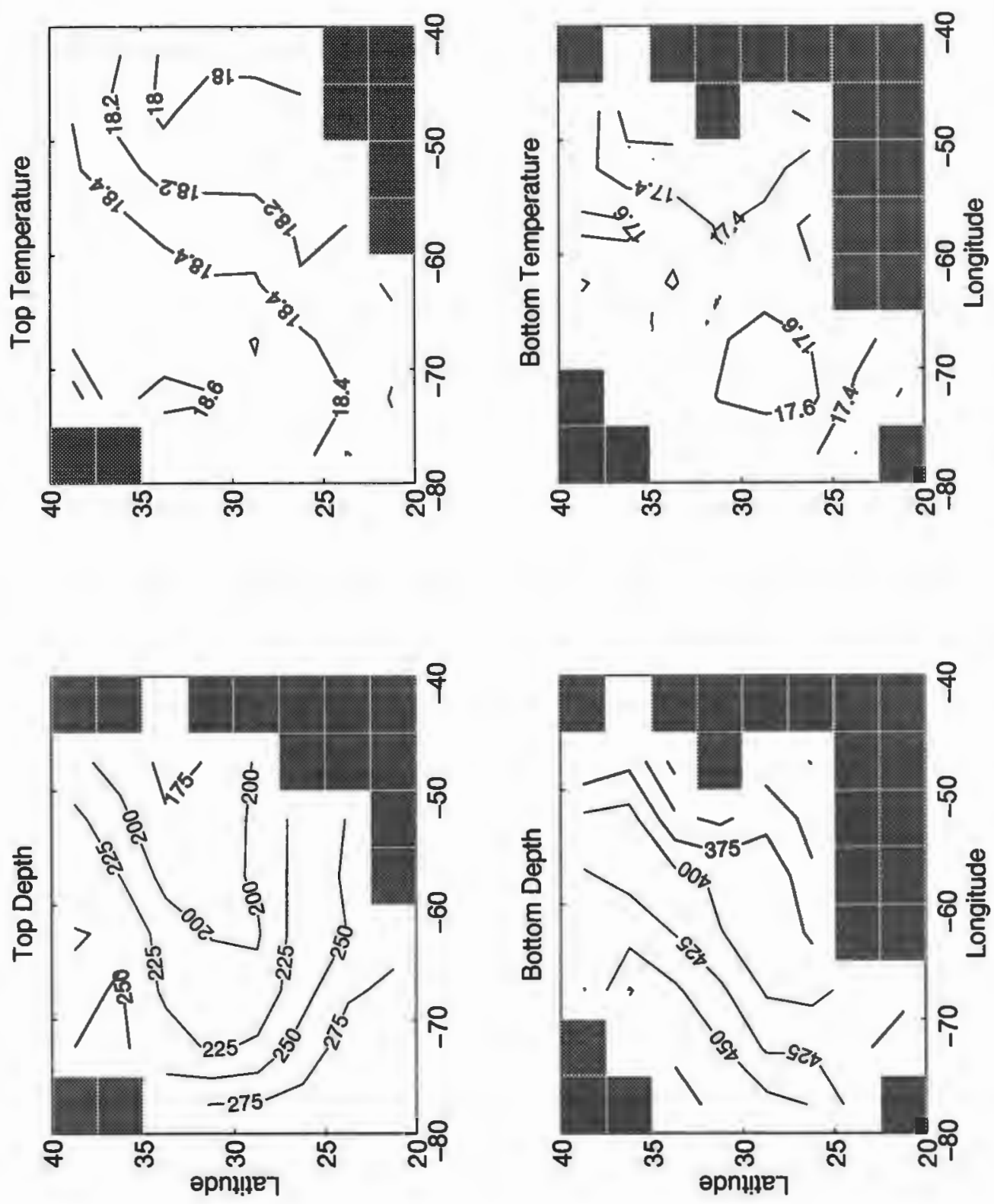

Figure 5.1: Contoured 2.5 Latitude x 5.0 $0^{\circ}$ Longitude Mean STMW Top and Bottom Depths $(\mathrm{m})$ and Temperatures $\left({ }^{\circ} \mathrm{C}\right)$. The contour intervals are more than twice as large as the standard errors for the depths $(<10 \mathrm{~m})$ and temperatures $\left(<0.1^{\circ} \mathrm{C}\right)$ over most of the region. 


\subsubsection{Temperature}

The mean temperatures at the top and bottom of the STMW layer are shown in Figure 5.1, while the average temperature of the layer is shown in Figure 5.2. The standard deviation of the annual means of the temperature at the top of the STMW layer is $\sim 0.35^{\circ} \mathrm{C}$, while it is $\sim 0.40{ }^{\circ} \mathrm{C}$ for the bottom temperatures.

There is good agreement between the average temperarture of the STMW layer in Figure 5.2 and Worthington (1959)'s original "classical" definition of the STMW temperature, $17.9 \pm 0.3^{\circ} \mathrm{C}$. The vertical temperature difference through the layer ranges from 0.8 to $1.0^{\circ} \mathrm{C}$ (Figure 5.1).

The east-west gradient in the temperature of the STMW layer (colder to the east, warmer to the west) is readily evident in both figures. This gradient is larger at the top of the STMW layer $\left(\sim 0.6^{\circ} \mathrm{C}\right.$ across the gyre) than at the bottom $\left(\sim 0.2-0.4{ }^{\circ} \mathrm{C}\right.$ across the gyre). This east-west temperature gradient has been widely reported by others (McCartney et al. 1980, Talley and Raymer 1982, Hall and Fofonoff 1993, Klein and Hogg 1996), but only in individual or pairs of hydrographic sections. The previously reported east-west temperature differences range from $0.6^{\circ} \mathrm{C}$ from 68 to $53^{\circ} \mathrm{W}$ (Talley and Raymer 1982) to $0.9^{\circ} \mathrm{C}$ from 68 to $55^{\circ} \mathrm{W}$ (Hall and Fofonoff 1993). The east-west temperature differences from the distribution of mean temperatures in Figure 5.1 are comparable to these instantaneous values. 

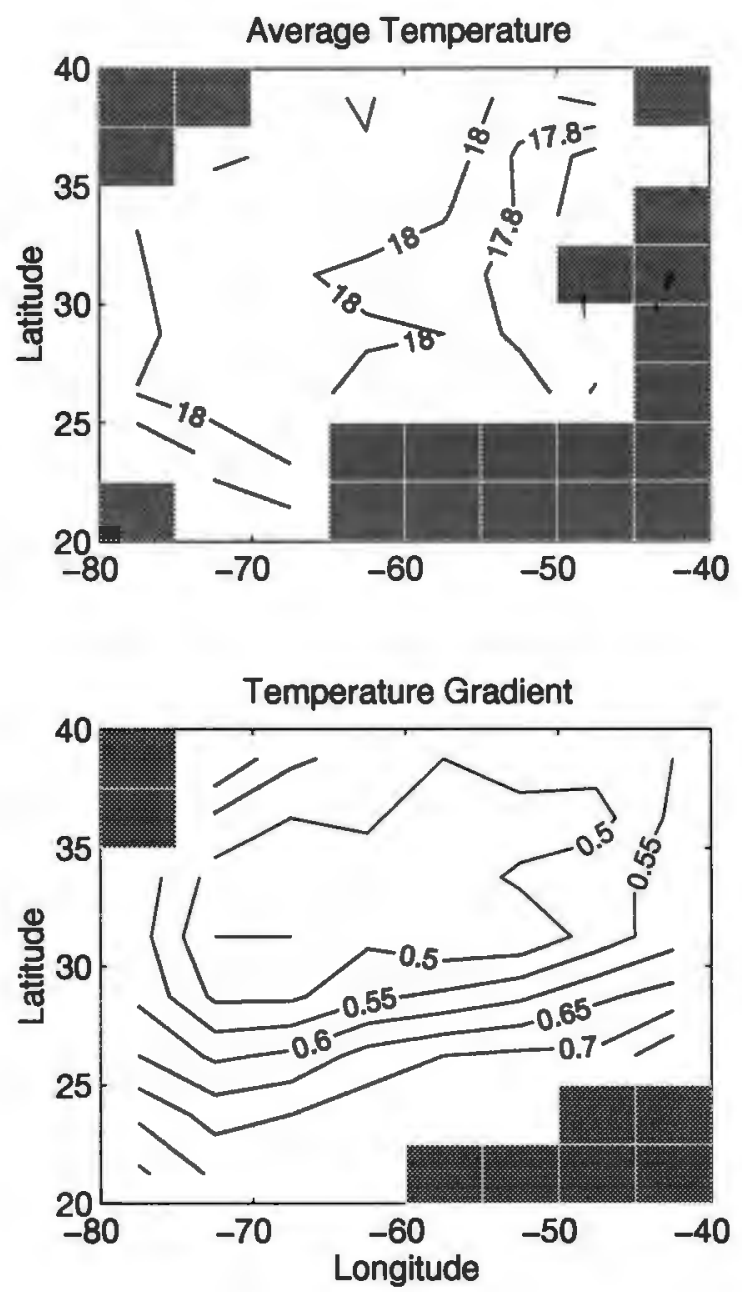

Figure 5.2: Contoured 2.5 Latitude x 5.0 $0^{\circ}$ Longitude Mean STMW Average Temperature $\left({ }^{\circ} \mathrm{C}\right)$ and Temperature Gradient $\left({ }^{\circ} \mathrm{C}\right.$ per $\left.100 \mathrm{~m}\right)$. The contour intervals are more than twice as large as the standard errors for the average temperature $\left(<0.1{ }^{\circ} \mathrm{C}\right)$ and temperature gradient $\left(<0.025{ }^{\circ} \mathrm{C}\right.$ per $\left.100 \mathrm{~m}\right)$ over most of the region. 


\subsubsection{Temperature Gradient}

The mean temperature gradient through the STMW layer is shown in Figure 5.2. On average, the STMW layer in September through December has a temperature gradient of $0.5-0.55^{\circ} \mathrm{C}$ per $100 \mathrm{~m}$ with the gradient through the layer increasing to the south of $30^{\circ} \mathrm{N}$. Therefore, a $150-200 \mathrm{~m}$ thick STMW layer (Figure 5.1) will again have a temperature difference through it of $\sim 0^{\prime} .8-1.1^{\circ} \mathrm{C}$. The standard deviation of the annual mean temperature gradients is $\sim 0.1{ }^{\circ} \mathrm{C}$ per $100 \mathrm{~m}$.

Other observations of the temperature gradient through the STMW layer range from $0.3^{\circ} \mathrm{C}$ per $100 \mathrm{~m}$ in recently renewed STMW (McCartney et al. 1980) to $0.8^{\circ} \mathrm{C}$ per $100 \mathrm{~m}$ in STMW with no recent exposure to convective mixing (Worthington 1977). Klein and Hogg (1996) found by comparing Panulirus hydrographic data with XBT data that the STMW layer near Bermuda was associated with temperature gradients less than $0.8^{\circ} \mathrm{C}$ per $100 \mathrm{~m}$. Again, the mean values shown in Figure 5.2 are comparable to these instantaneous observations of the STMW layer temperature gradient.

There are no previous observations of the spatial variations in the temperature gradient through the STMW layer. McCartney (1982), however, did note that the potential vorticity (potential density gradient) of the STMW layer does increase to the south, which agrees with the increase in the temperature gradient to the south seen here. In addition McDowell et al. (1982) mapped the variation of potential vorticity in the North Atlantic. They calculated the potential vortcity between the $\sigma_{\theta}=26.0-26.3,26.3-26.5,26.5-27.0,27.0-27.3$, and 27.3-27.6 isopycnal surfaces. From Table 2.5, the potential vorticity found between the 26.3-26.5 
isopycnals corresponds to the range of densities in the STMW layer found here. Their Figure 17 showing potential vorticity between these isopycnals as a function of latitude is shown in Figure 5.3. First, the mean potential vorticity of the STMW layers found in this study with potential densities between 26.3 and 26.5 , and from 25 to $35^{\circ} \mathrm{N}$ (3020 profiles), was $6.13 \times 10^{-11} \mathrm{~m}^{-1} \mathrm{~s}^{-1}$, which corresponds well with the values in the region of relatively constant potential yorticities between these latitudes in Figure 5.3. Second, the variation of potential vorticity with latitude in Figure 5.3 mimics the change in the temperature gradient through the STMW layer with latitude shown in Figure 5.2. Both show a plateau of homogeneous values to the north of $\sim 29^{\circ} \mathrm{N}$ and a rapid increase to the south of $\sim 29^{\circ} \mathrm{N}$.

The features shown in Figure 5.2 (region of uniform temperature gradients south of the western boundary current with a "ramp" of rapidly increasing temperature gradients farther to the south) also agree with the results of Rhines and Young (1982)'s theory of potential vorticity homogenization in unventilated layers of planetary gyres. Their theory predicts a pool of homogenized potential vorticity created by weak horizontal diffusion down the potential vorticity gradient, if the wind-driven motion above the unventilated layer is strong enough to cause lines of constant potential vorticity to close on themselves. Outside this homogenized region, the potential vorticity contours tend to be oriented east-west. In support of their hypothesis, they presented the unpublished results of a 3-layer numerical model of the wind-driven circulation by W.B. Holland. The potential vorticity structure of the middle, unventilated region (Rhines and Young (1982) Figure 3) again compares well with Figure 5.2, showing a plateau of homogeneous potential 


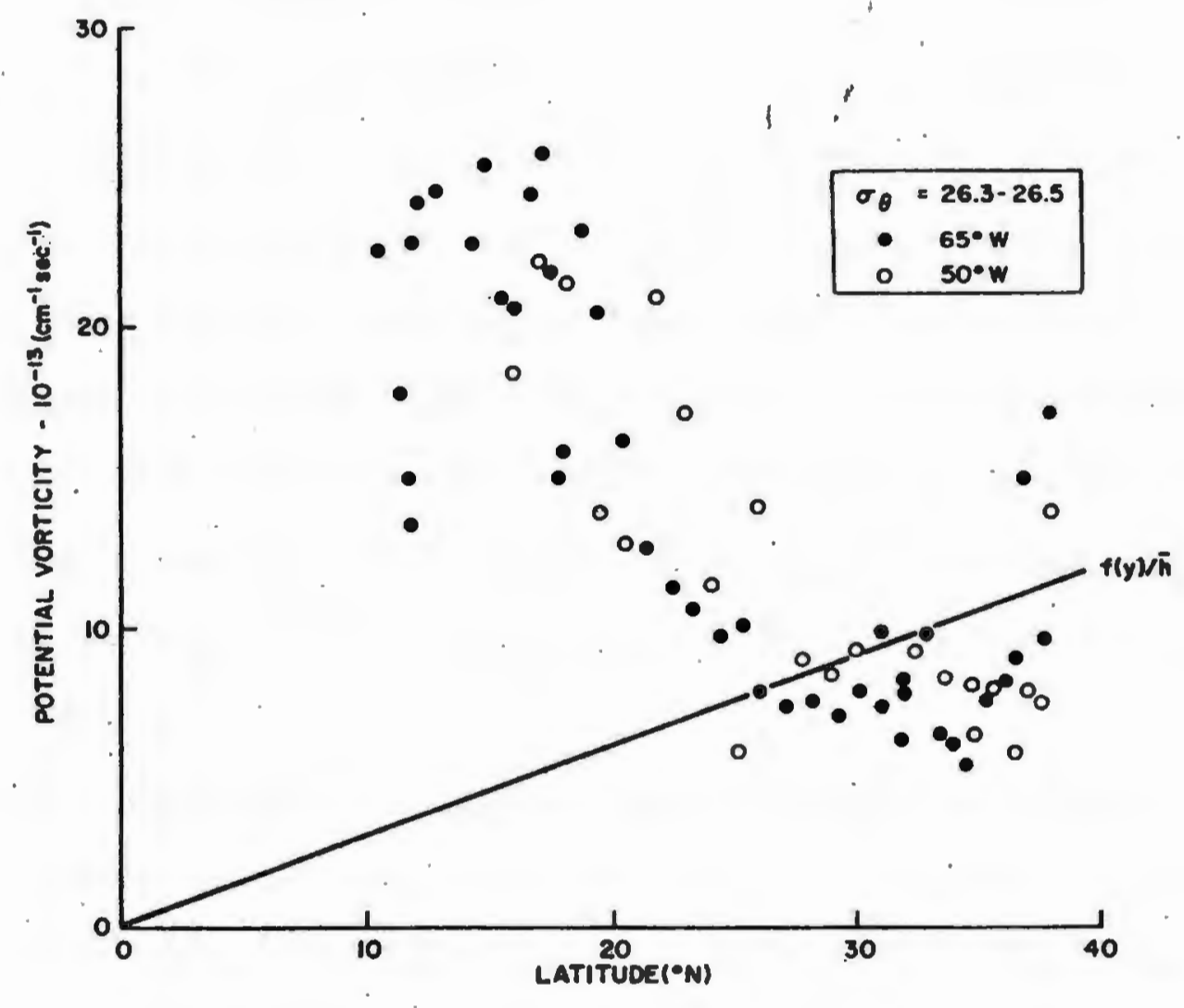

Figure 5.3: Potential vorticity computed between the $\sigma_{\theta}=26.3$ and 26.5 surfaces at individual stations along 65 and $50^{\circ} \mathrm{W}$, from McDowell et al. (1982). 
vorticity south of the western boundary current and a ramp of rapidly changing potential vorticity oriented east-west south of the pool of homogenized potential vorticity.

Rhines and Young (1982)'s model was of an unventilated layer isolated from direct atmospheric forcing. The STMW layer can be exposed to direct atmospheric cooling during renewal years, and is thus not striçtly unventilated. Dewar (1986) examined the potential structure of a "weakly" ventilated layer by allowing a small region within the closed potential vorticity contours to experience diabatic forcing driven by surface heat exchange. His results found a homogenized potential vorticity region at the center of the closed geostrophic contours which was a local minimum and corresponded to the unventilated region within the closed geostrophic contours, and a "bowl-shaped region" near the edges of the region of closed geostrophic contours where the potential vorticity increased due to the diabatic forcing.

There is some indication in Figure 5.2 that the temperature gradients do increase on the northern, eastern, and western edges of the plateau of homogeneous temperature gradients. At this point however, the ramp of increasing temperature gradients to the south seems to be a more prevalent feature. The difference between the STMW layer here and Dewar's weakly ventilated layer is that, in Dewar's model, the diabatic forcing was always acting on the layer whereas in the STMW layer the diabatic forcing acts on the layer for a limited amount of time. Comparing Figure 5.2 to Dewar's results, then, seems to suggest that the STMW layer behaves more as an unventilated layer than a ventilated layer once it has 
been isolated from the atmosphere by the seasonal thermocline.

\subsection{Distribution of STMW Properties in Renewal versus Non-renewal Years}

The spatial distributions of STMW properties in renewal yẹars versus non-renewal years were compared by finding the September-December means for two years of repeated renewal and four years of repeated no renewal. The consecutive years of renewal chosen here were 1969 and 1970, while the consecutive years of no renewal were $1971,1972,1973$, and 1974 (Table 3.3). While there will likely be significant variations in other renewal and non-renewal years from these specific years, the results here will help determine what variations in the STMW properties in renewal and non-renewal years might be expected

The means for each two year period (1969-1970, 1971-1972, and 1973-1974) were again found by first averaging all September through December clusters/profiles for each year using $2.5^{\circ}$ latitude by $5.0^{\circ}$ longitude bins and Equation 2.6. The standard error of these annual means were again found using Equation 2.7. The two-year averages were then found by weighting each year's mean by its standard error and using Equation 2.6.

Figures 5.4, 5.5, and 5.6 compare the 1969-1970, 1971-1972, and 1973-1974 STMW mean top depth and temperature, and temperature gradient. Bins with less than two profiles over each two year period are shaded gray. The STMW bottom depth and temperature, and average temperature, were not found due to the lack of deep $(>600 \mathrm{~m}$ ) profiles to find suitable averages for each bin. 

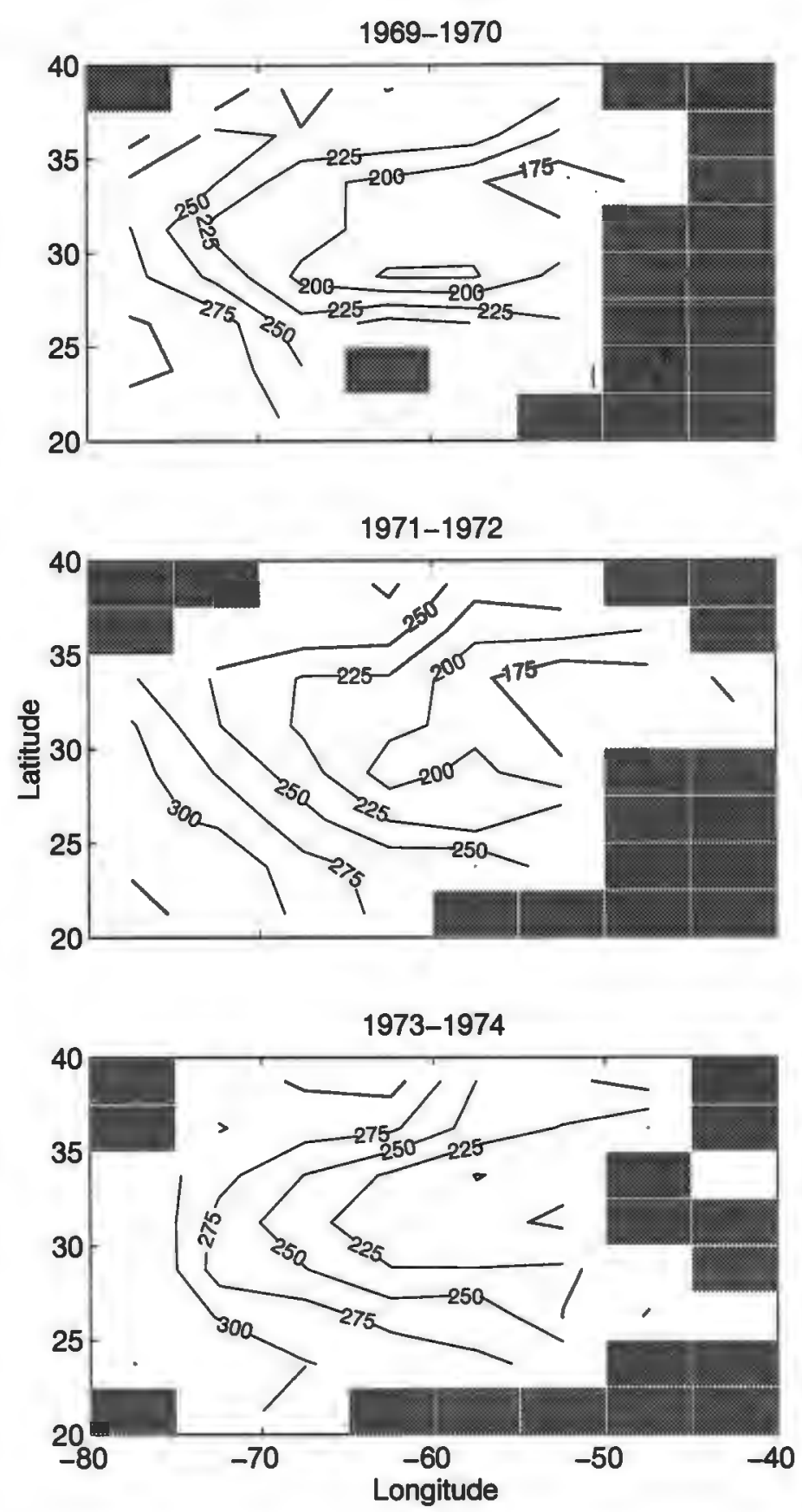

Figure 5.4: 1969-1970, 1971-1972, and 1973-1974 STMW Top Depth (m). 

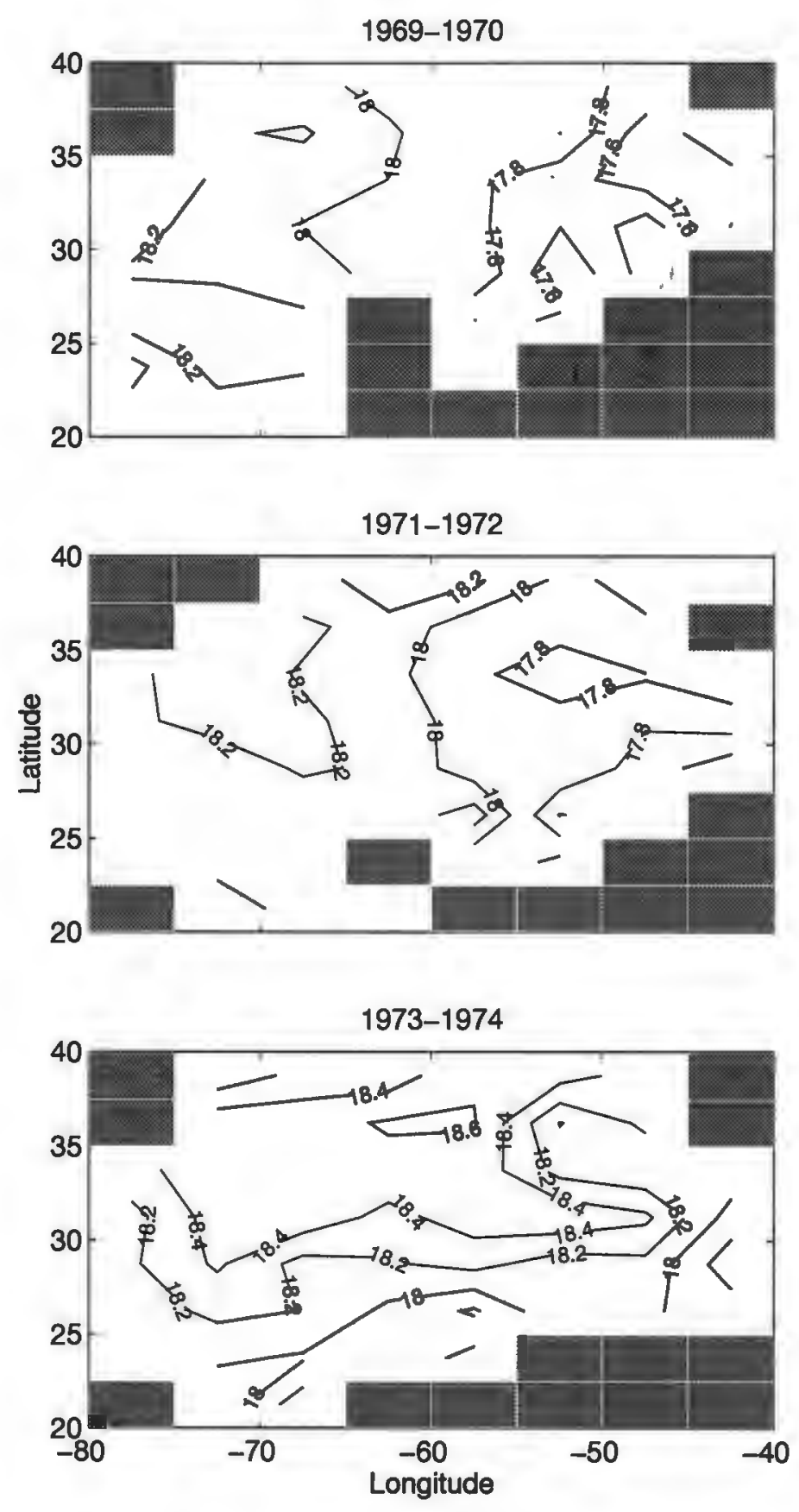

Figure 5.5: 1969-1970, 1971-1972, and 1973-1974 STMW Top Temperature $\left({ }^{\circ} \mathrm{C}\right)$. 

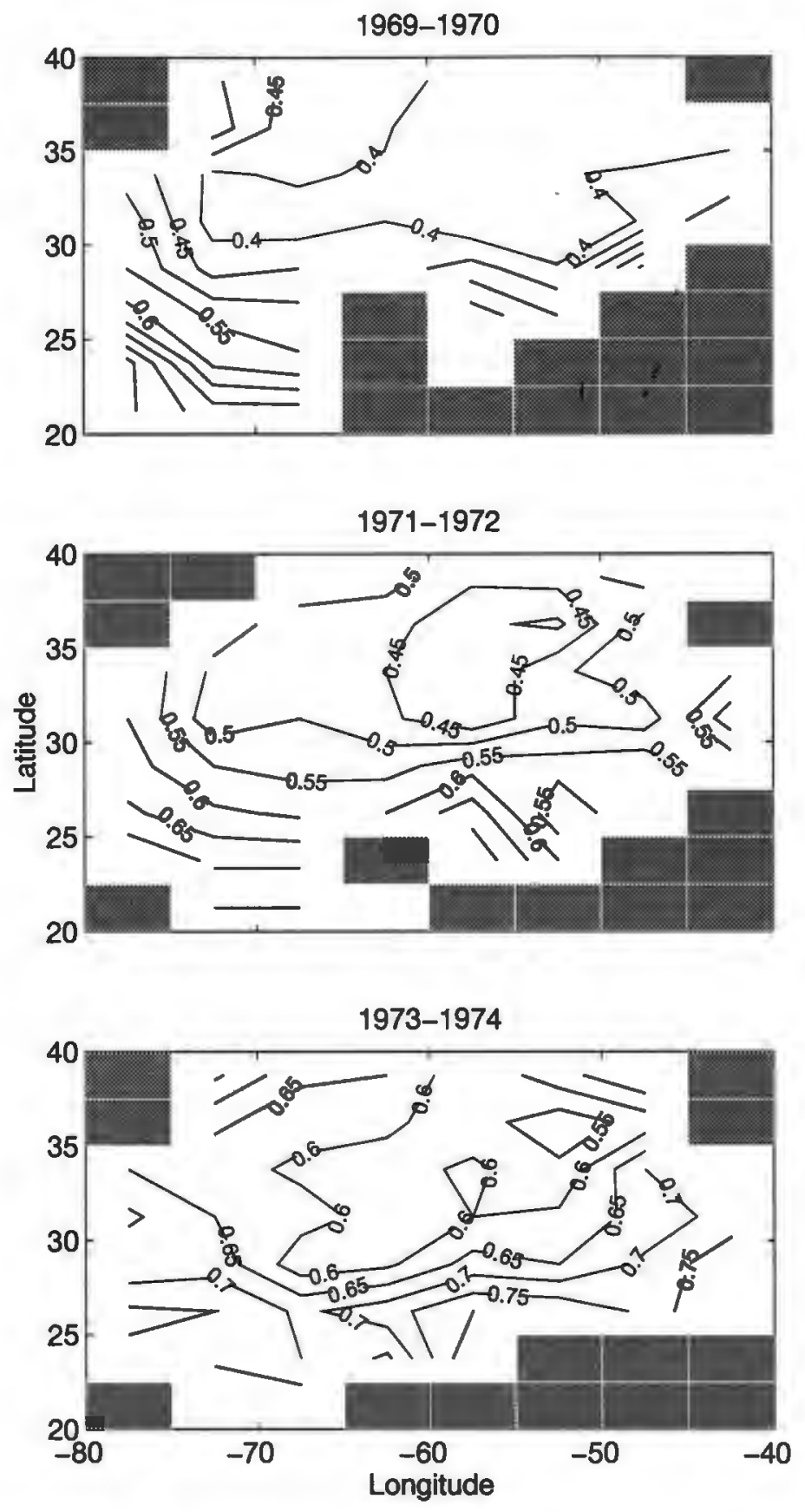

Figure 5.6: $1969-1970,1971-1972$, and $1973-1974$ Temperature Gradient $\left({ }^{\circ} \mathrm{C}\right.$ per $100 \mathrm{~m}$ ). 
The STMW layer is $\sim 25 \mathrm{~m}$ deeper and $\sim 0.2-0.6^{\circ} \mathrm{C}$ warmer after several years of no renewal than after several years of renewal (Figures 5.4 and 5.5). It is interesting that the spatial patterns of the top depth are similar in renewal and non-renewal years (only $25 \mathrm{~m}$ deeper), but the spatial distribution of top temperature in the two periods is fundamentally different. The contours are oriented more north-south in renewal years (1969-1970) than non-renewal years (1973-1974), indicating a stronger east-west gradient in the temperature in renewal years than non-renewal years. McCartney et al. (1980) also found the STMW layer was relatively horizontally uniform in 1976, a year of no STMW renewal, while there was a $0.3{ }^{\circ} \mathrm{C}$ east-west temperature difference (colder to the east) in 1977 , following large-scale renewal of the STMW layer. Talley and Raymer (1982) and Hall and Fofonoff (1993) also observed an east-west gradient in the temperature of newly formed STMW.

Although the STMW layer appears to have a larger east-west gradient in its temperature in renewal than non-renewal years, it is vertically more homogeneous in renewal years than following several years of no renewal (Figure 5.6, as has been discussed in Section 4.2). Other observations of the vertical temperature gradient through the STMW layer range from $0.3^{\circ} \mathrm{C}$ per $100 \mathrm{~m}$ (McCartney et al. 1980) in newly formed STMW to $0.8^{\circ} \mathrm{C}$ per $100 \mathrm{~m}$ (Worthington 1977) in STMW with no recent exposure to convective mixing. The mean gradients shown in Figure 5.6 are comparable to these instantaneous values. 


\subsection{Conclusions}

On average, the STMW layer which is the remnant of the previous winter's convective mixing is found between 175 and $450 \mathrm{~m}$, has an average temperature near $18^{\circ} \mathrm{C}$, and a temperature gradient of $0.5^{\circ} \mathrm{C}$ per $100 \mathrm{~m}$. The north-south variations in the STMW layer temperature gradient correspond with observations of potental vorticity, as well as numerical model results of the potential vorticity structure of an unventilated layer with weak horizontal diffusion. Finally, the distribution of properties in two specific renewal years and four non-renewal years suggests the STMW layer is shallower, colder, less vertically stratified, but more horizontally stratified, following winters of convective renewal than following winters when there is no convective mixing into the STMW layer. 


\section{Chapter 6}

\section{Conclusions}

This study examined STMW properties between 1968 and 1988 using a temperaturebased characterization. The results obtained from this characterization are comparable to those previously obtained using density-based characterizations. However, the characterization developed here was able to take advantage of the large volume of XBT data to look at STMW properties on larger temporal and spatial scales than previous studies.

Three different characterizations were used to assess the degree of renewal of the STMW layer during the 1968-1988 winters. Two characterizations were based on comparing the winter mixed layer properties to the STMW layer properties in the previous fall, while the third characterization involved comparing the temperature gradient through the STMW layer in the fall before convective mixing to the temperature gradient in the spring after convective mixing. The results found here indicate the STMW layer can experience in a given winter

1. Total renewal of its vertical homogeneity when cold mixed layers penetrate to the bottom of the STMW layer, convectively mixing it from its previous 
top to bottom.

2. Partial renewal of its vertical homogeneity when cold mixed layers penetrate the pre-existing top of the STMW layer, but are not cold/deep enough to reach its bottom.

3. No renewal of its vertical homogeneity because the winter mixed layers are too warm and shallow to penetrate the top of the pre-existing STMW layer.

4. Formation of a dual-layer STMW layer when a relatively shallow, warm thermostad forms at the top of the pre-existing STMW layer. How this thermostad forms (by vertical mixing and/or horizontal advection) is uncertain. Much of this shallow, warm thermostad will be eroded later in the year by the deepening seasonal thermocline.

STMW renewal events were defined here by the penetration of cold mixed layers more than $50 \mathrm{~m}$ into the STMW layer, renewing the STMW layer's vertical homogeneity. There was considerable spatial and temporal variability in the renewal of the STMW layer's vertical homogeneity from 1968 to 1988. Basin-wide renewal occurred in 1969, 1970,1977, 1978, 1981, and 1985, with more localized renewal, usually east of $55^{\circ} \mathrm{W}$, in other years.

While STMW is nearly vertically homogeneous upon renewal by convective mixing, the temperature gradient through the layer increases after renewal. The annual rate of increase in the temperature gradient in the year following renewal is $\sim 5-6 \times 10^{-4}{ }^{\circ} \mathrm{C}$ per $100 \mathrm{~m}$ per day, while the interannual rate of increase following winters with no renewal of the STMW layer is $\sim 2.0 \times 10^{-4}{ }^{\circ} \mathrm{C}$ per $100 \mathrm{~m}$ per day. 
The annual and interannual increases in the temperature gradient are due to a thinning of the STMW layer and an increase in the temperature difference through the layer. Three general types of processes could explain these changes in the STMW layer:

1. Heat flux into/out of the STMW layer through vertical/lateral diffusion/mixing.

2. Advection of water into the STMW layer.

3. Compression of the STMW layer through Ekman pumping and/or subduction.

The rate of increase in the temperature difference through the STMW layer is the same order of magnitude on annual and interannual time scales, indicating the same process(es) are changing the temperature difference through the STMW layer on both time scales. The annual rate of thinning of the STMW layer following a winter of convective mixing/renewal is an order of magnitude larger than the interannual rate of thinning. This indicates different processes are responsible for thinning the STMW layer on annual and interannual time scales.

The presence of dual-layer STMW layers, formed in winters of partial renewal of the STMW layer, with small temperature gradients due to their large thickness, made it difficult to determine

1. whether the STMW layer was indeed renewed in some years,

2. the annual rate of increase of the temperature gradient in the year following a winter with no renewal of the STMW layer, and 
3. the mechanisms responsible for the annual/interannual increase in the STMW layer's temperature gradient.

Identifying these dual-layer STMW layers and separating the more recently formed STMW from the older STMW will be an important next step in the continuation of this work.

The STMW layer which is the remnant of the previous winter's convective activity is typically found between 175 and $450 \mathrm{~m}$, has an average temperature near $18{ }^{\circ} \mathrm{C}$, and has a mean temperature gradient of $0.5^{\circ} \mathrm{C}$ per $100 \mathrm{~m}$. STMW layers in years following winter renewal are shallower, colder, and less vertically stratified, but more horizontally stratified, than STMW layers following winters of no renewal.

The fact that the potential vorticity of the STMW layer seems to mimic both the temporal and horizontal changes in the temperature gradient through the layer suggests that a relationship exists between the two such that the temperature gradient may be used as a surrogate for the potential vorticity of the STMW layer. However, processes affecting the distribution of temperature and salinity in the STMW layer, and the relative importance of changes in temperature and salinity in determining changes in the potential vorticity of the STMW layer, need to be more fully examined in order to define this relationship more thoroughly. 


\section{Bibliography}

Belkin, I. and A. Gordon (1996). Southern Oceah frónts from the Greenwich meridian to Tasmania. Journal of Geophysical Research 101(C2), 3675-3696.

Bingham, F. M. (1992). Formation and spreading of subtropical mode water in the North Pacific. Journal of Geophysical Research 97, 11177-11189.

Boyd, J. and R. Linzell (1992). The temperature and depth accuracy of Sippican T-5 XBTs. Journal of Atmospheric and Oceanic Technology 10, 128-136.

Boyer, T. and S. Levitus (1994). Quality Control and Processing of Historical Oceanographic Temperature, Salinity, and Oxygen Data. NOAA Technical Report NESDIS 81, NOAA National Environmental Satellite, Data and Information Service, Washington, D.C. 64 pp.

Brundage, W. and J. Dugan (1986). Observations of an anticyclonic eddy of $18^{\circ} \mathrm{C}$ Water in the Sargasso Sea. Journal of Physical Oceanography 16(4), $717-727$.

Casey, K. S. and P. Cornillon (1997). A comparison of satellite and in situ based sea surface temperature climatologies. Journal of Climate. Submitted.

Cayan, D. (1992a). Latent and sensible heat flux anomalies over the Northern 
Oceans: driving the sea surface temperature. Journal of Physical Oceanography 22, 859-881.

Cayan, D. (1992b). Latent and sensible heat flux anomalies over the Northern Oceans: the connection to monthly atmospheric circulation. Journal of Climate 5, 354-369.

Cornillon, P., C. Gilman, L. Stramma, O. Brown, ,R. Evans, and J. Brown (1987). Processing and analysis of large volumes of satellite-derived thermal infrared data. Journal of Geophysical Research 92, 12993-13002.

Cushman-Roisin, B. (1987). On the role of heat flux in the Gulf Stream-Sargasso Sea subtropical gyre system. Journal of Physical Oceanography 17, 21892202.

Dewar, W. K. (1986). On the potential vorticity structure of weakly ventilated isopycnals: A theory of subtropical mode water maintenance. Journal of Physical Oceanography 16, 1204-1216.

Dickson, R., J. Lazier, J. Meincke, P. Rhines, and J. Swift (1996). Long-term coordinated changes in the convective activity of the north atlantic. Progress in Oceanography 38, 241-295.

Ebbesmeyer, C. and E. Lindstrom (1986). Structure and origin of $18^{\circ} \mathrm{C}$ water observed during the POLYMODE local dynamics experiment. Journal of Physical Oceanography 16, $443-453$.

Fieux, M. and H. Stommel (1975). Preliminary look at feasibility of using marine reports of sea surface temperature for documenting climatic change in the 
western North Atlantic. Journal of Marine Research 33(Supplement), 83 95.

Gong, X. and M. B. Richman (1995). On the application of cluster analysis to growing season precipitation data in North America east of the Rockies. Journal of Climate 8, 897-931.

Halkin, D. and T. Rossby (1985). The structure and tránsport of the Gulf Stream at $73^{\circ} \mathrm{W}$. Journal of Physical Oceanography 15(11), 1439-1452.

Hall, M. (1989). Velocity and transport structure of the Kuroshio extension at $35^{\circ} \mathrm{N}, 152^{\circ} \mathrm{E}$. Journal of Geophysical Research 94(C10), 14445-14459.

Hall, M. and M. Fofonoff (1993). Downstream development of the Gulf Stream from $68^{\circ}$ to $55^{\circ} \mathrm{W}$. Journal of Physical Oceanography 23, 225-249.

Hallock, Z. and W. Teague (1992). The fall rate of the T-7 XBT. Journal of Atmospheric and Oceanic Technology 9, 470-483.

Hanawa, K. (1987). Interannual Variations of the Winter-time Outcrop Area of Subtropical Mode Water in the Western North Pacific Ocean. AtmosphereOcean 25(4), 358-374.

Hanawa, K. and I. Hoshino (1988). Temperature structure and mixed layer in the Kuroshio region over the Izu Ridge. Journal of Marine Research 46(4), 683-700.

Hanawa, K., P. Rual, R. Bailey, A. Sy, and M. Szabados (1995). A new depthtime equation for Sippican or TSK T-7, T-6, and T-4 expendable bathythermographs (XBT). Deep Sea Research 42(8), 1423-1451. 
Hanawa, K. and T. Suga (1995). A review on the subtropical mode water of the North Pacific (NPSTMW). In H. Sakai and Y. Nozaki (Eds.), Biogeochemical Processes and Ocean Flux in the Western Pacific, pp. 613-627. Terra Scientific Publishing Company.

Hanawa, K. and H. Yoritaka (1987). Detection of systematic errors in XBT data and their correction. Journal of the Oceqnographic Society of Japan 43, $68-76$.

Hanawa, K. and Y. Yoshikawa (1991). Reexamination of the depth error in XBT data. Journal of Atmospheric and Oceanic Technology 8(3), 422-429.

Huang, R. (1990). Does atmospheric cooling drive the Gulf Stream recirculation? Journal of Physical Oceanography 20, 750-757.

Hurrell, J. (1995). Decadal trends in the north atlantic oscillation: Regional temperatures and precipitation. Science 269, 676-679.

Istoshin, Y. (1961). Formative area of 'eighteen-degree' water in the Sargasso Sea. Deep Sea Research 9, $384-390$.

Jenkins, W. (1982). On the climate of the subtropical gyre: decade timescale variations in water mass renewal in the Sargasso Sea. Journal of Marine Research 40(Supplement), 265-290.

Jenkins, W. (In Press). Studying thermocline ventilation and circulation using Tritium and ${ }^{3}$ He. In P. Schlosser, W. Smethie, and W. Broecker (Eds.), Application of Trace Substance Measurements to Oceanographic Problems, Proceedings of the Ewing Symposium. 
Johns, E., D. Watts, and H. Rossby (1989). A test of geostrophy in the Gulf Stream. Journal of Geophysical Research 94(C3), 3211-3222.

Kawabe, M. (1985). Sea level variations at the Izu Islands and typical stable paths of the Kuroshio. Journal of the Oceanographic Society of Japan 41, $307-326$.

Klein, B. and N. Hogg (1996). On the interannual varíability of 18 Degree Water formation as observed from moored instruments at $55^{\circ} \mathrm{W}$. Deep Sea Research 43(11-12), 1777-1806.

Lamb, P. (1984). On the mixed-layer climatology of the North and Tropical Atlantic. Tellus 36A, 292-305.

Lappo, S., G. Alekseev, and V. Efimov (1995). On oceanological results of the program Sections. Atmospheric and Oceanic Physics 31(3), 373-384.

Leetmaa, A. (1977). Effects of the winter of 1976-1977 on the northwestern Sargasso Sea. Science 198, 188-189.

Marsh, R. and A. L. New (1996). Modeling $18^{\circ}$ Water variability. Journal of Physical Oceanography 26(6), 1059-1080.

Masuzawa, J. (1969). Subtropical mode water. Deep Sea Research 16, 463-472.

Masuzawa, J. (1972). Water characteristics of the North Pacific central region. In H. Stommel and K. Yoshida (Eds.), Kuroshio: Its Physical Aspects, pp. 95-127. University of Tokyo Press.

McCartney, M. (1982). The subtropical recirculation of Mode Waters. Journal 
of Marine Research 40(Supplement), 427-464.

McCartney, M., L. Worthington, and M. Raymer (1980). Anomalous water mass distributions at 55W in the North Atlantic in 1977. Journal of Marine Research $38(1), 147-172$.

McDowell, S., P. Rhines, and T. Keffer (1982). North Atlantic Potential Vorticity and its relation to the general circulation. Jourhal of Physical Oceanography 12(12), 1417-1436.

Qui, B. and R. Huang (1995). Ventilation of the North Atlantic and North Pacific: subduction versus obduction. Journal of Physical Oceanography 25, 2374-2390.

Qui, B. and T. Joyce (1992). Interannual variability in the mid- and low-latitude Western North Pacific. Journal of Physical Oceanography 22, 1062-1079.

Rhines, P. B. and W. R. Young (1982). Homogenization of potential vorticity in planetary gyres. Journal of Fluid Mechanics 122, 347-367.

Roemmich, D. and B. Cornuelle (1992). The Subtropical Mode Waters of the South Pacific Ocean. Journal of Physical Oceanography 22, 1178-1187.

Rossby, T., J. Price, and D. Webb (1986). The spatial and temporal evolution of a cluster of SOFAR floats in the POLYMODE Local Dynamics Experiment (LDE). Journal of Physical Oceanography 16(3), 428-442.

Schroeder, E., H. Stommel, D. Menzel, and W. S. Jr. (1959). Climatic stability of Eighteen Degree Water at Bermuda. Journal of Geophysical Research 64(3), $363-366$. 
Shen, C. Y., J. C. McWilliams, B. A. Taft, C. C. Ebbesmeyer, and E. J. Lindstrom (1986). The mesoscale spatial structure and evolution of dynamical and scalar properties observed in the Northwestern Atlantic Ocean during the POLYMODE Local Dynamics Experiment. Journal of Physical Oceanography $16(3), 454-482$.

Shoji, D. (1972). Time variation of the Kuroshio, south of Japan. In H. Stommel and K. Yoshida (Eds.), Kuroshio: Its Physical Aspects, pp. 217-234. University of Tokyo Press.

Singer, J. (1990). On the error observed in electronically digitized T-7 XBT data. Journal of Atmospheric and Oceanic Technology 7, 603-611.

Speer, K. and E. Tziperman (1992). Rates of water mass transformation in the North Atlantic Ocean. Journal of Physical Oceanography 22, 93-104.

Spiegel, M. R. (1961). Schaum's Outline of Theory and Problems of Statistics. McGraw-Hill Inc.

Suga, T. and K. Hanawa (1990). The mixed layer climatology in the northwestern part of the North Pacific subtropical gyre and the formation area of Subtropical Mode Water. Journal of Marine Research 48, 543-566.

Suga, T. and K. Hanawa (1995a). Interannual variations of North Pacific Subtropical Mode Water in the $137^{\circ}$ E Section. Journal of Physical Oceanography 25, 1012-1017.

Suga, T. and K. Hanawa (1995b). The Subtropical Mode Water circulation in the North Pacific. Journal of Physical Oceanography 25(5), 958-970. 
Suga, T. and K. Hanawa (1995c). Subtropical Mode Water south of Honshu, Japan in the spring of 1988 and 1989. Journal of Oceanography 15(1), 1-19.

Suga, T., K. Hanawa, and Y. Toba (1989). Subtropical mode water in the $137^{\circ}$ E Section. Journal of Physical Oceanography 19, 1605-1618.

Taft, B. (1972). Characteristics of the flow of the Kuroshio south of Japan. In H. Stommel and K. Yoshida (Eds.), Kuroshio:'Its Physical Aspects, pp. 165-216. University of Tokyo Press.

Taft, B. A., E. J. Lindstrom, C. C. Ebbesmeyer, C. Y. Shen, and J. C. McWilliams (1986). Water mass structure during the POLYMODE Local Dynamics Experiment. Journal of Physical Oceanography 16(3), 403-426.

Talley, L. and M. Raymer (1982). Eighteen Degree Water variability. Journal of Marine Research 40(Supplement), 757-775.

Warren, B. (1972). Insensitivity of subtropical mode water characteristics to meteorological fluctuations. Deep Sea Research 19, 1 - 19.

Woods, J. and W. Barkmann (1986). A lagrangian mixed layer model of Atlantic $18^{\circ}$ water formation. Nature $319,574-576$.

Worthington, L. (1959). The $18^{\circ}$ water in the Sargasso Sea. Deep Sea Research 5, 297-305.

Worthington, L. (1972). Negative oceanic heat flux as a cause of water-mass formation. Journal of Physical Oceanography 2(3), 205 - 211.

Worthington, L. (1976). On the North Atlantic Circulation, Volume 6 of The 
Johns Hopkins Oceanographic Studies. Johns Hopkins University Press. 110 pages.

Worthington, L. (1977). Intensification of the Gulf Stream after the winter of 1976-77. Nature 270, $415-417$.

Yasuda, T. and K. Hanawa (1997). Decadal changes in the Mode Waters in the Midlatitude North Pacific. Journal of Physical Oéeanography 27, 858-870. 